فاعلية استخدام استراتيجية التعلم المدمج نموذج تناوب المواقع في تدريس مادة

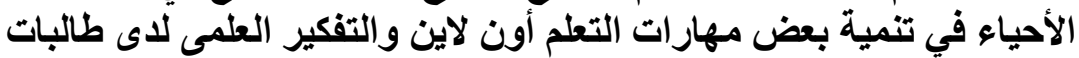
المرحلة الثانوية بالسعودية الاين والفية

إعداد:د/ سوزان محمد حسن السيد على*

مقدمة:

تتعدد التحديات الراهنة التي تواجه منظومة التعليم والتعلم نتيجة للتسارع

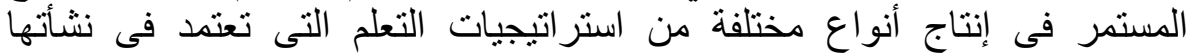

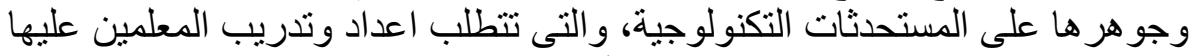

لتوفير عو امل النجاح لها، ومنها: "مزج أو دمج التهات التدريس التقليدى Instruction مع بعض الأساليب التى تعتمد على التكنولوجيا مثل التندريس أون لاين التين Online Instruction

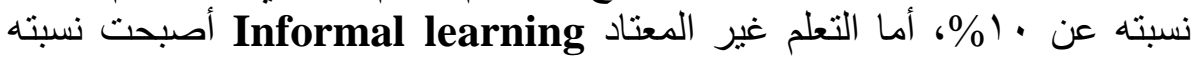
•9\%". (Rabin, R., 2014, 1)، ويُعزى ذللك لثورة التكنولوجيا فى التعليم

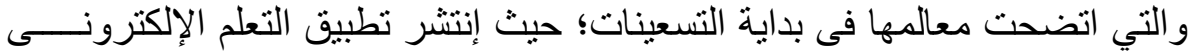

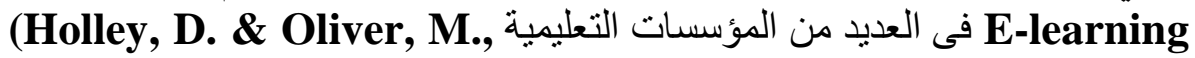
2009, 1: 8)

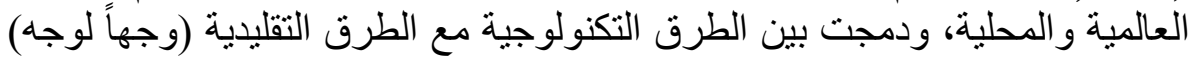

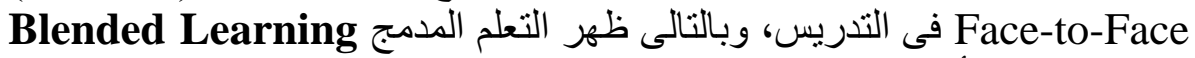

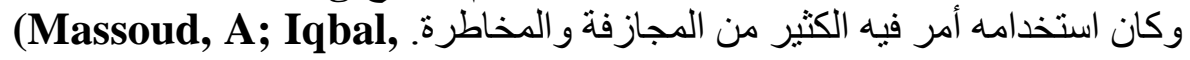
U. \& Stockley, D., 2011, 2: 5) وتجدر الإشارة إلى أن مفهوم التعلم المدمج يرتبط بعدة مصطلحات مثل: التعلم

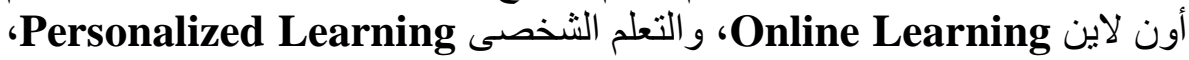
و التعلم المعدل والمعد وفق حاجات المتعلم Customized Learning، و التعلم

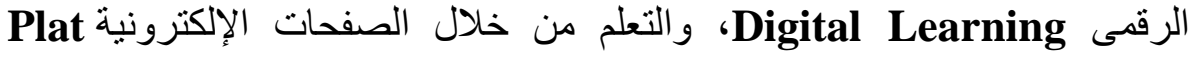
(Yapici, I.U. \& Ak Bayin, H., 2012, 6: 7) .Forms Learning وتعد إستراتيجية التعلم المدمج Blended Learning Strategy تحورة الاً

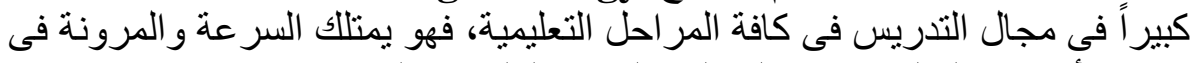

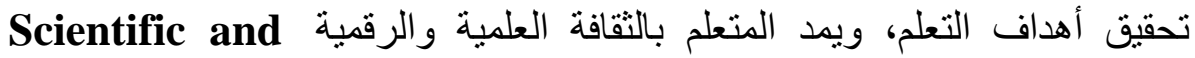
وخigital Literacy

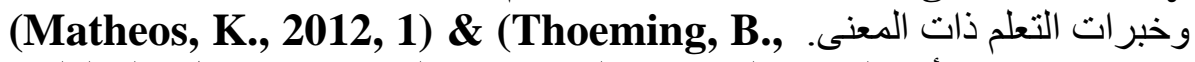

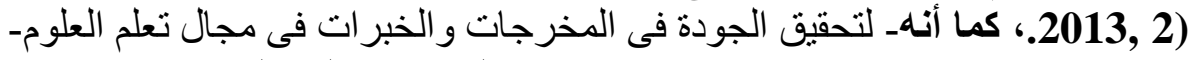

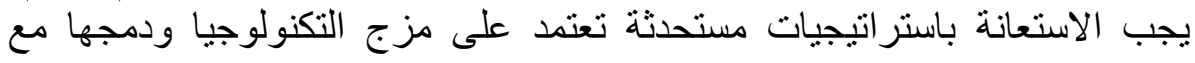


أساليب التعليم المتنوعة التى تصحح الفهم، وتنمى أنواع التفكير المختلفة. (Winkler, S., Korner, A. \& Brei Tenecker, F., 2014, 12) يعتبر التعلم المدمج أحد مرتكزات صناعة وتوصيل المعرفة، وذللك فى ضوء

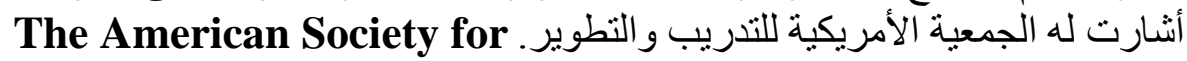

\section{Training and Development (ASTD)}

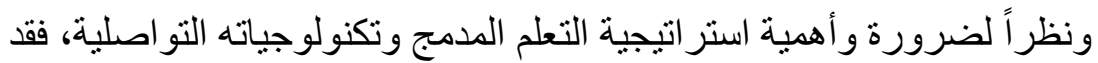

قام كل من جرينرج (Greenberg, A.D., 2012, 1:15) وفورست (Forres) بعمل مجموعة من المعايير والمقاييس التى تقيس كفاءته، J., J., T., 2014, 2)

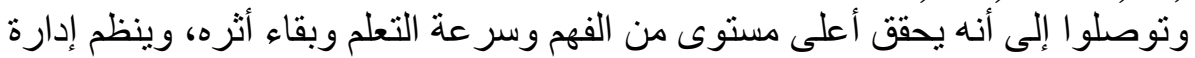

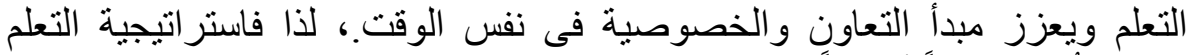
المدمج تُعد مرتكز اً أساسياً في تجويد والتعليد عمليات التجديد والإبداع في العملية التدريسية.

(Wilka, M. \& Cohen, J., 2012, 1: 10)

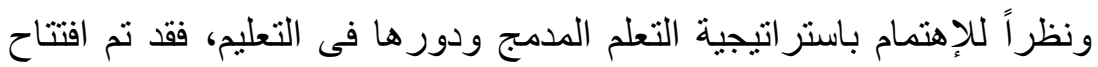

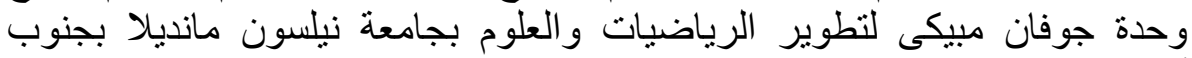

أفريقيا. Govan M beki Mathemati's \& Sciences Development ،University (S.A.) Nelson Mandela Metro Politan University

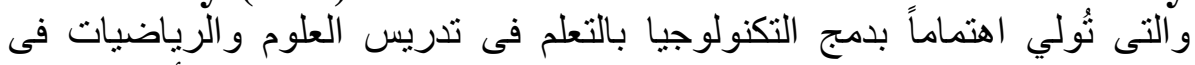

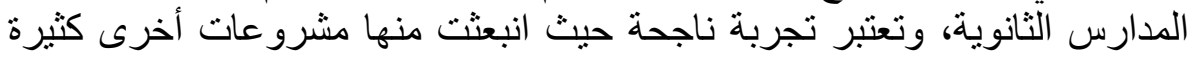
ترتبط بالتعلم المدمج. (Olivier, W., 2014, 1: 2)، كما قام مركز هانوفر اللبحث العلمى (Hanover Research (HR), 2011, 1: 35)، وبر باى ور الى وبينكس (Bray, S., Raley, N. \& Pinkus, A., 2012, 24: 26) من قصص التميز كدر اسات حالة، و التى أكدت فاعلية التعلم المدمج فى تحقيق أهداف تدريس العلوم وتوصيل التعلم.

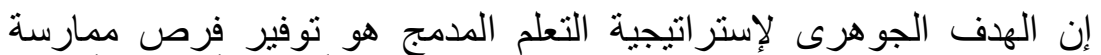

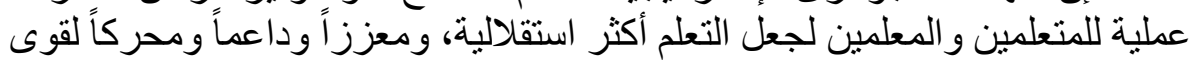

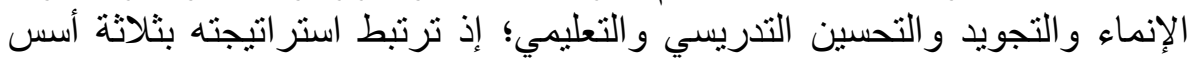

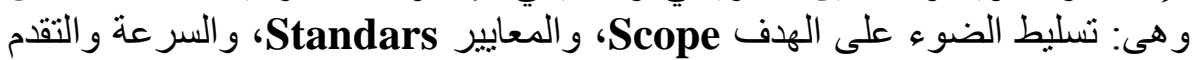
Speed

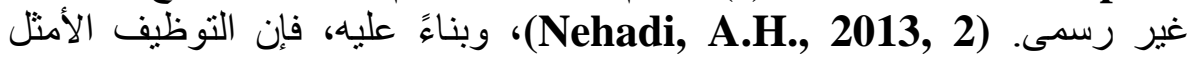

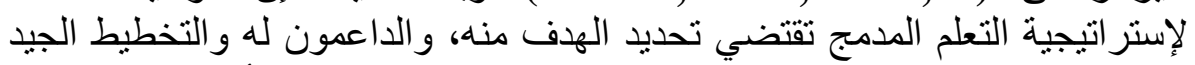

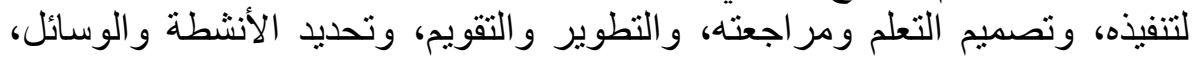
و إدارة الأنشطة والتعلم. (Honemond, F., 2010, 10), (Krause, K.L., 2010, 8)

وقد اتفق كل من تزيمو بيولوس (Tzimopoulos, N., 2014, 5)، وونج أننا بحاجة ملحة للعديد من الأبحاث لتطبيق استر اتيجية (Wong, M., 2014, 4) 


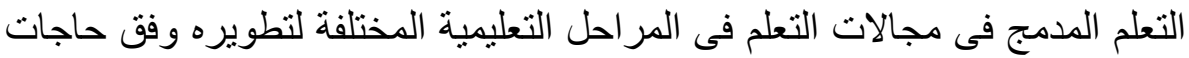

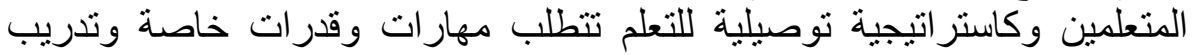

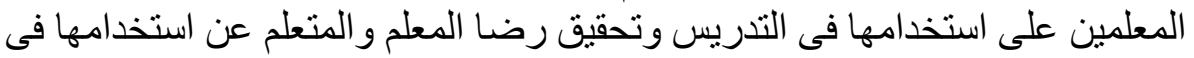
تدريس العلوم.

وقد تعددت الدراسات السابقة في كافة المراحل التعليمية التي أنثارت إلى إلى

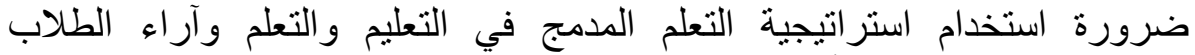
و المعلمين فيها، وبيان أهمها على النحو التحو التالي: استهدفت دراسة جينز تحديد آراء طلاب السنة الثالثة (Ginns, P. \& Ellis, R., 2007, 53: 64)

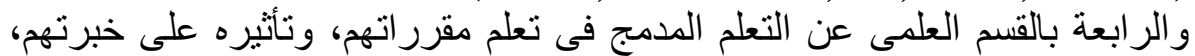

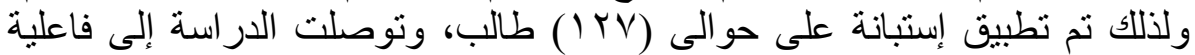

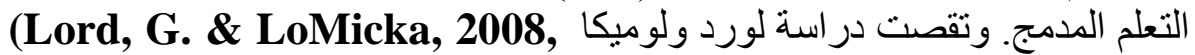
(158: 174) عن كيفية تطوير مهار ات العمل والتعلم فى مجمو عات تعاونية لدى الدى

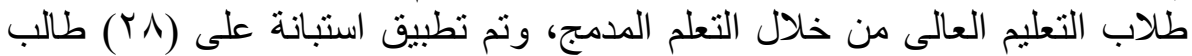

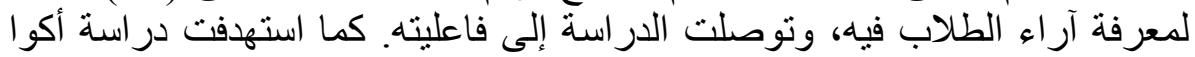

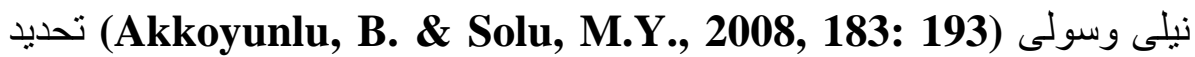
آراء الطلاب عن بيئة التعلم المدمج المرتكزة إلى أنماط التعلم المختلفة، وتم تطبيق

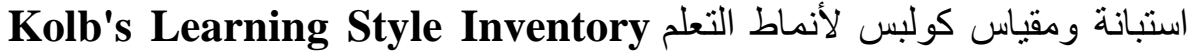

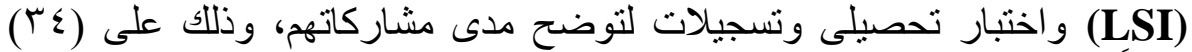
طالباً من جامعة هاسيتب بأنقرة بتركيا Hacettepe University Ankara Turkey

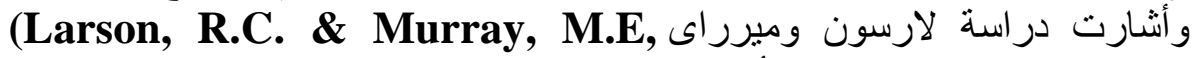
2008, 1: 19)

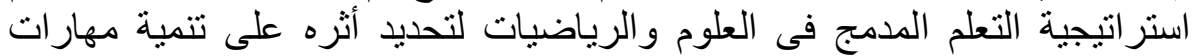
التفكير الناقد لاى الطلاب متعددى الجنسيات، وتم تطبيق استبانات واختبار التبات التفكير

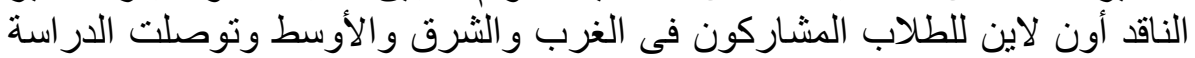
إلى فاعليته. وتناولت در اسة ألاديجانا (Aladejana, F., 2008, 1:4) تقييم تأثير

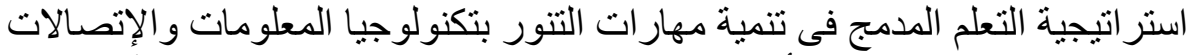

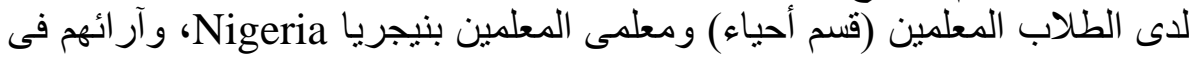

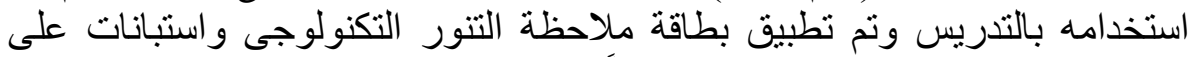

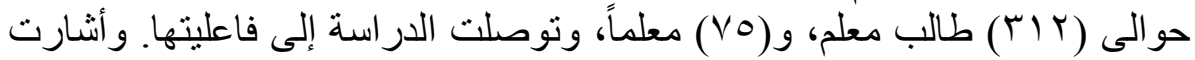

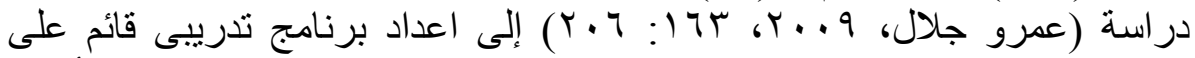

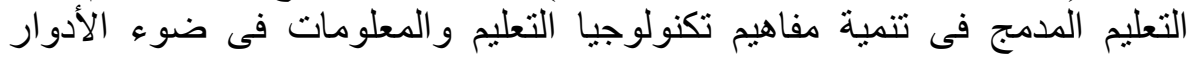

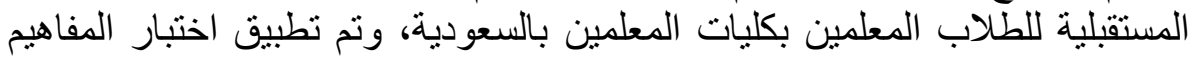

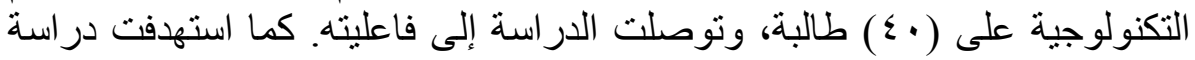

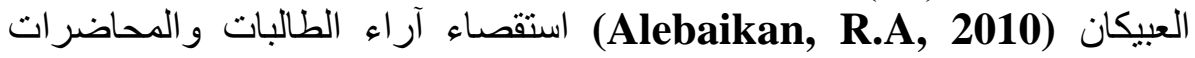
بالجامعات السعودية حول استخدام التعلم المدمج فى جامعة الملك سعود بالرياض، 
وتم تطبيق مقابلات معهن، وتوصلت الدراسة إلى تعزيز استخدام التعلم المدمج في العملية التعليمية. و استقصت دراسة أوكالك (Okak, M.A., 2010, 196: 210)

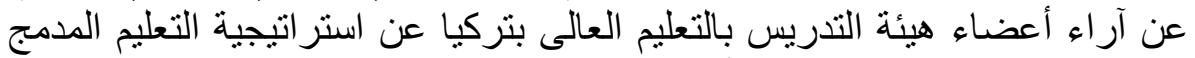

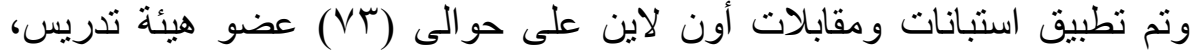

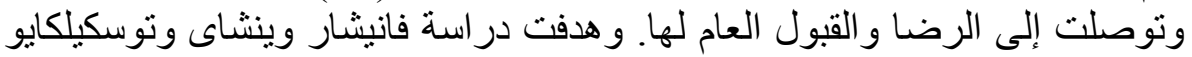
(Vanicharoenchai, V. \& Toskulkaew, T., 2010, 33: 40) أثر استخدام استراتيجية التعلم المدمج فى تنمية مهار ات البحات البحث العلمى و التحصيل

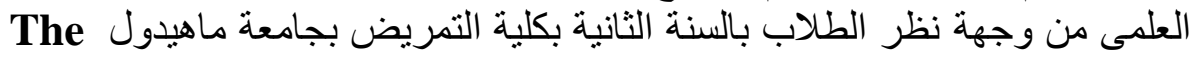
و Faculty of Nursing Mahidol University

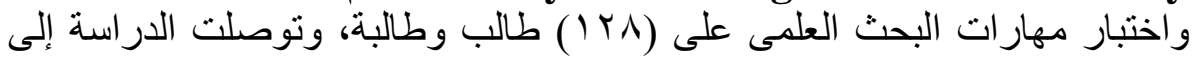

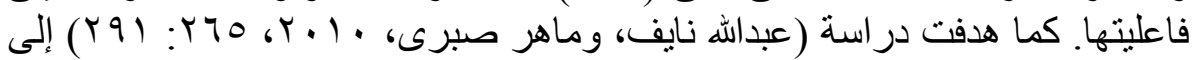

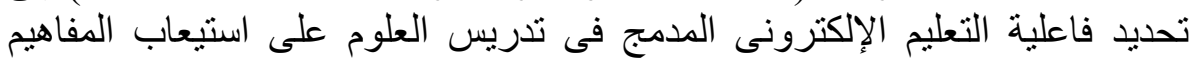

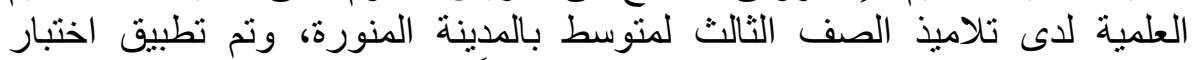

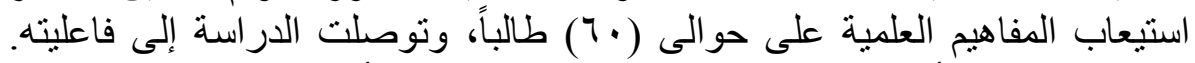

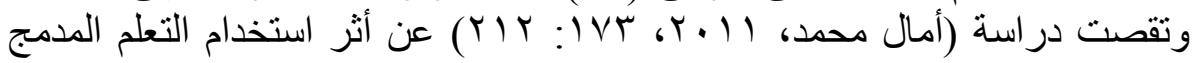

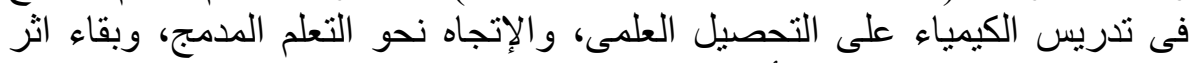

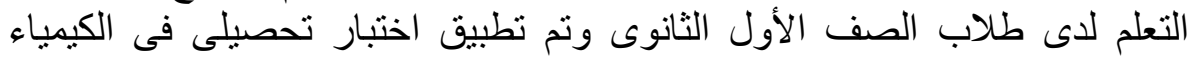

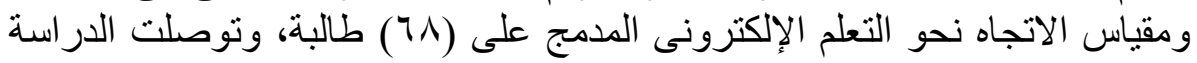

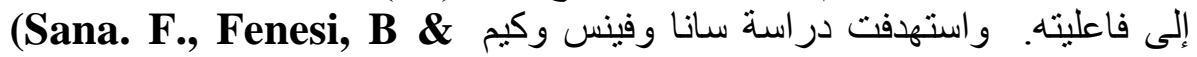
(Tim, J.A., 2011, 1:10)

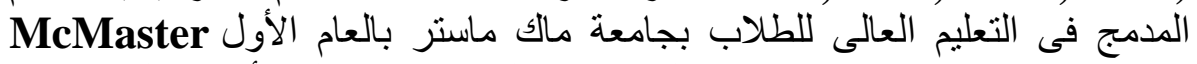
University

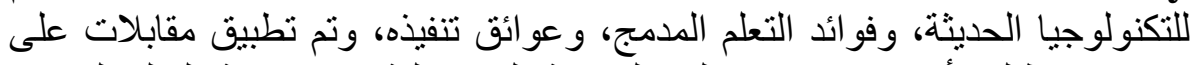

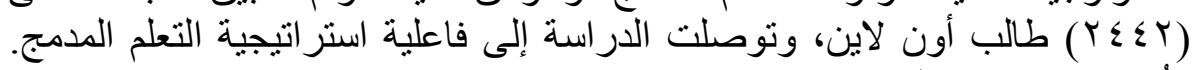

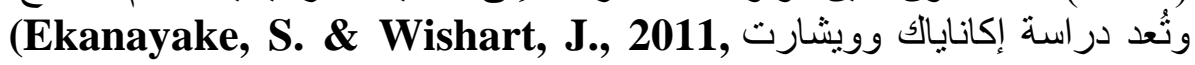

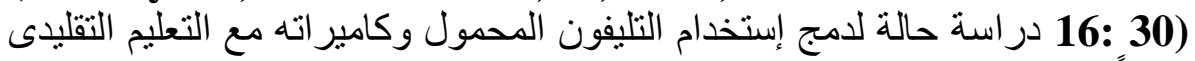

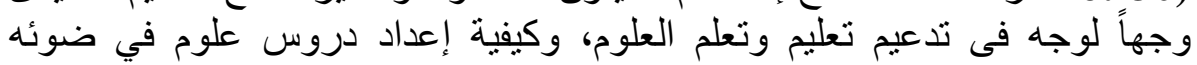

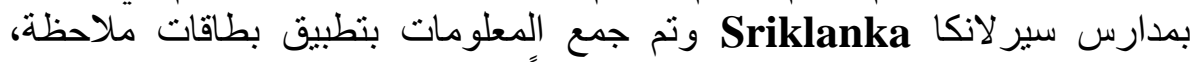

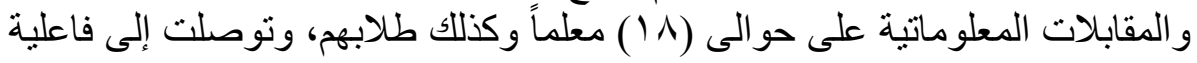

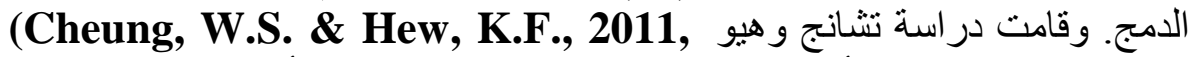

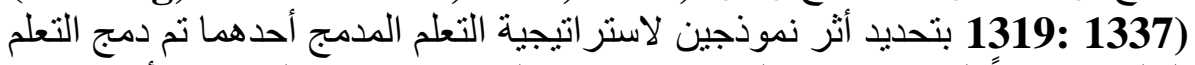

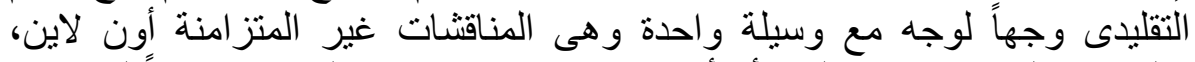

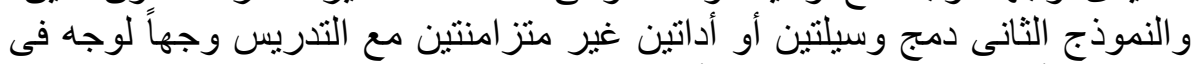

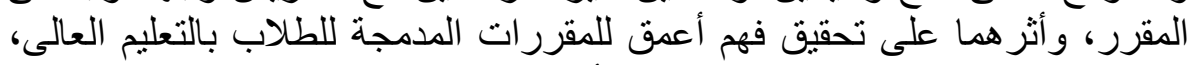

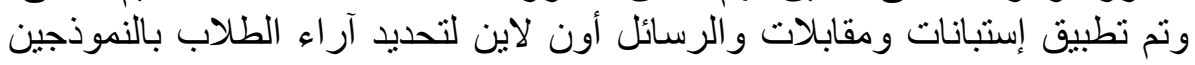

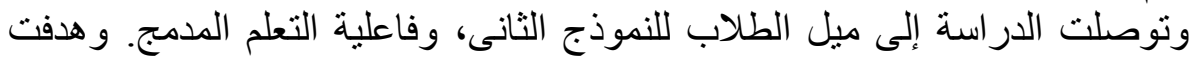


(Dahinden, M. \& Faessler, L., 2011, 401: در اسة داهيندين وفيسلر

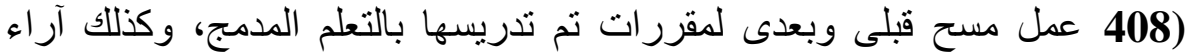

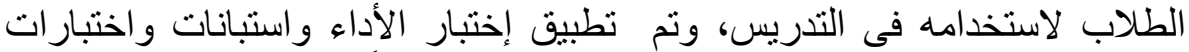

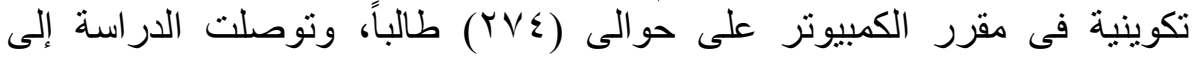

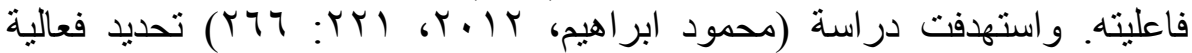

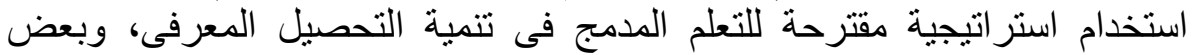

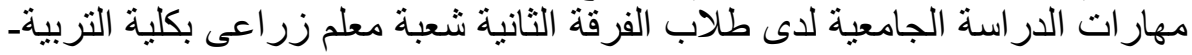

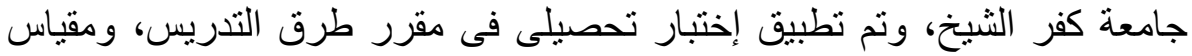

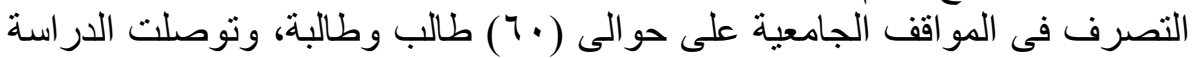

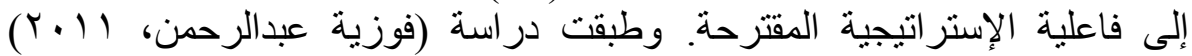

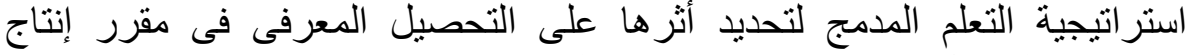
و إستخدام الوسائل التعليمية لدى طالبات كلية التربية جامعة الملك سعود بالئل الرياض، وكذلك أثره على مهارات تصميم وتتفيذ الوسائل التعليمية، وتم تطبية التيقية إختبار

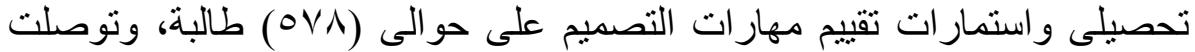

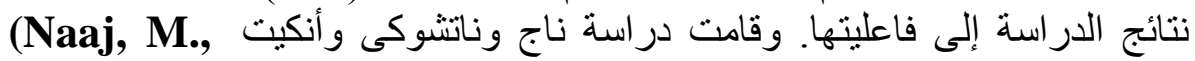
بتقييم رضا الطلاب بكلية Nachouki, M. \& Ankit, A., 2012, 185: 200)

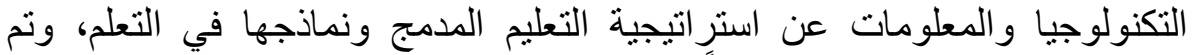

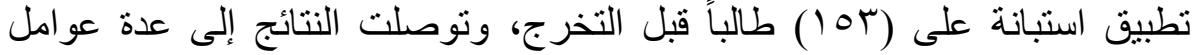

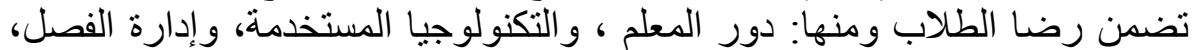

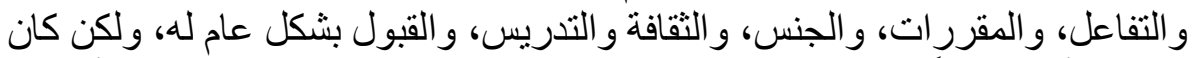

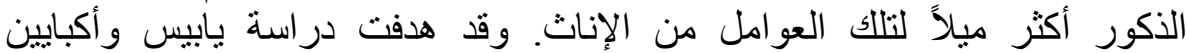
(Yapici, I.U. \& Akbayin, H., 2012, 228: 237) استراتيجية التعلم المدمج على تحصيل طلاب المدارس العليا فى مادة الأحياء

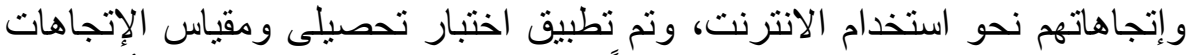

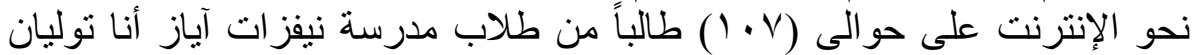
العليا بديار باكير Nevzat Ayaz Anatolian high School in Diyar Bakir وتوصلت الدراسة لفاعليتها، والإتجاهات الإيجابية نحو استخدام الإنترنت.

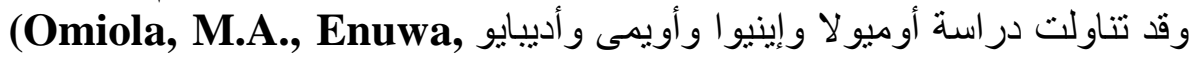
تقييم M.R., Awoyemi, S.O. \& Abdebayo, R.F., 2012, 38: 40) فاعلية استخدام استراتيجية التعلم المدمج و إستر اتيجية التعلم الفردى على مخرجات التحات

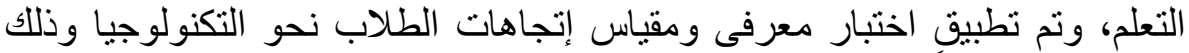

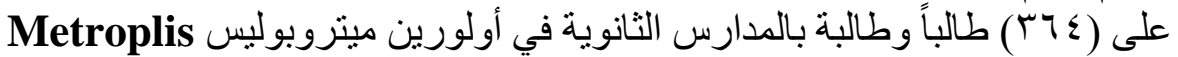
Secondary Schools in Ilorin

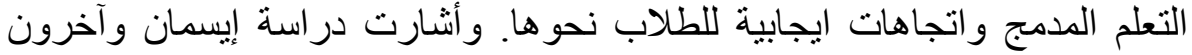
(Isman, A., et al., 2012, 336: 345) التعلم المدمج فى تطوير مهار ات التدريس للطلاب المعلمين فى كلية المعلمين بجامعة 
الملك سعود بالسعودية، وتم تطبيق بطاقات الملاحظة، على (Y) طالباً معلماً من تخصصات علوم ورياضيات، وتوصلت نطين الدر اسة إلى فاعليتها.

واستهدفت دراسة بوون (Poon, J., 2013, 271: 289) اجراء دراسة

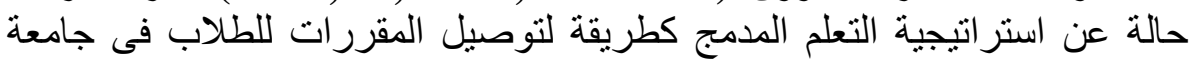
نويتنجهام ترنت فى المملكة المتحدة United Kingdom وكذلك تحديد آراء الطلاب في استخدامها فى اعداد وتنفيذ

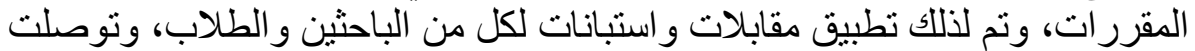

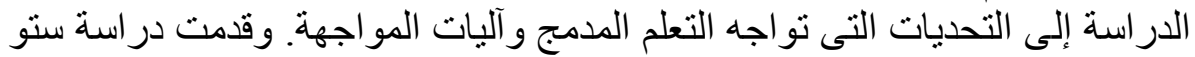
(Stolten Kamp, J \& Kabaka, M., 2013, 2321: لتنكامب وكابانة (2454 دراسة حالة لتنفيذ وأداء استرتيجية التعلم المدمج لمعلمى العلوم فى مركز The Centre for التجديد التعليمى وتكنولوجيا التواصل بجامعة ويسترن Innovative Educational and Communication Technologies (CIECT) of The University of The Western Cape (Uwc) تدرييهم عليها، وتم تطبيق البرنامج واستبانات على حوالى الى (Y9) معلى (Y) معلم علوم، ونوصلت الدراسة إلى فاعليتها. و هدفت دراسة والش

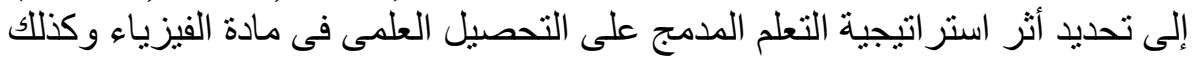

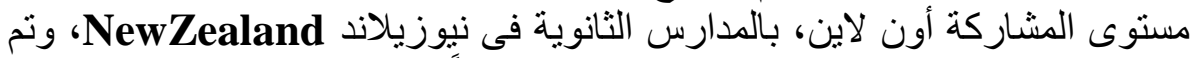

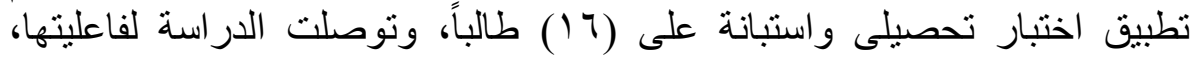

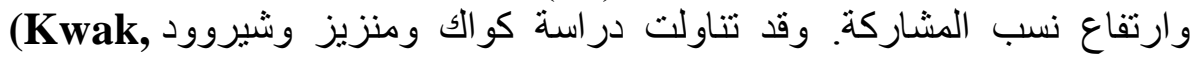
D.W. \& Mene zes, F.M. \& Sherwood, C., 2013, 1: 24) الكمى لأثر استراتيجية التعلم المدمج على آداء الطلاب ببعض كليات جامعة كوينزلاند The university of Queensland، وتم تطبيق حوالى ست

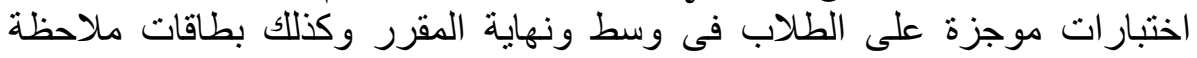
الأداء، وتوصلت الدراسة إلى ارتفاع معدل أداء الطلاب من خلال استر اتيجية التعلم

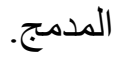

وهدفت دراسة زاكا (Zaka, P., 2013, 24: 40) إلى در اسة حالة التعلم

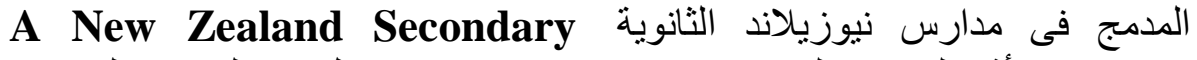
School وتم تطبيق استبانات ومقابلات بمدارس نيوزيلاند على (VO.

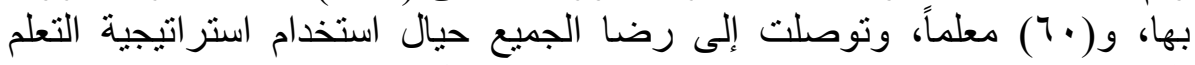

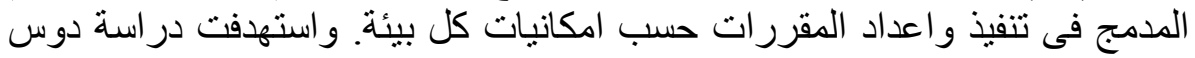

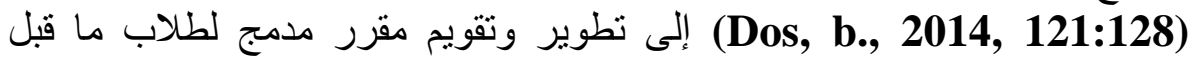

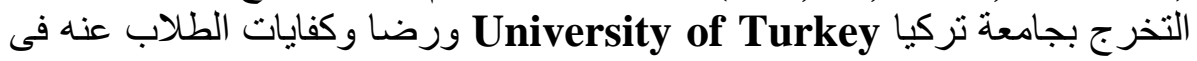

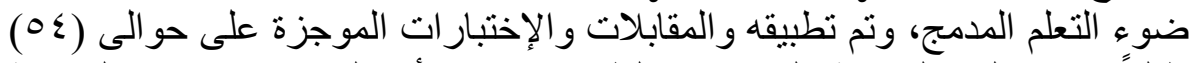

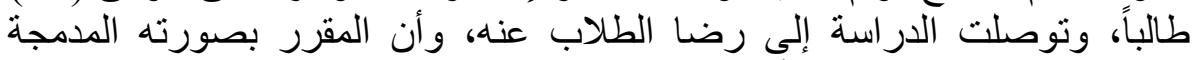

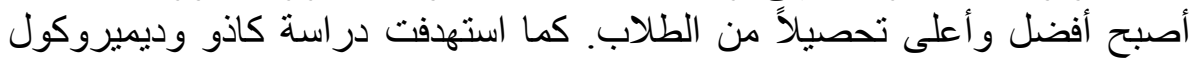


(Kazu, I.Y. \& Demirkol, M., 2014, 78:87)

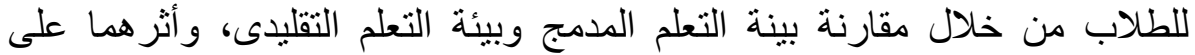

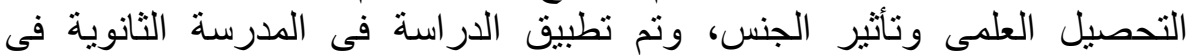

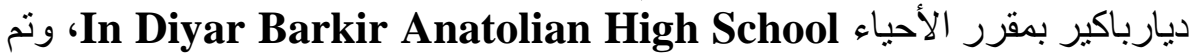

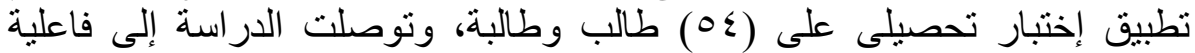
استر اتيجية التعلم المدمج، وكانت النبات أكثر تحصيلاً من الذكور.

وإن كان الإهتمام الدائم ينصب على إلى مهار ات تدريس المعلم و إكسابه كفايات

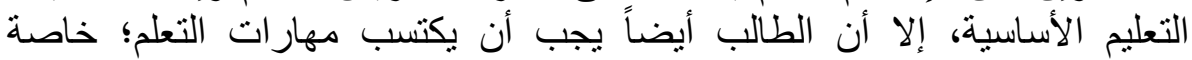

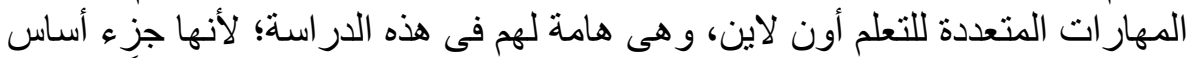

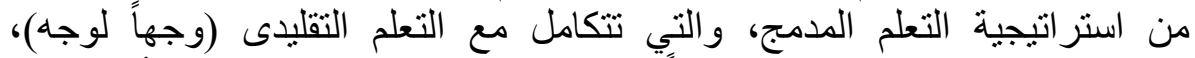

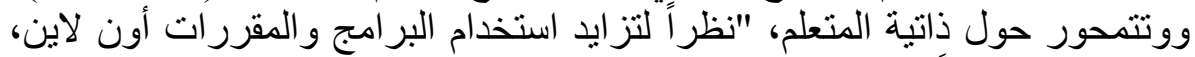

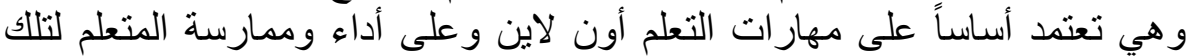

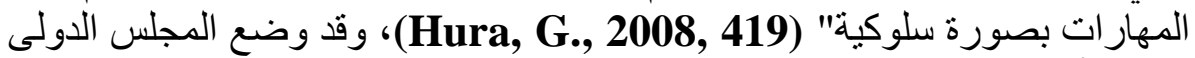
(International Association for K-12 online للتعلم أون لاينة Learning (INACOL)

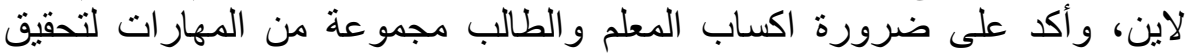

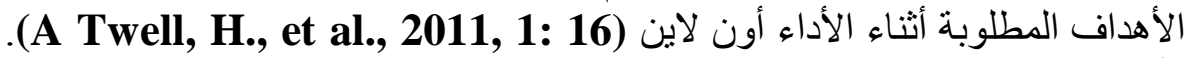

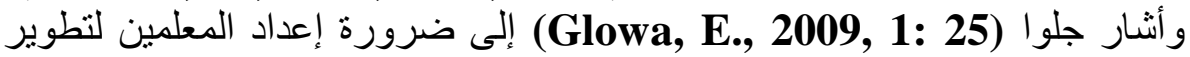

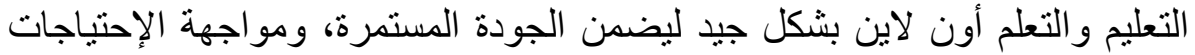

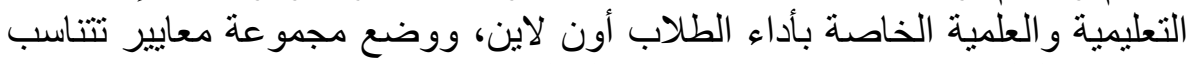

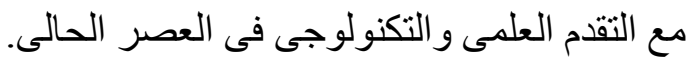

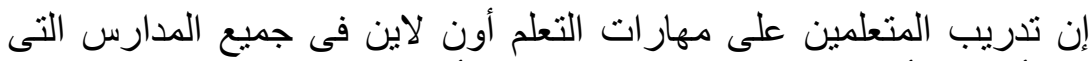

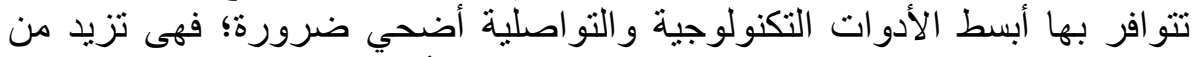

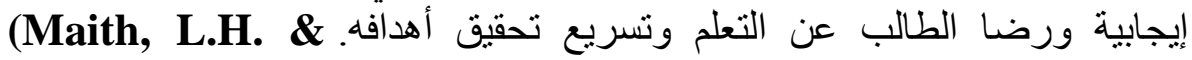
بإكسب (Mauch, C., 2012, 351: 358)

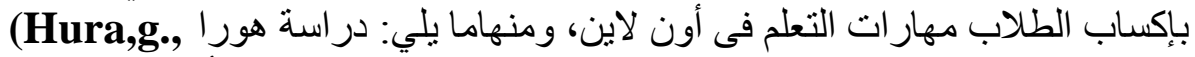

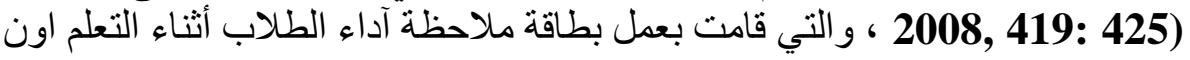

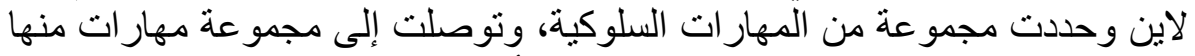

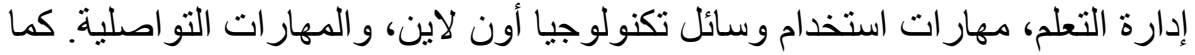

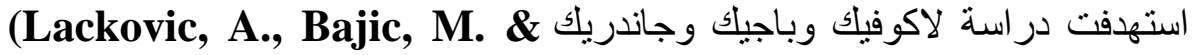
تحديد مهارات التواصل على الهو اء Jandric, P., 2013, 1487: 1496) مباثرة أون لاين أثناء أداء الطلاب وتعلمهح الفيزياء، وتم تطبيق استبانات وبطاقة

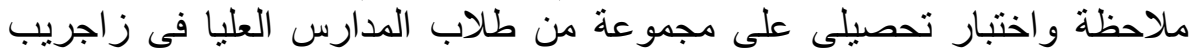
Zagreb

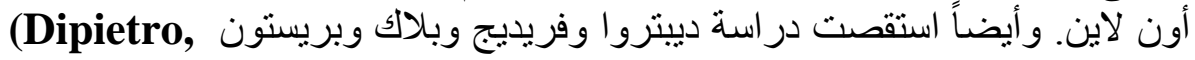
M., Fredig, R.E., Black, E.W. \& Preston, M., 2008, 10: 35) 


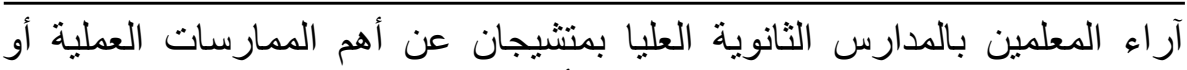

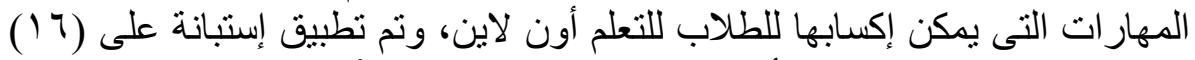

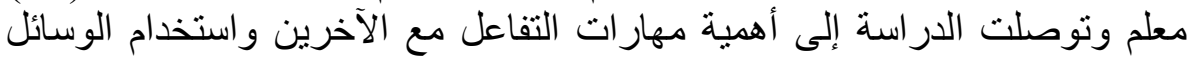
التكنولوجية و التو اصل و المهار ات الإجتماعية و التعاون.

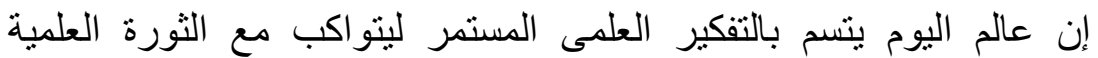

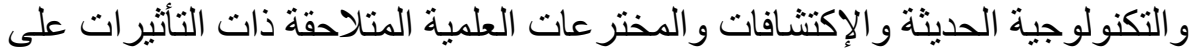

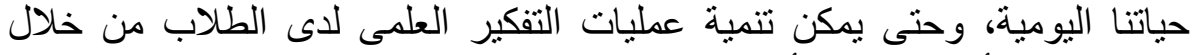

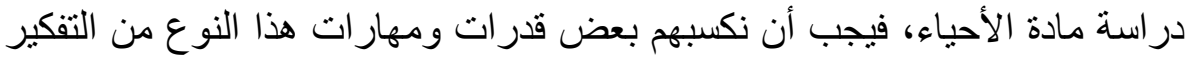

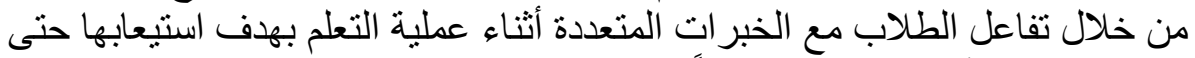

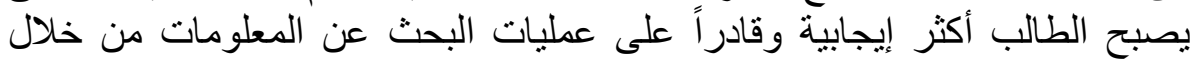

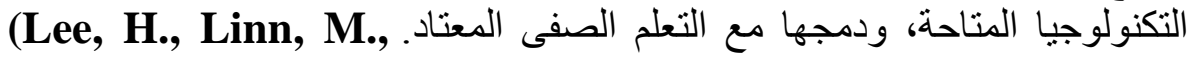
Varma, K. \& Liu, O., 2010, 71: 90)

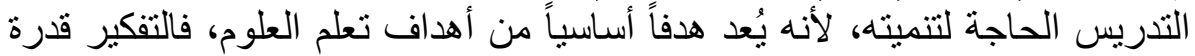

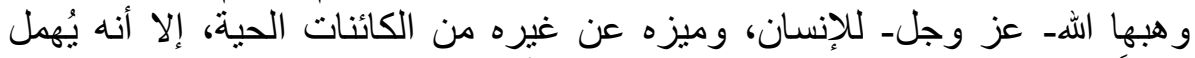

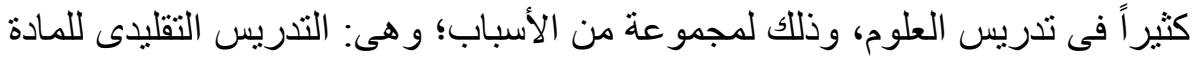

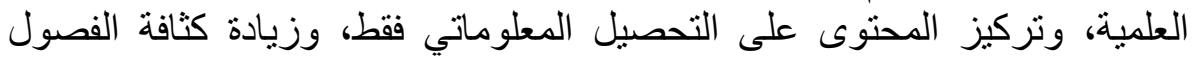
الطلابية، ووقت التدريس القصير و المقتصر على التى حجرة الصف فقلى فقط، وقلة الدر اسات

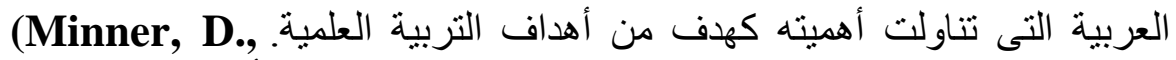
Levy, A. \& Century, J., 2010, 474: 496)

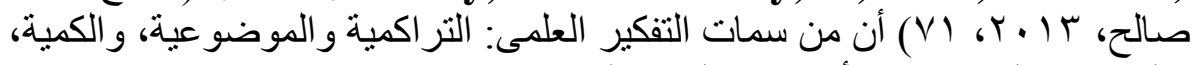

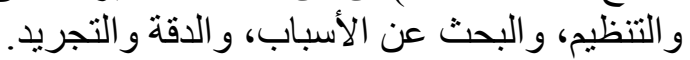

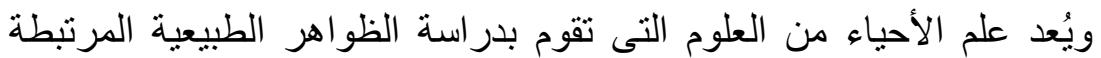

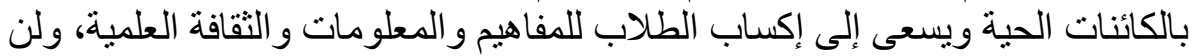

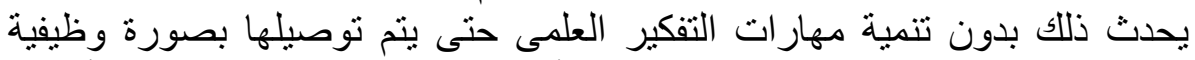

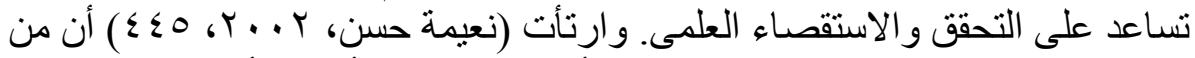

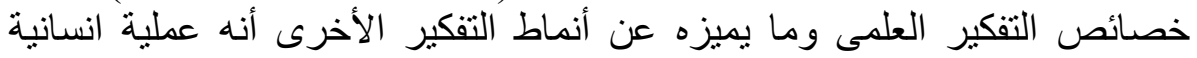

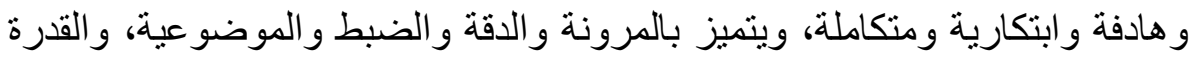
على مر اجعة صدق نتائجه وتعميماته.

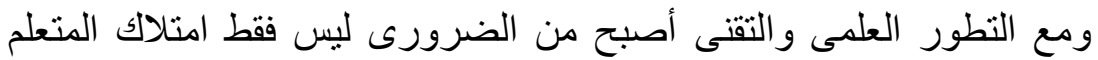

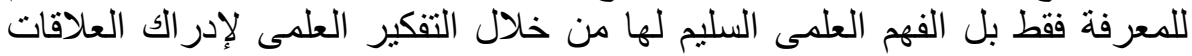

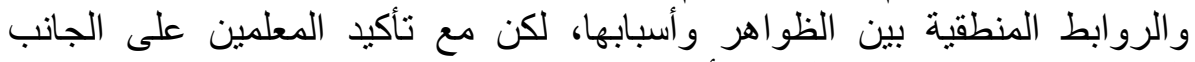

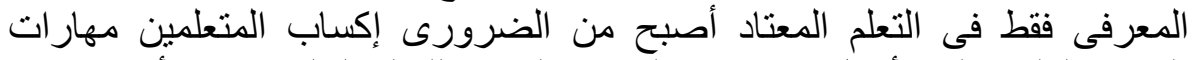

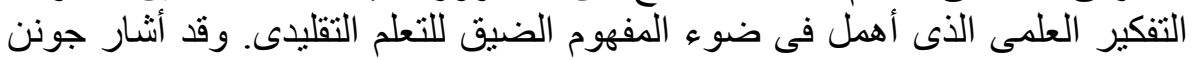

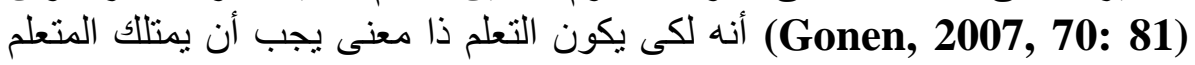


مهار ات التفكير المتتوعة ويستخدمها بشكل جيد فى مواقف بناء المعارف الجديدة وربطها بالخبرات السابقة.

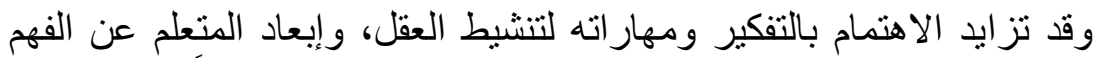

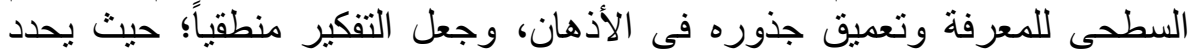

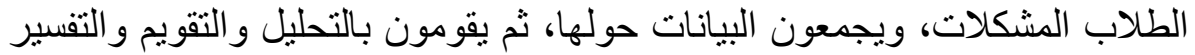

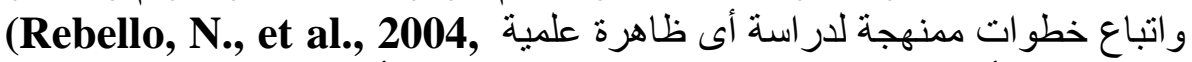

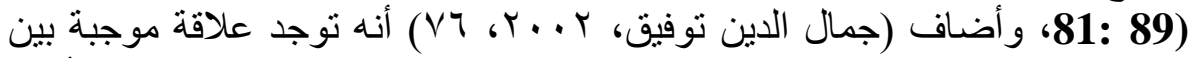

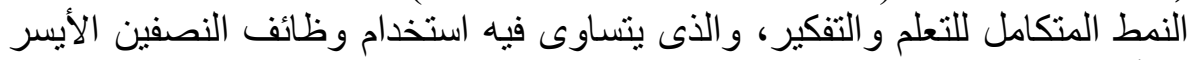

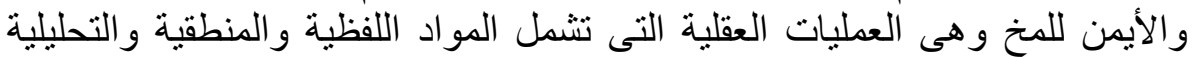

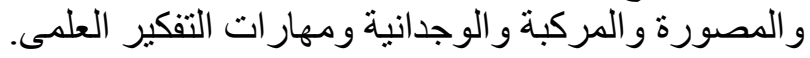

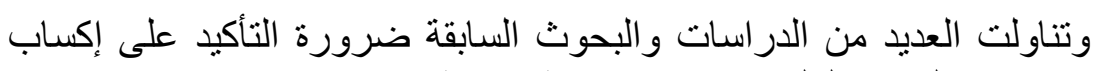

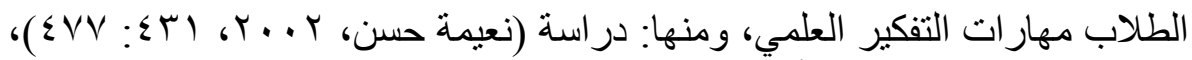

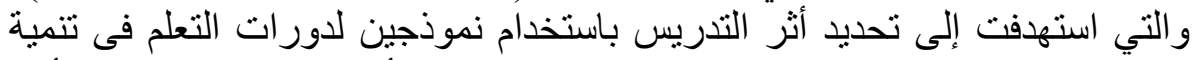

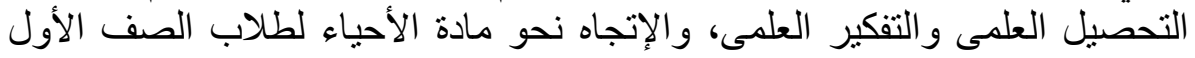

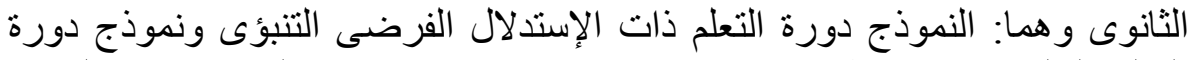

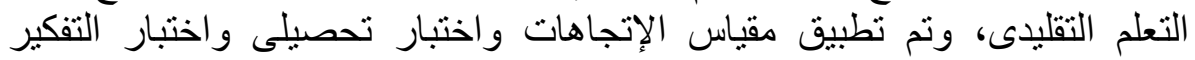

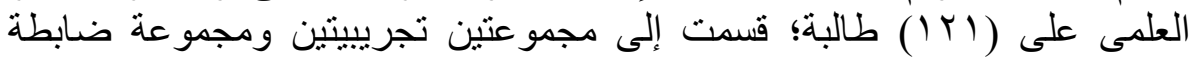

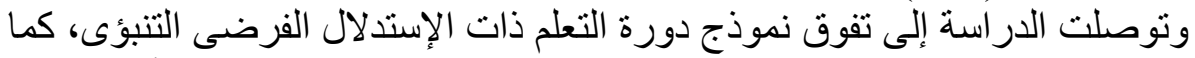

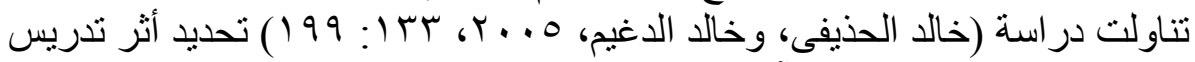

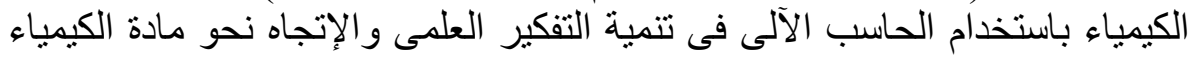

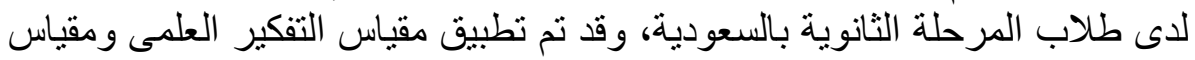

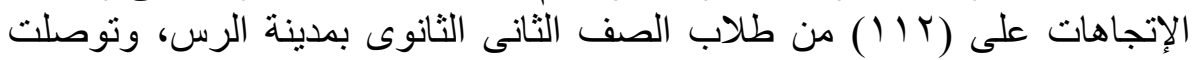

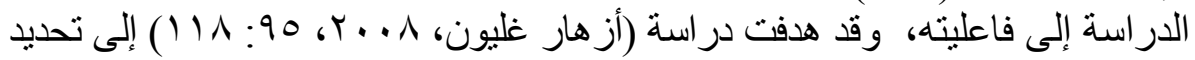

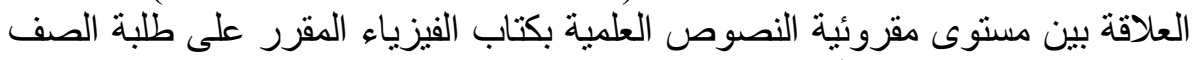

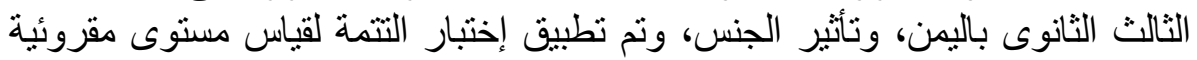

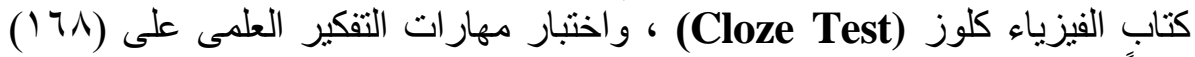

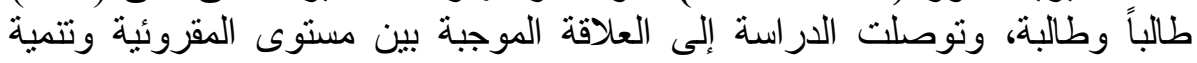

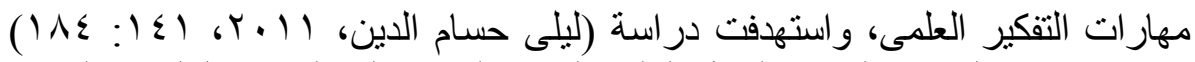

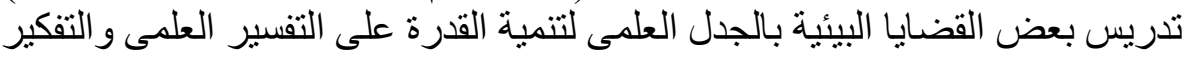

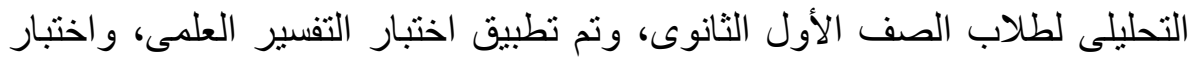

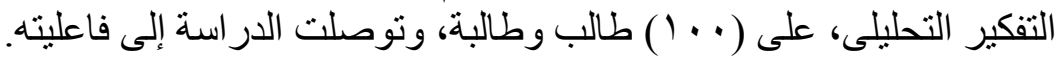

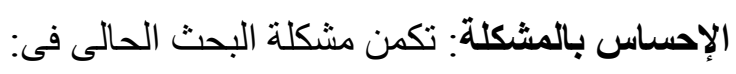

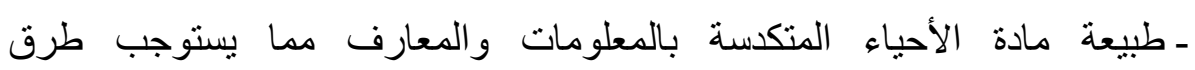
و استر اتيجيات تدريس تيسير إستيعابها وفهمها. 
ـ تأكيد الدراسات و البحوث السابقة التى تم عرضها على الهيل أهمية استراتيجية التعلم

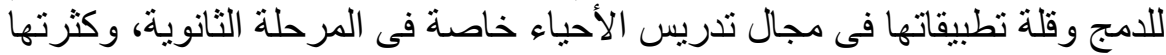
في المرحلة الجامعية.

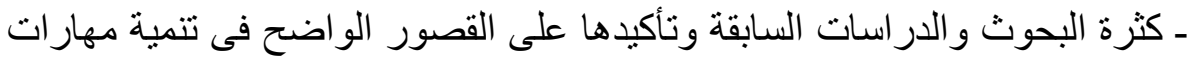

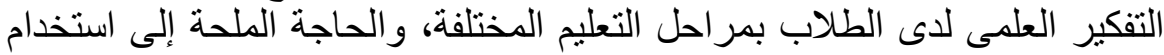

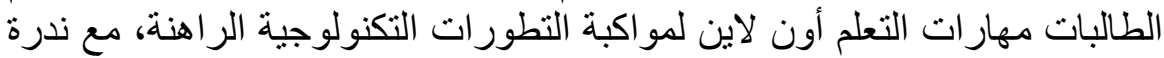

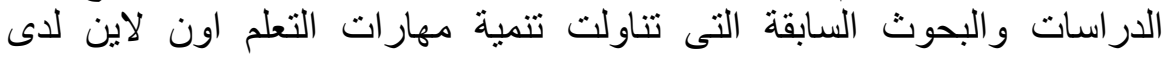

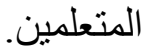

ـ تحقيق التكامل و الدمج فى طرق التدريس المختلفة لتحقيق أهداف تدريس المادة

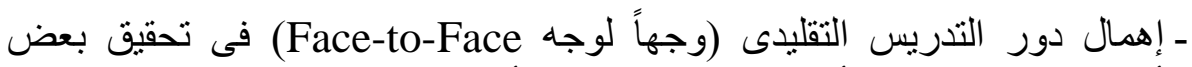

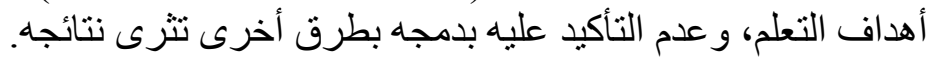

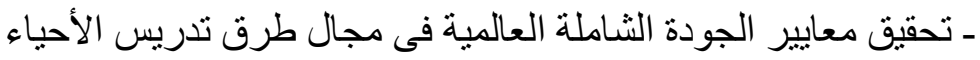

ـ توجه المؤسسات التعليمية العربية اهتمامها حيال استر اتيجيات التدريس التى تعتمد

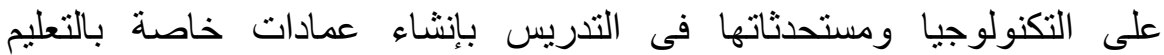
الإلكترونى والتعليم عن بعد بمعظم الجامعات العربية وتسعى إلى تحديث طرق بالثياء

$$
\text { التدريس. }
$$

ـ الحاجة إلى الإرتقاء بمستوى الطالبات ليحققن المتعة و الحماسة فى تعلم المادة،

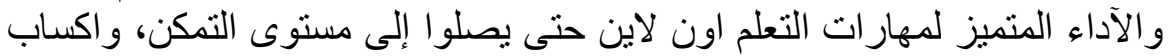

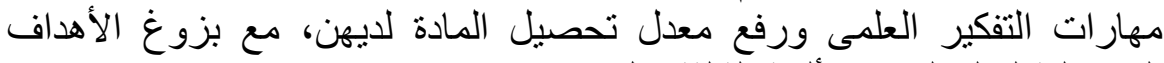
المستقبلية لتعلم المادة بالألفية الثالثة بكل متغير اتها وتحدياتها.

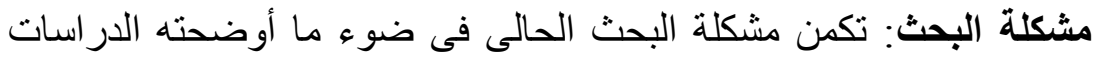
والبحوث السابقة القصور الواضح فى استخدام استراتيجيات التدريس المبتكرة

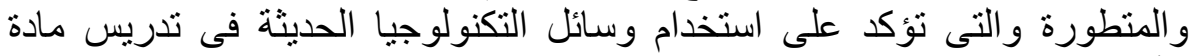

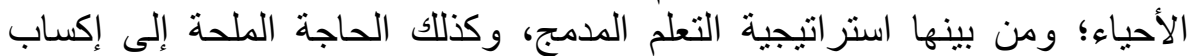

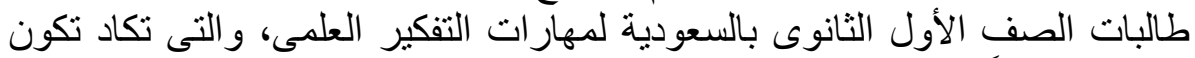

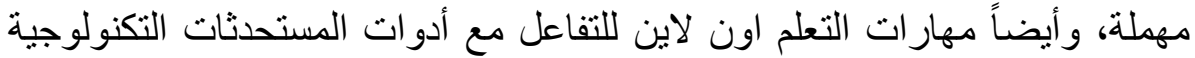

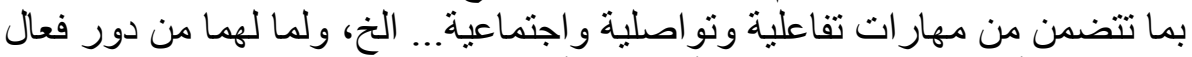

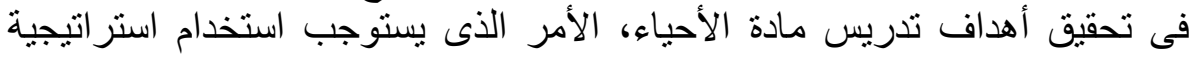

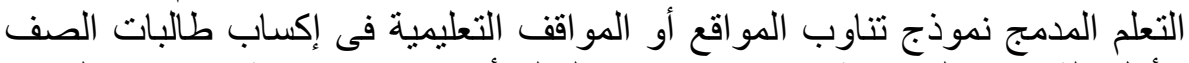

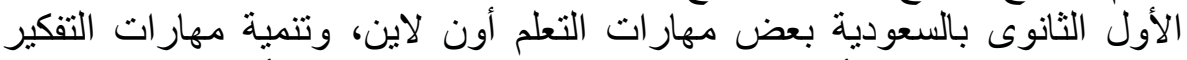
العلمى لديهن فى مادة الأحياء، وعليه يحاول البحث الإجابة عن الأسئلة الحالية:

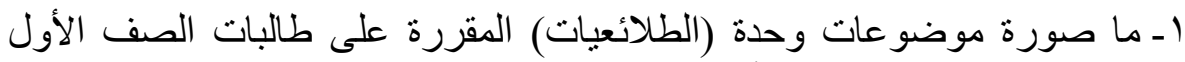

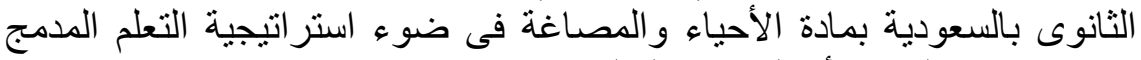

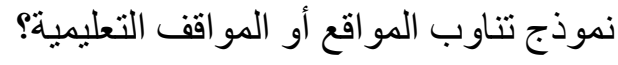




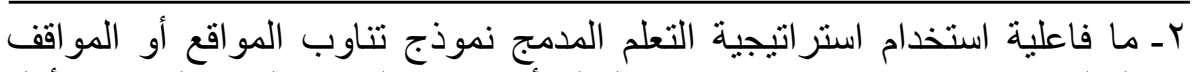

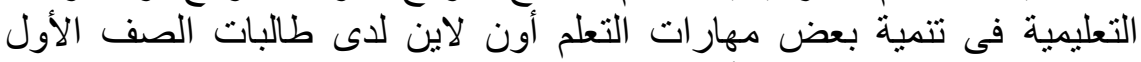

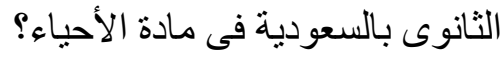

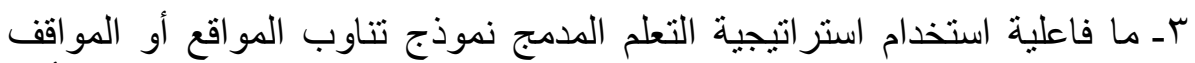

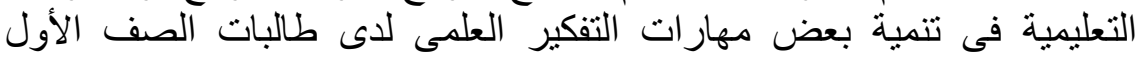
الثانوى بالسعودية فى مادة الأحياء؟ أهداف البحث: ويهدف البحث الحالى إلى:

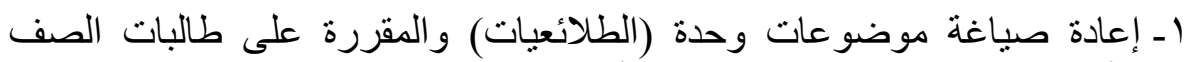

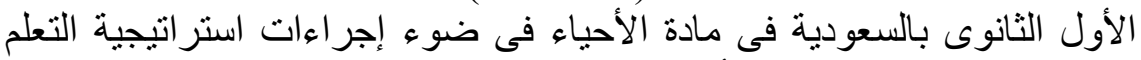
المدمج نموذج تناوب المو اقع أو المو اقف التعان التعليمية.

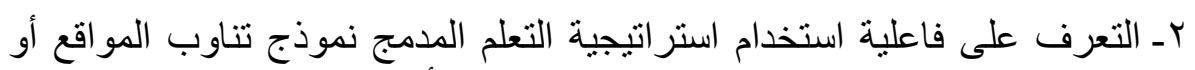

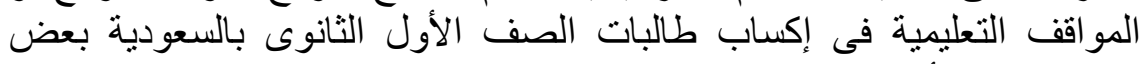

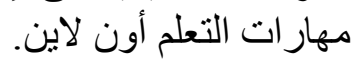

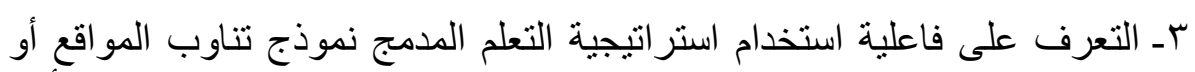

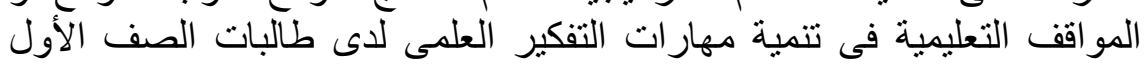
الثانوى بالسعودية. أهمية البحث: تتضح أهمية البحث الحالى فيما يلى:

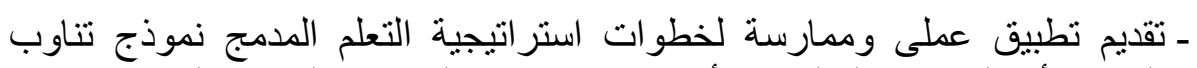

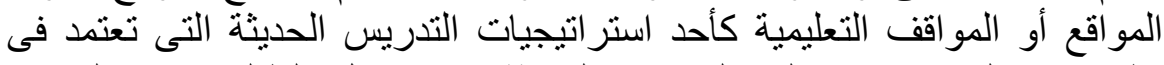

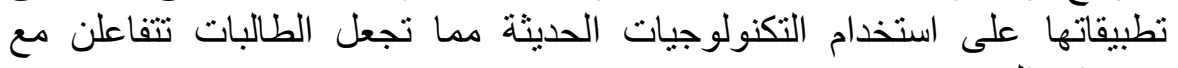
متغير ات العصر.

- جذب انتباه الطالبات عند استخدام مهار ات التعلم أون لاين لتحقيق متعة التعلم.

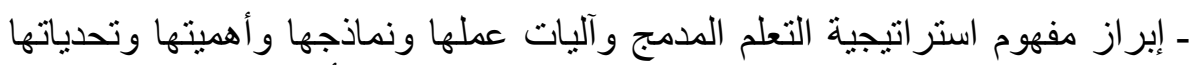
واجر اءاتها، وكذللك مهار ات التفكير العلمى ومهار التهات التهات التعلم أون لاين للمعلمين.

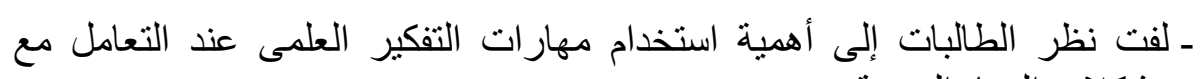
مشكلات الحياة اليومية.

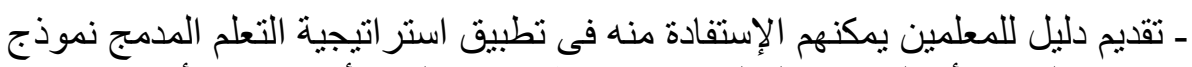

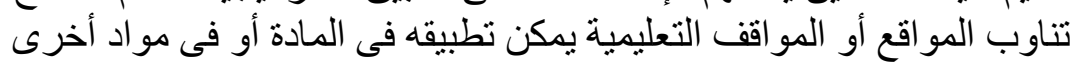

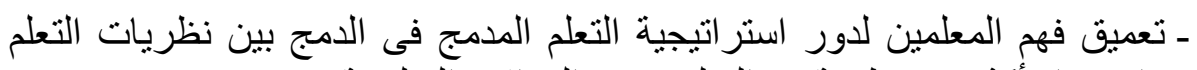

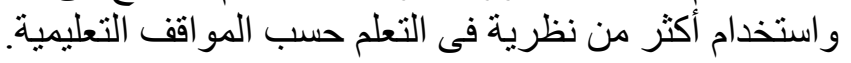

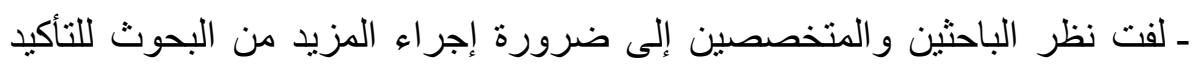

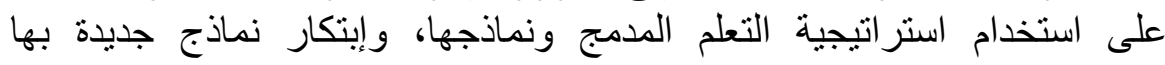


لاستخدامها فى التدريس، وتأكيد السياسات التعليمية على تتمية مهارات التفكير

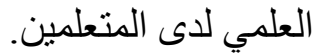

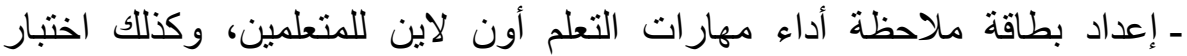

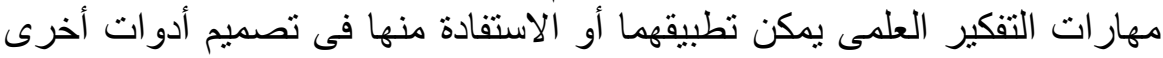

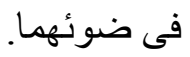

- يفيد البحث الحالى القائمين على العملية التعليمية فى مو اكبة تغيرات العيلى العصر و التقدم العلمى و التكنولوجى عند إعداد المناهج وتقديم استر اتيجيات تدريس حديثة الفئة

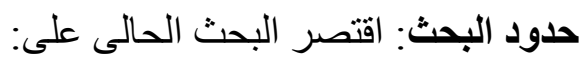

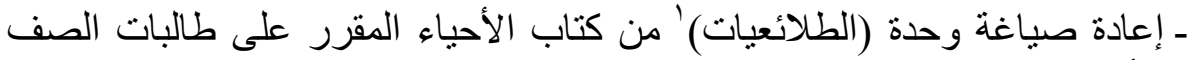

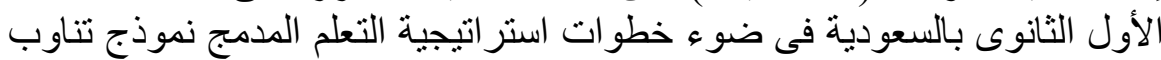

$$
\text { المو اقع أو المواقف التع التعليمية. }
$$

ـ طالبات الصف الأول الثانوى بمحافظة الطائف بالسعودية وتم اختيار هن من مدرسة

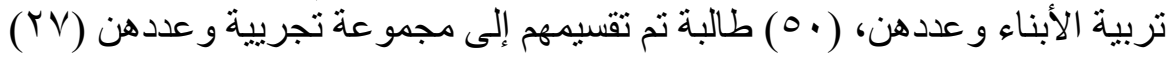

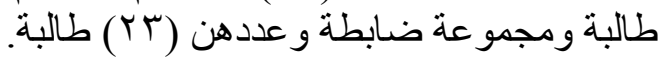

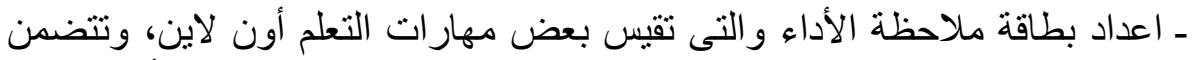

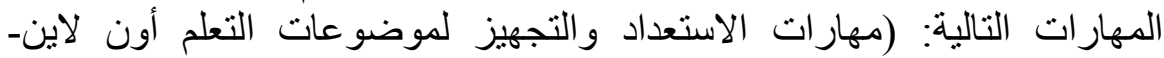

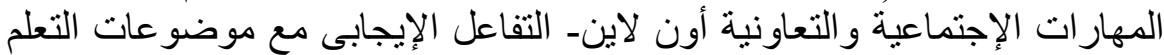

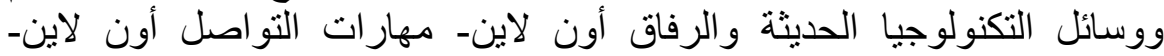
مهار ات استخدام التكنولوجيا الحديثة أون لاين- ومهار التات التان التقويم الذاتى أون لاين).

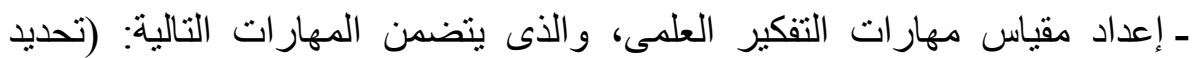
المشكلة فرض الفروض- اختبار صحة الفروض- التفسير - التعميم). فروض البحث: فى ضوء ما سبق عرضه من نتائج الدراسات والبحوث البهات السابقة، يفترض البحث الفروض فى التالية:

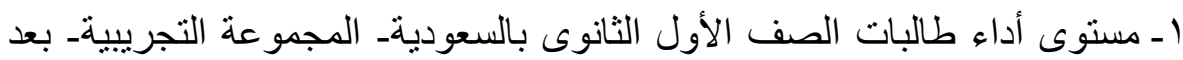

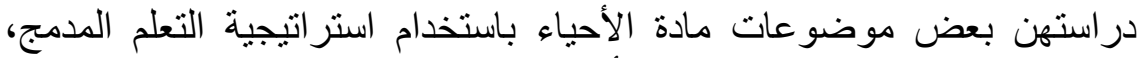

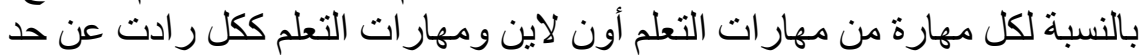

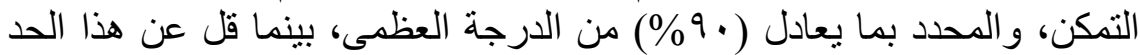
طالبات المجمو عة الضابطة اللاتي درسن بالطريقة التقليدية.

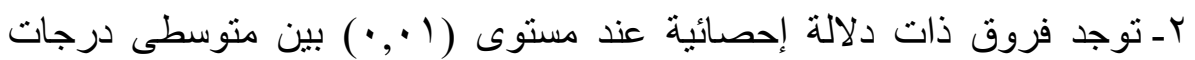
طالبات المجموعتين الضابطة والتجريبية فى التطبيق البعدى لمقياس مهارئ 
التفكير العلمى وذللك فى المقياس ككل، وفى كل مهارة من مهار اته وهى (تحديد

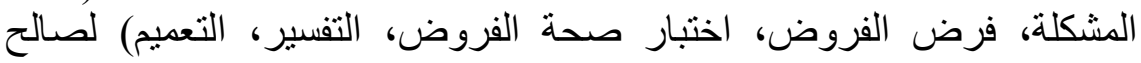
المجمو عة التجريبية.

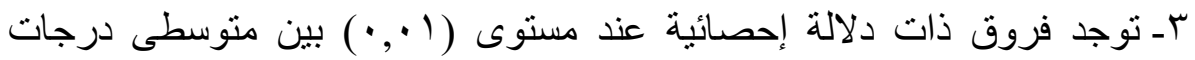

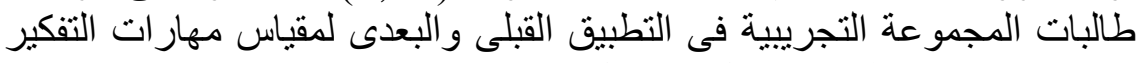

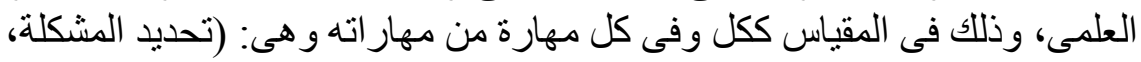

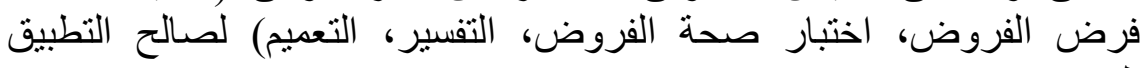
البعدى.

منهج البحث: اتبع البحث الحالى المنهج شبه التجريبى ذا المبه المبو عتين

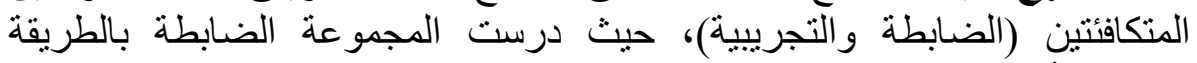

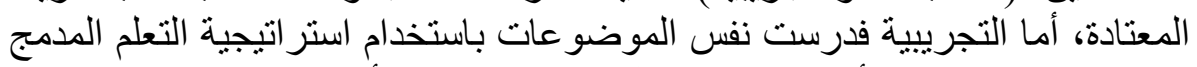

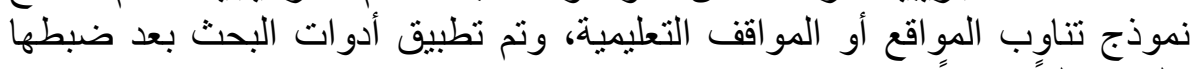
عليهما قبلياً وبعدياً. مصطلحات البحث:

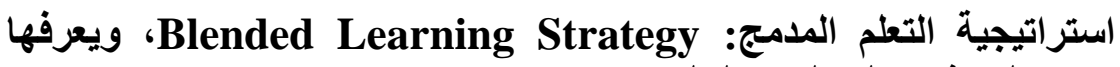
بعض الباحثين على النحو التالي:

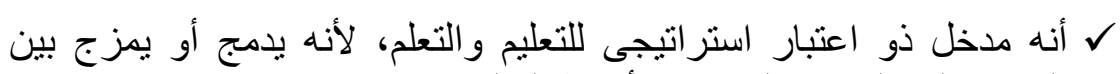
النماذج المختلفة من التدريس و أنماط التعلم. (Battye, G. \& Carter,

\section{9, 11}

ل أنه تكامل إثنين أو أكثر من مداخل التعلم المعتادة أو الرسمية (الصفية) وغير

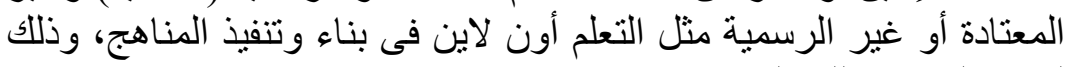

لتنمية الخبر ات للمتعلمين. (Honemond, F., 2010, 7)

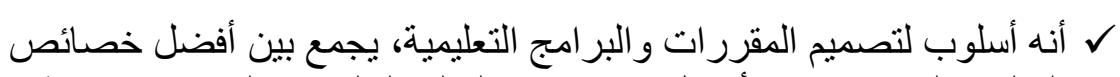

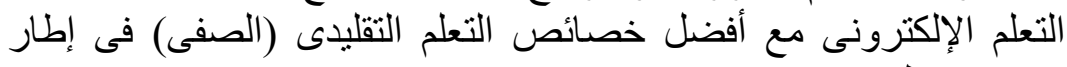

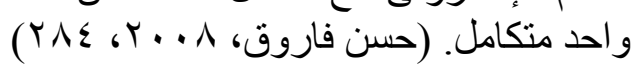

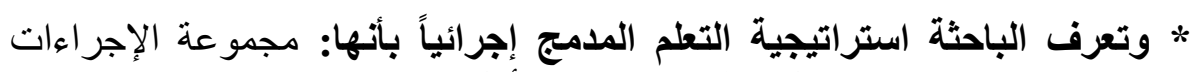

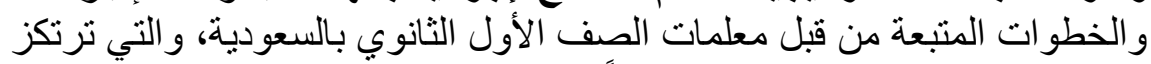

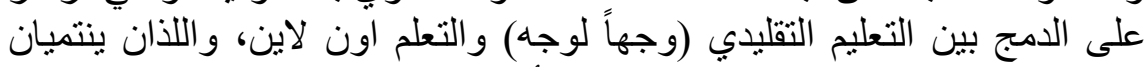

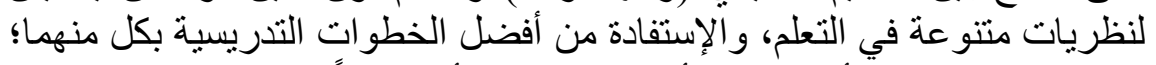

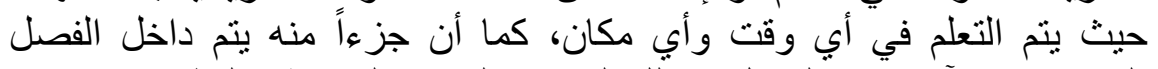

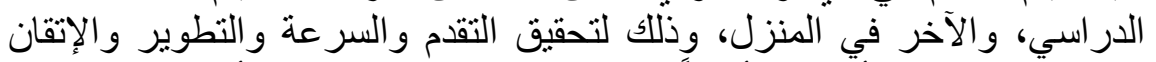

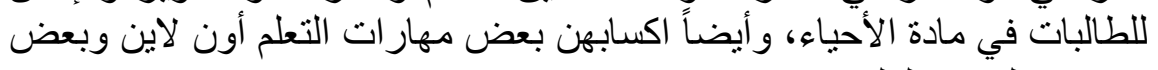

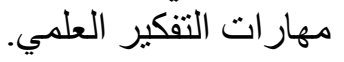


(Y) مهارات التعلم أون لاين: Online Learning Skills، ويعرفها بعض عندئ الباحثين على النحو التالي:

ل أنها مجموعة المهار ات السلوكية و التواصلية التي يتبعها المتعلم لإدارة تعلمه

باستخدام وسائل التقنيات الحديثة أون لاين. (Hura, G., 2008, 421)

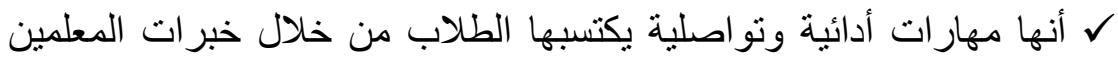

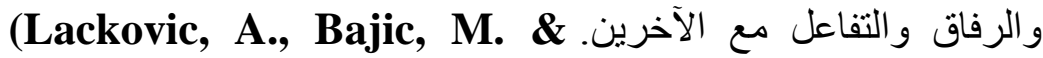

Jandric, P., 2013, 1487) * وتعرف الباحثة مهارات التعلم أون لاين إجرائياً بأنها:

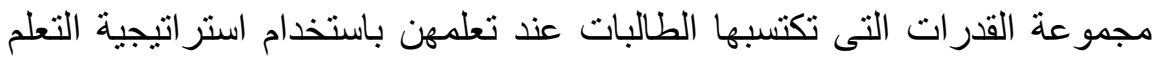

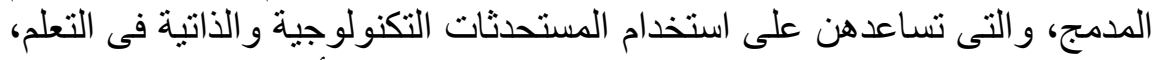

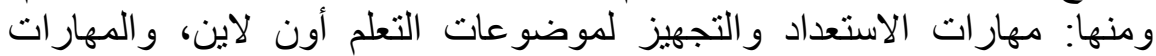

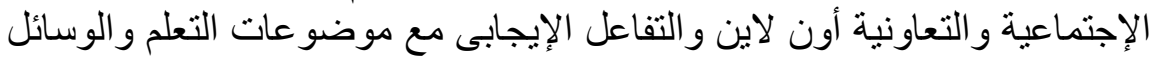

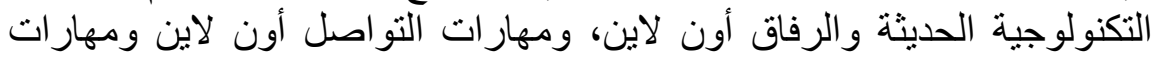

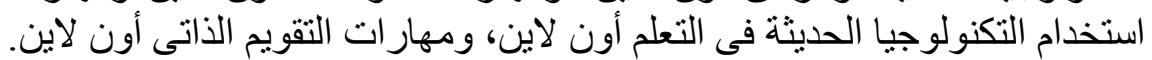

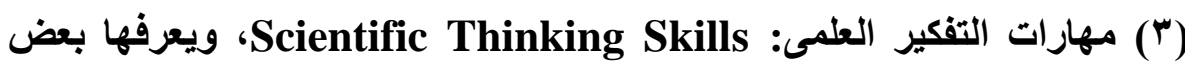
الباحثين على النحو التالي:

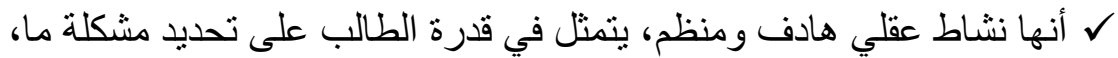

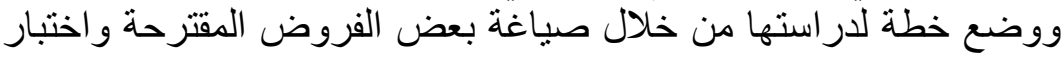

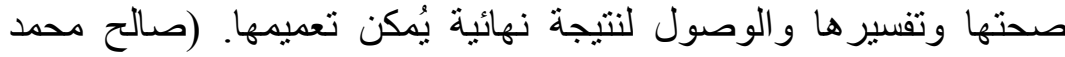

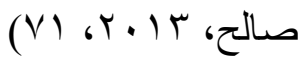

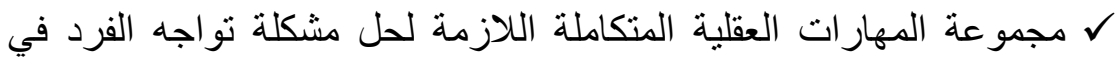

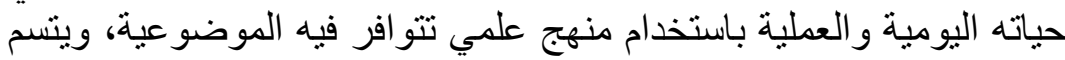

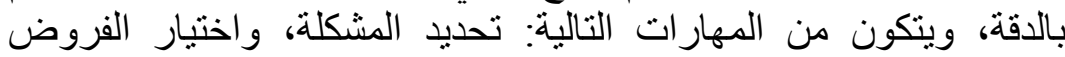

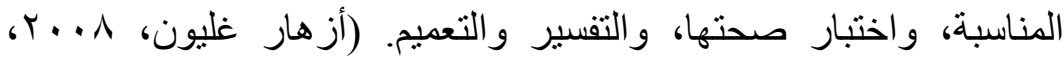

$$
\text { (1. }
$$

ل مجموعة العمليات العقلية المستخدمة في تنظيم الأفكار و المعارف، هادفة

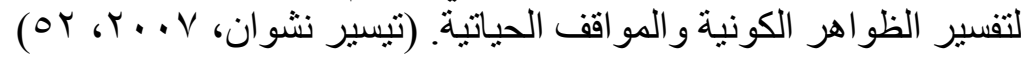
* وتعرف الباحثة مهارات التفكير العلمى إجرائياً بأنها:

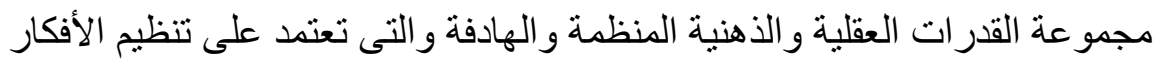

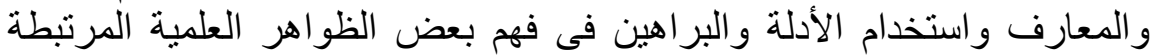

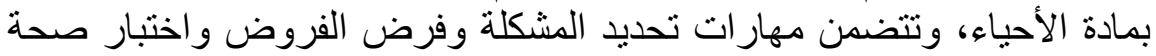

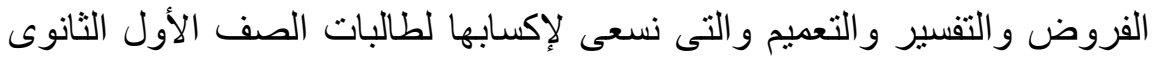


بالسعودية أثناء در استهن للمادة باستخدام استر اتيجية التعلم المدمج لحل المشكلات

(1) استراتيجية التعلم المدمج والنظريات التى ترتكز عليها، مفهومها، أساسياتها،

عو امل نجاحها:

(1/1) نظريات التعلم المرتكزة إليها استراتيجية/التعلم المدمج:

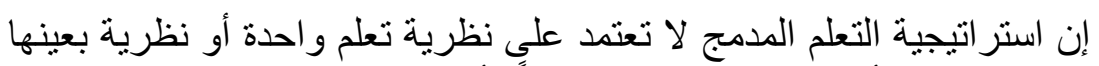

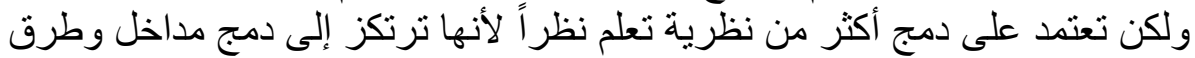

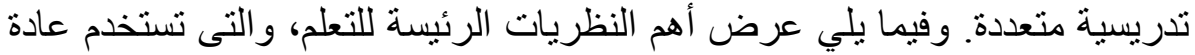
(Alebaikan, R.A, فى بيئات التعلم المدمج فى ضوء وفئ در اسة كل من: العبيكان

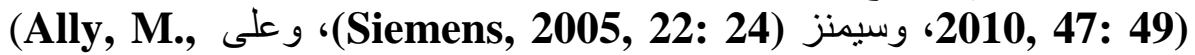
(Saliba, g., Rankina, L. \& 2008, 16: 44) (AyGun, M., 2012, 25:28) وأيجانز Cortez 28 H., 2013, 12: 13)

| النظرية السلوكية Behaviourism Theory: وهئ وهى تعتمد على ملاحظة

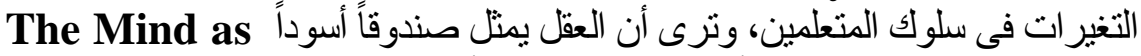
وترف ، Black Box وترفضه ، و بالتالي، فإنها تتو اجد فى طرق أنى التعلم القائمة على الحفظ و التلقين. | النظرية المعرفية Cognitive Theory: وهى ونى تظهر لتعزية لتعزيز عمليات التفكير

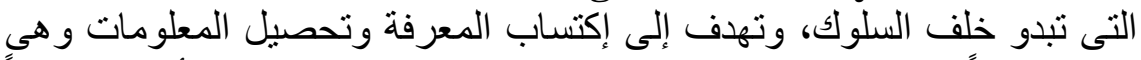

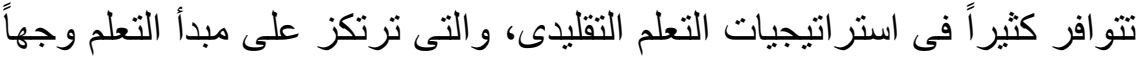

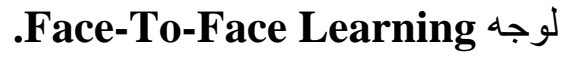

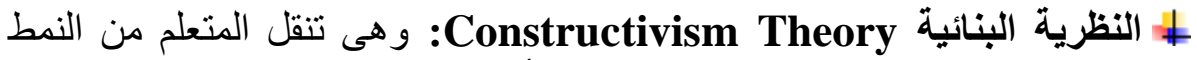

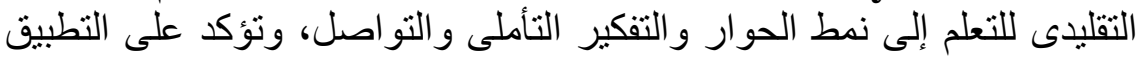

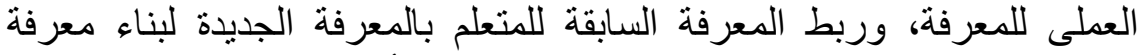

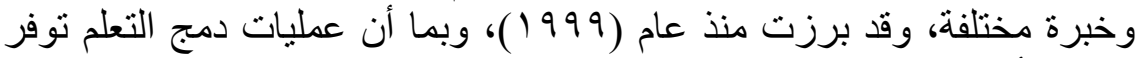

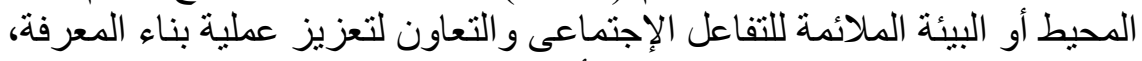

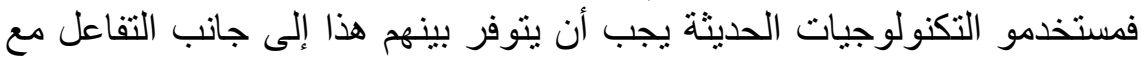

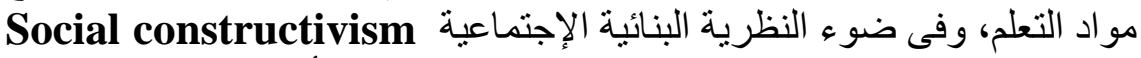
theory

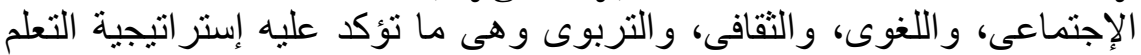

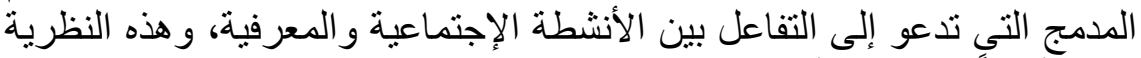

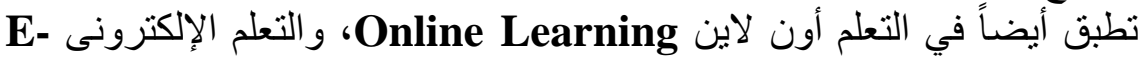


Learning و التعلم الافتراضى Virtual Learning و التعلم المرتكز إلى بلى الويب الفيب ل........ الخ. | النظرية التواصلية Connectivism Theory: وهى من نظريات التعلم

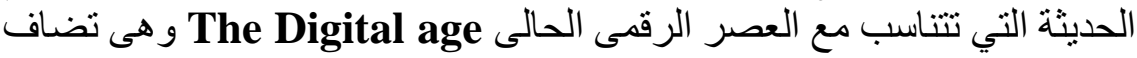

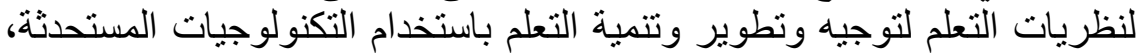
وتعرف بواسطة سمينز (Siemens, 2005, 22: 24) بانها: دمج واتو أو تكامل العناصر المكتشفة فى خلال التعقدية Complexity، والثبكات

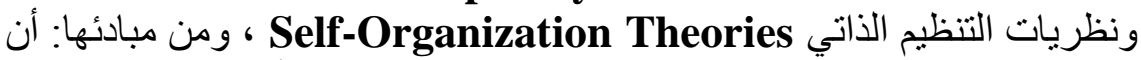

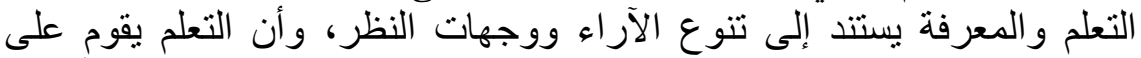

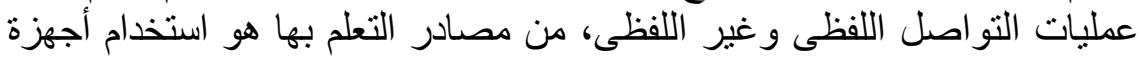

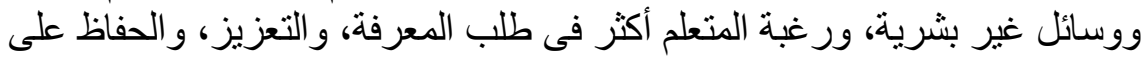

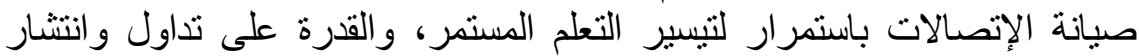

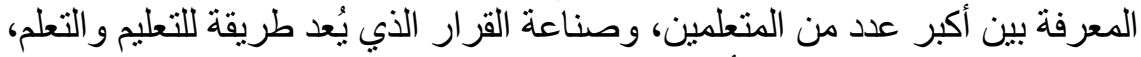

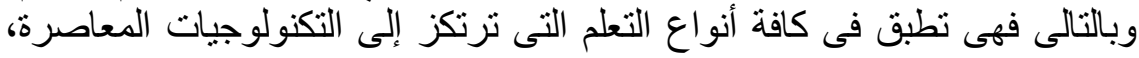

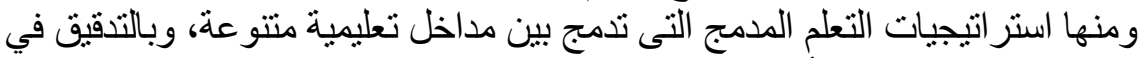
نظريات التعلم، يُلاحظ أنه:

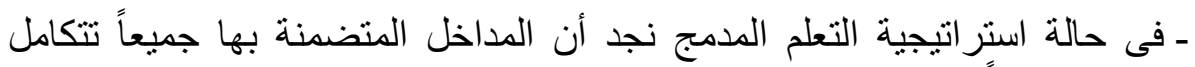
ليحدث تنوعاً في نظريات التعلم المرتكزة إليها.

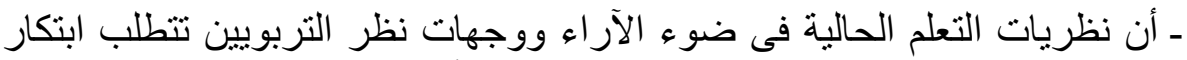

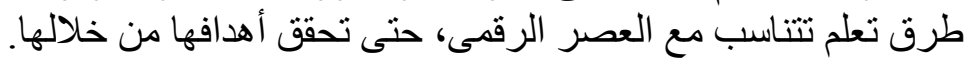

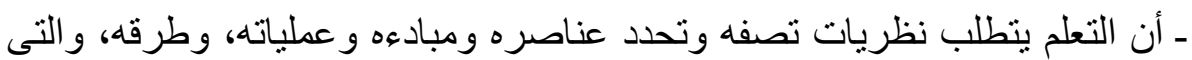
يجب أن تعكس ذللك فى إطار وسياق اجتماعى.

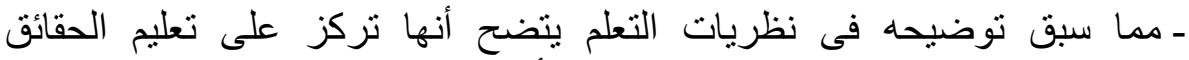

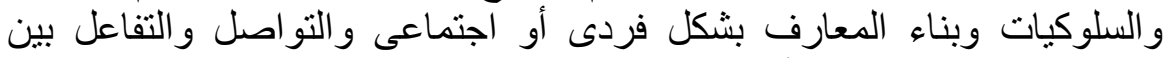
الطلاب، و هذه جميعها من أسس ومبادئ استر اتيجية التعلم المدمج.

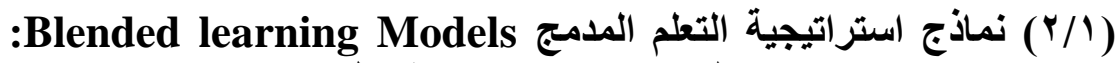

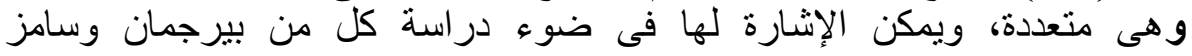
(Bergmann, J. \& Sams, A., 2012, 5: 16) (Vanderkam, L, \& Zinsmeister, K., 2013, 15: 17) (Staker, H. \& Horn, وستاكر وهورن)، (Walne, M., 2012, 1: 26) (Cheung, W.S. \& Hew, K.F., وتشانج و هيور وشنو (M.B., 2012, 1:17 )

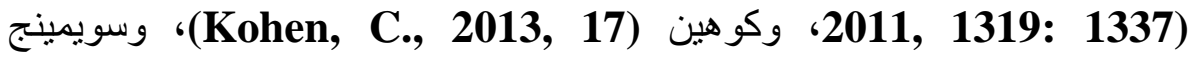
(Nordine, D., 2011, 1:4) (Thoeming, B., 2013, 1: 5)

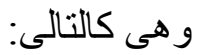




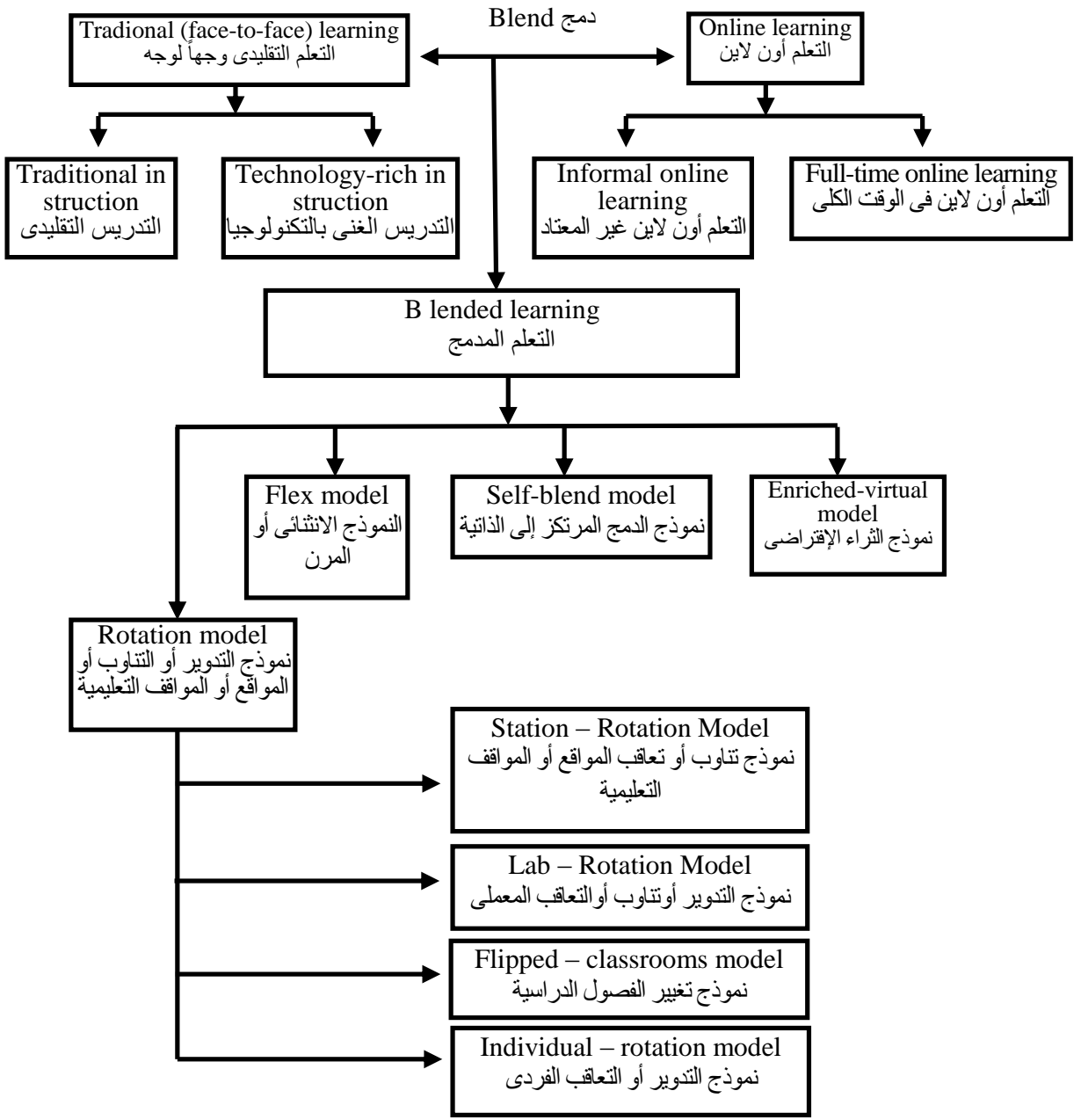

شكل توضيحى ( ( ): لتصنيف نماذج استر اتيجية التعلم المدمج (Staker, H. \& (5.2012) Horn, M. B., 2012, 2:5)

$$
\text { ويمكن تنيان تللك النماذج كما يلى: }
$$

مـ نموذج الثراء الإفتراضى Enrich-virtual Model: وتنغلب عليه صفة التعلم

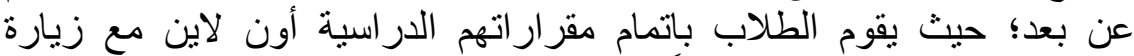

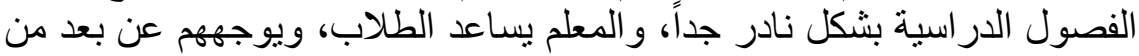

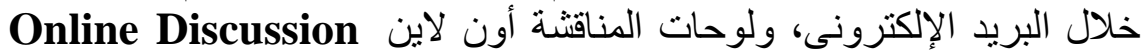
Boards

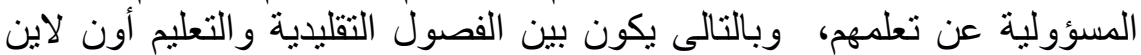

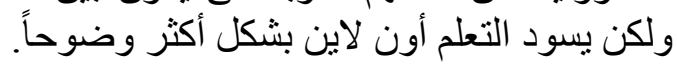




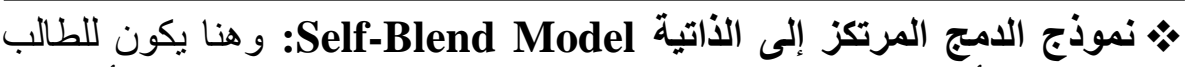

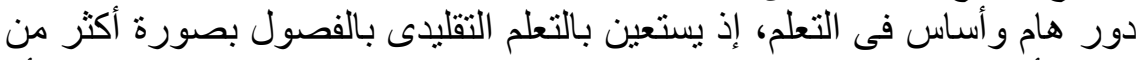

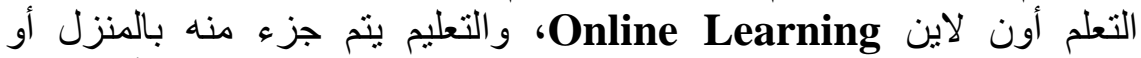

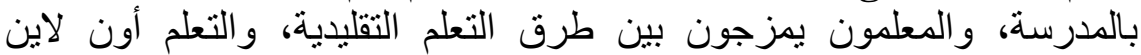

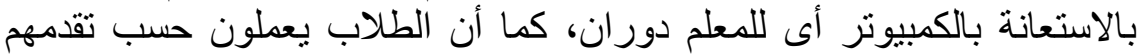

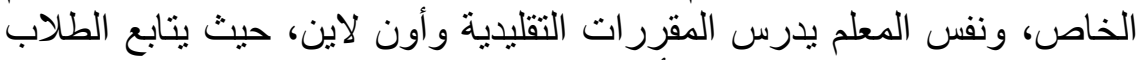

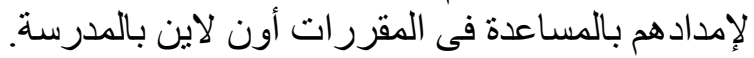

•. النموذج الإنثائى أو المرن Flex Model: ويستخدم التعلم التقليدي أو التعلم

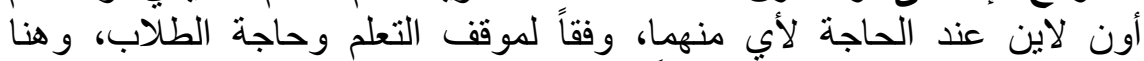

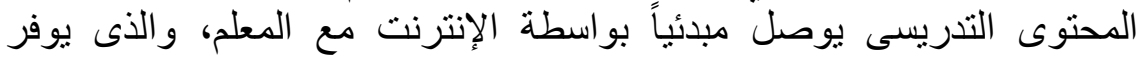

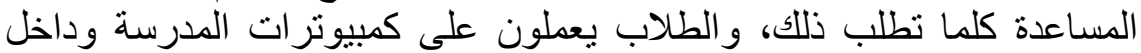

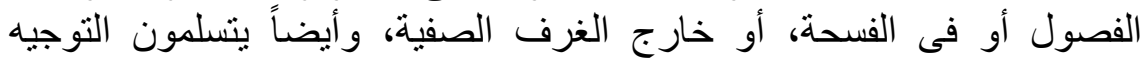

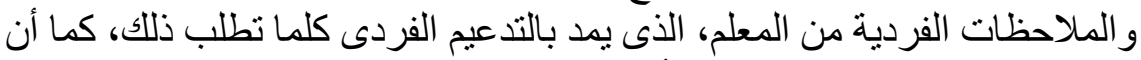

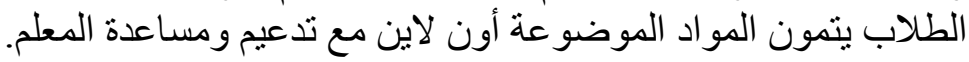

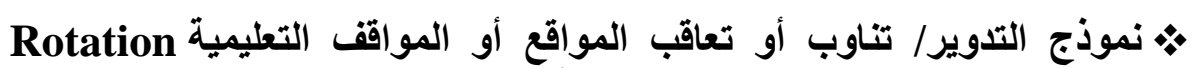
Model

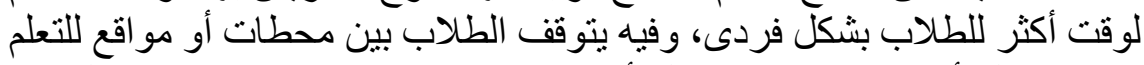

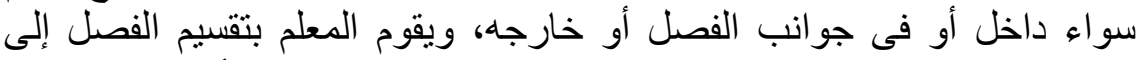

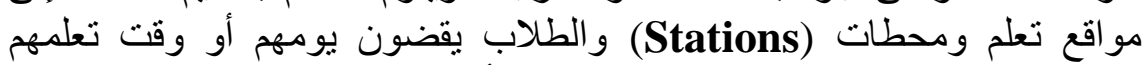

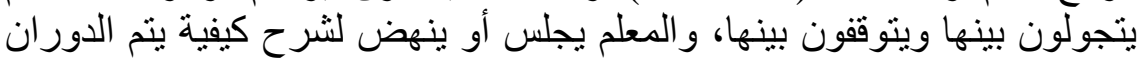

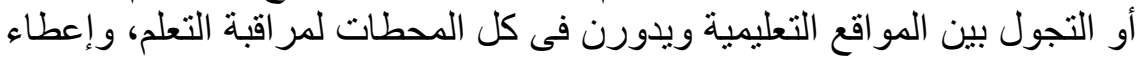

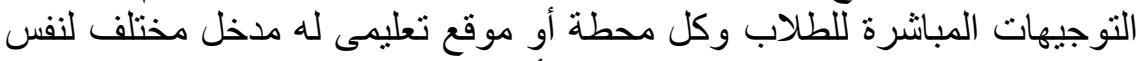

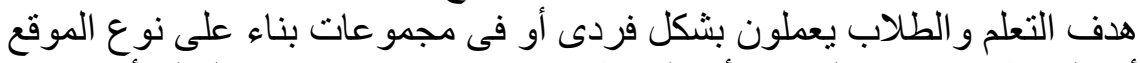

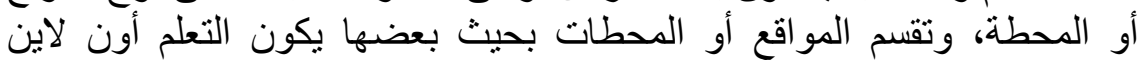

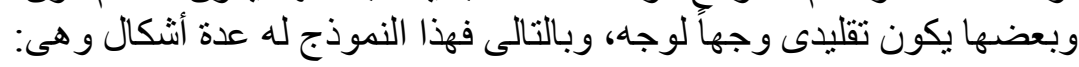

$$
\begin{aligned}
& \text { ـ تدوير أو تناوب أو تعاقب المو اقع أو المو اقف. } \\
& \text { ـ التدوير أو التناوب أو التعاقب المعملى. } \\
& \text { ـ تغيير تتظيم الفصول الدراسية. } \\
& \text { ـ التدوير أو التناوب أو التعاقب الفردى. }
\end{aligned}
$$

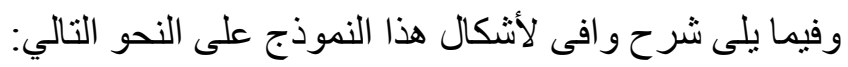

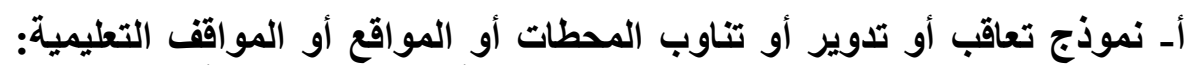
أ Station- Rotation Model

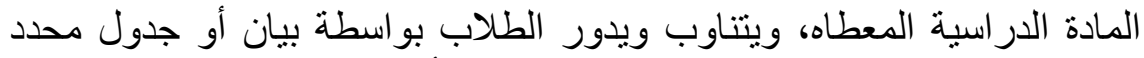
بوقت معين يحتفظ به المعلم، وتتضمن المواقع أنشطة في مجموعات المول صغيرة 


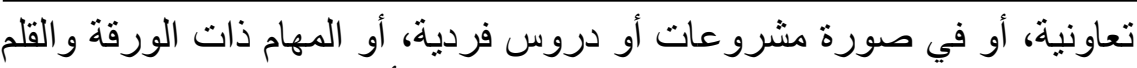

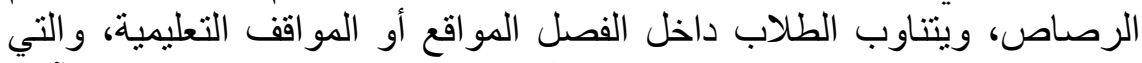

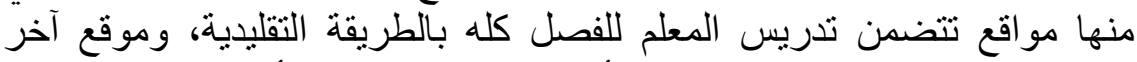

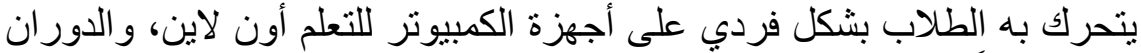

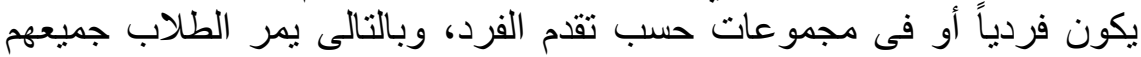
على جميع المو اقع التعليمية حتى تتحقق أهداف التعلم.

موقع أو موقف تعليمي (r)

Individualized online instruction

التدريس أون لاين بثكل فردى باستخدام الكمبيوترات, حيث

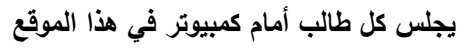

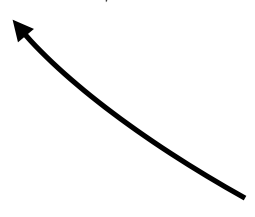

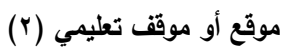
Collaborative activities \& stations

أنشطة تعاونية فى مواقف متنوعة

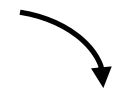

موقع أو موقف تعليمي (1) (1) موان

Teacher-led instruction المعلم يدرس للطلاب المجتمعون حوله وجهاً

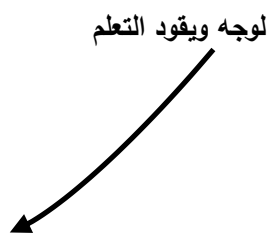

شكل توضيحى (r): لنموذج تعاقب أو تدوير أو تناوب المواقع أو المواقف التعليمية.

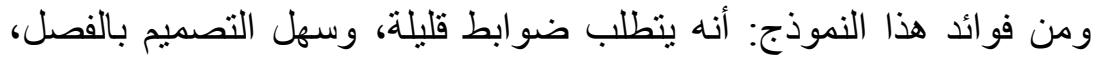

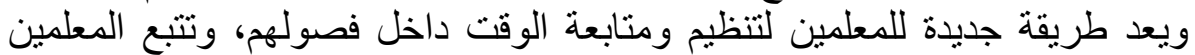

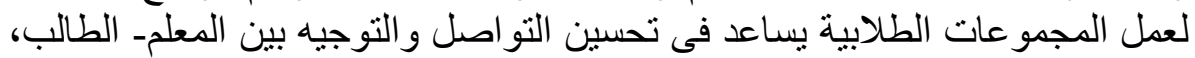

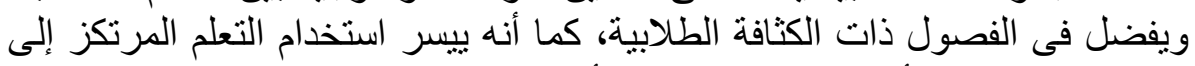
المشرو عات كموقع أوموقف ذات لإنجاز التعلم أون لإين.

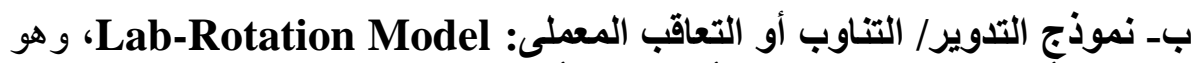

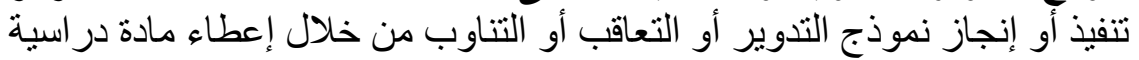

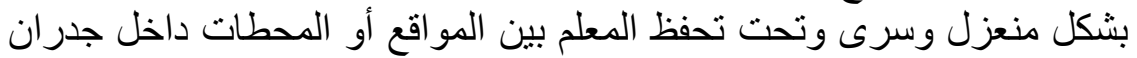

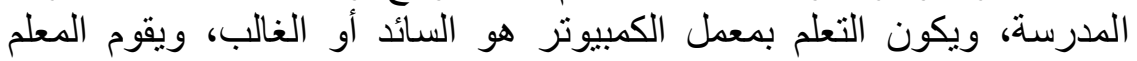

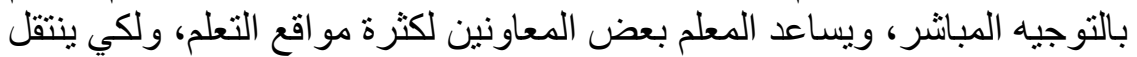

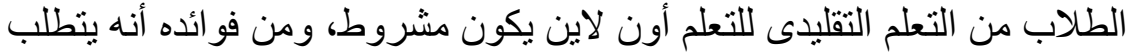

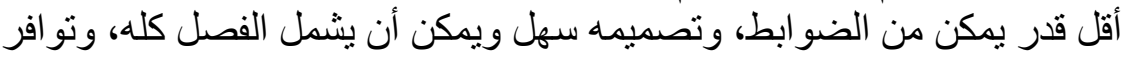

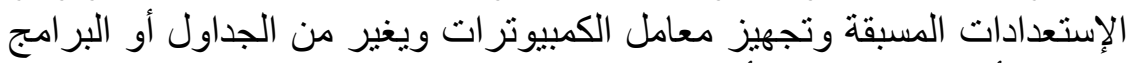

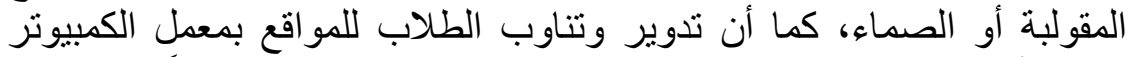

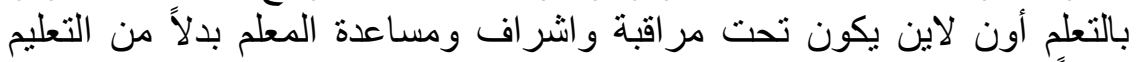

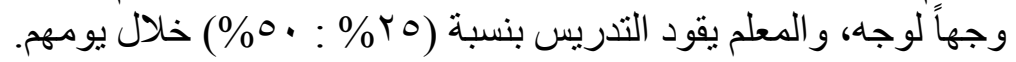


ج- نموذج تغيير تنظيم أو تحريك الفصول الدراسية Flipped-Classroom Model

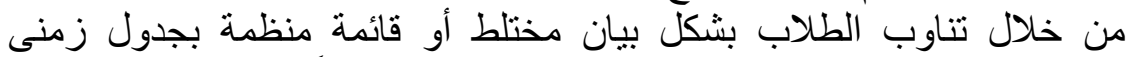

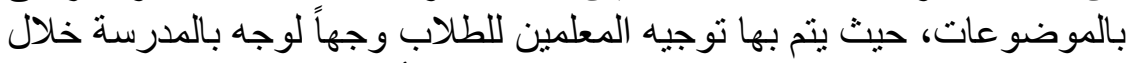

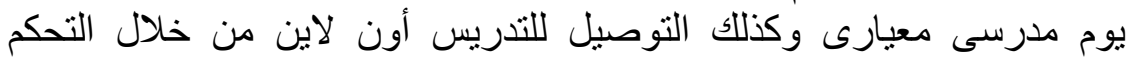

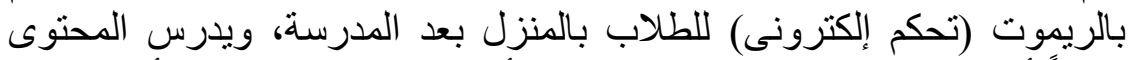

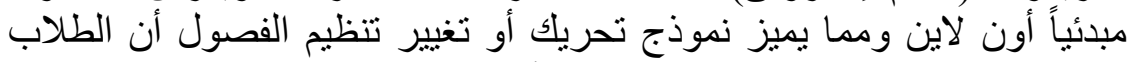

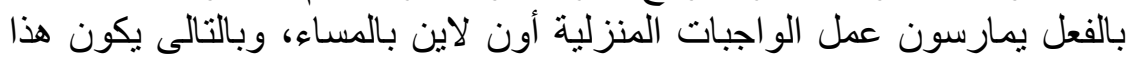

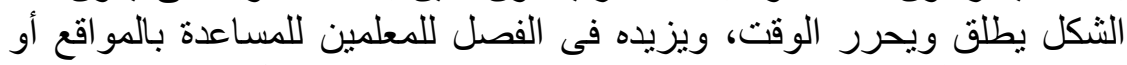

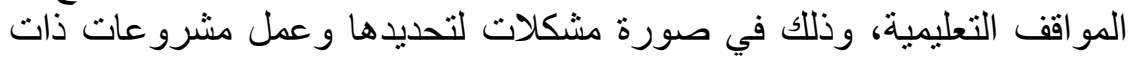

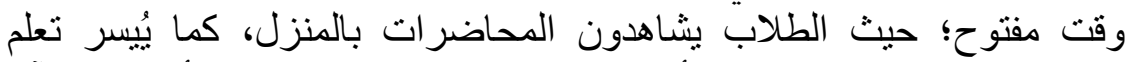

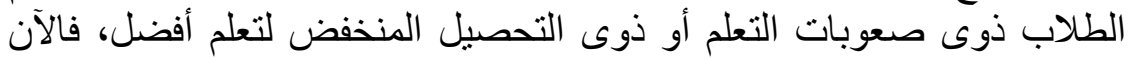

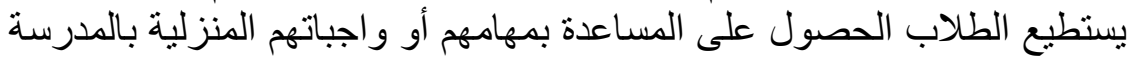

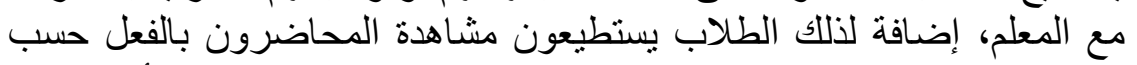

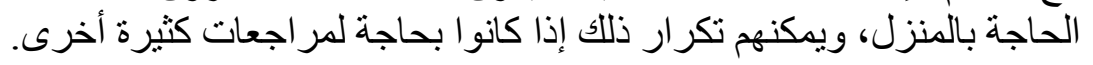

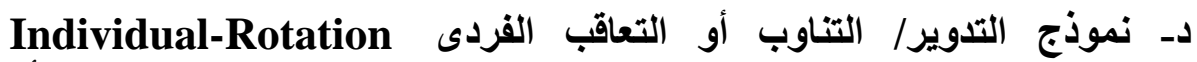
Model

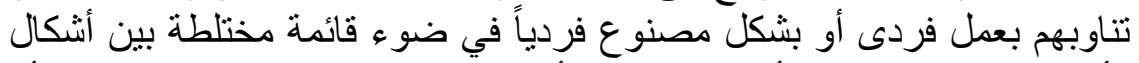

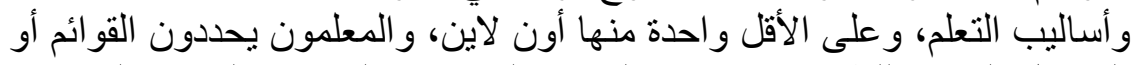

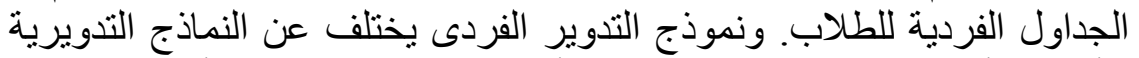

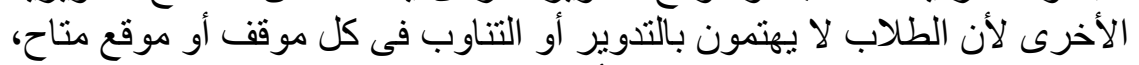

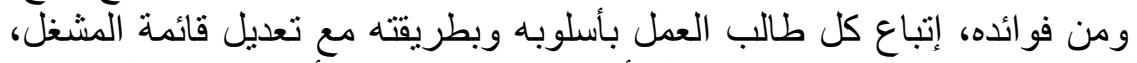

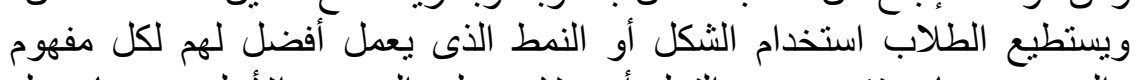

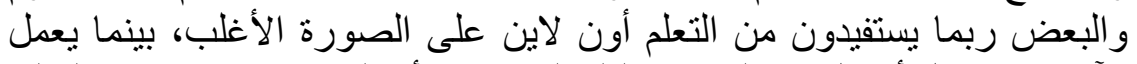

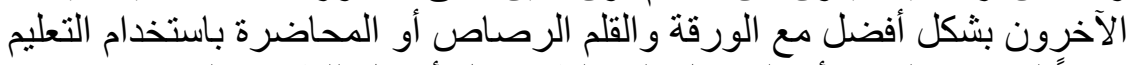

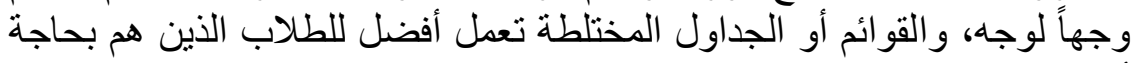

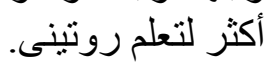

\section{Definition of Blended مفهوم استراتيجية التعلم المدمجي (}

\section{:Learning Strategy}

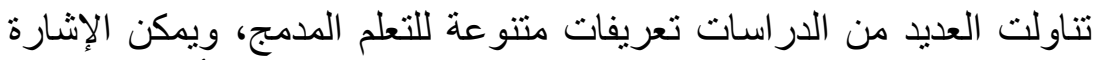

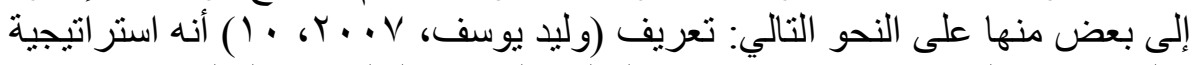

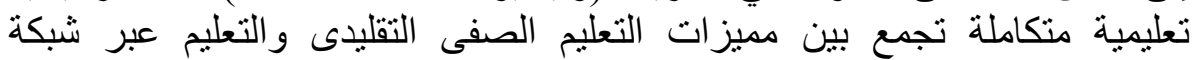

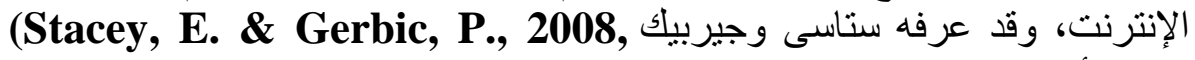
960)

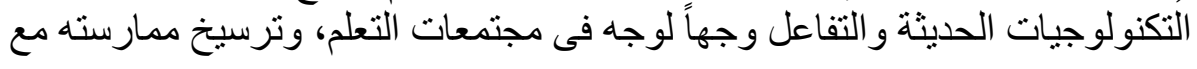




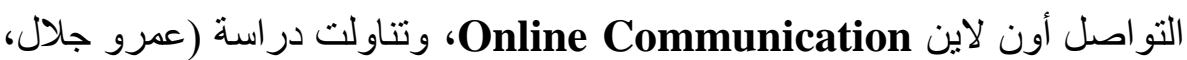

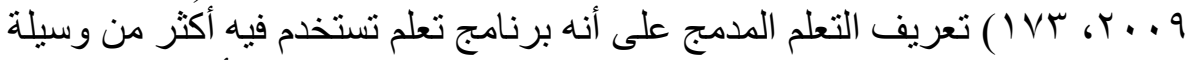

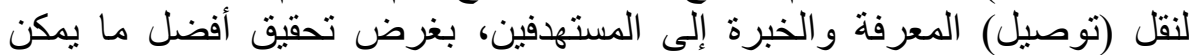

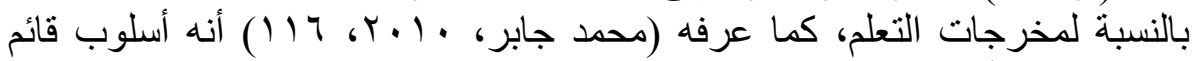

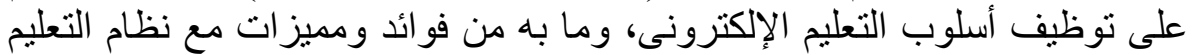

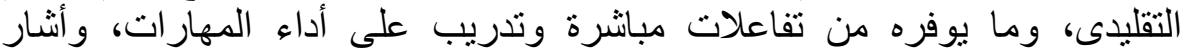

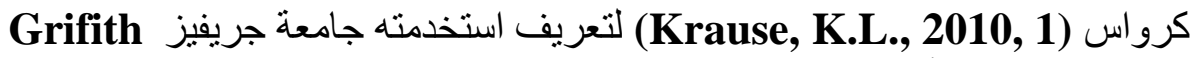
University والاتصالات Information and Communication Technologies لتتجيع التعليم والتعلم، حيث يمزج بين عدة أنماط أو أساليب تعليمية

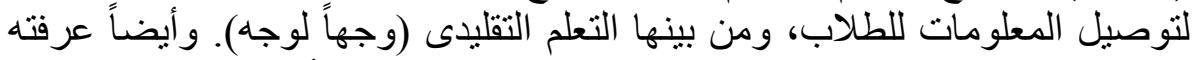

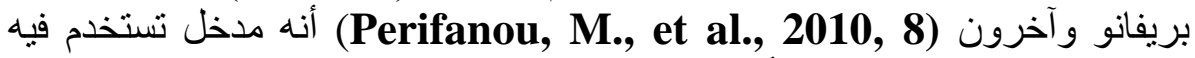

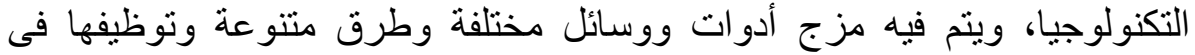

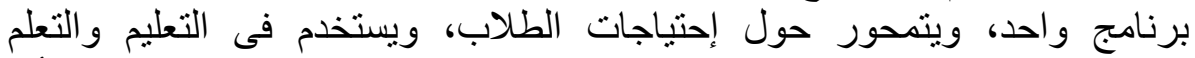
و التدريب. وكذلك عرفته ريم العبيكان (Alebai Kan, R.A., 2010, 221) أنه إنه

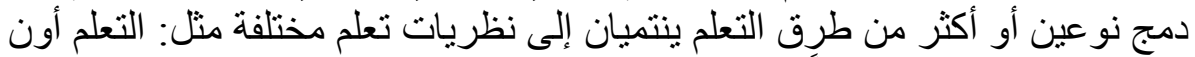

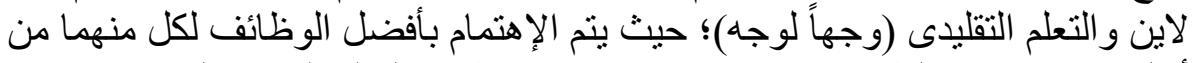

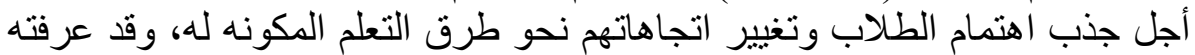

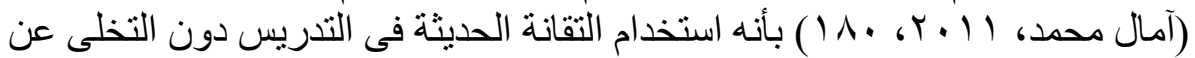

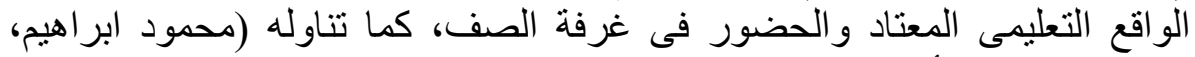

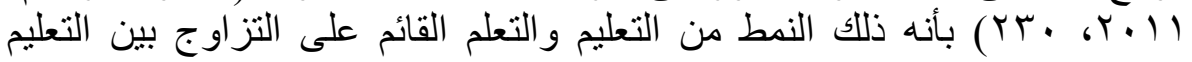

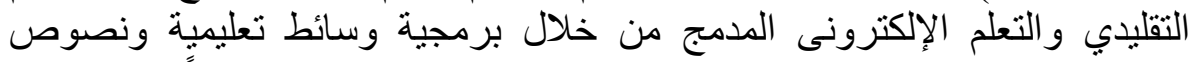

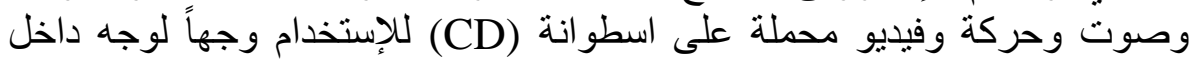

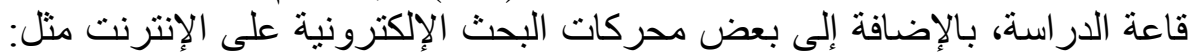

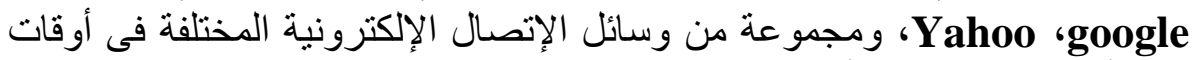

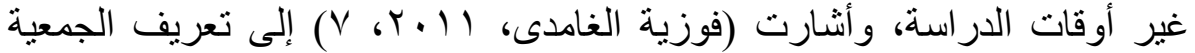
American Society for Training And الأمريكية للندريب و التطوير بأنه التعلم الذى يتم بالدمج المخطط له لأى من التفاعل

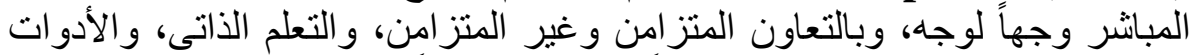

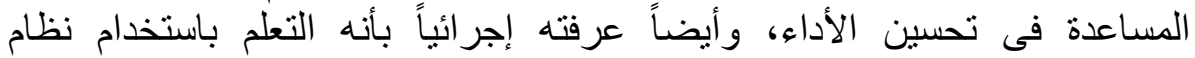

البلاكبورد ونظام إدارة التعلم الإلكترونى الإنى

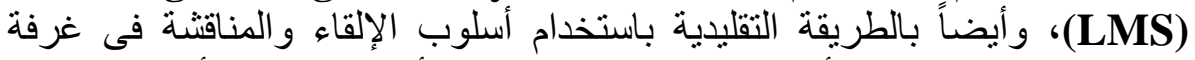

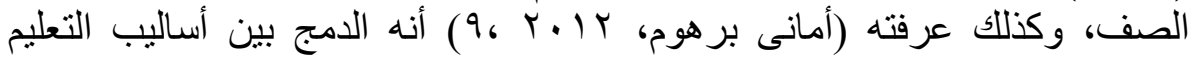

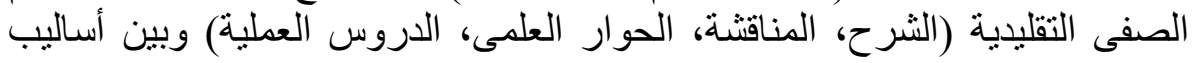
التعلم الإلكترونى (إنترنت- بريد إلكترونى الكنى مكتبة إلكترونية تفاعلية، محادثة منتديات

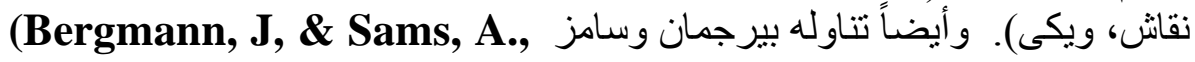




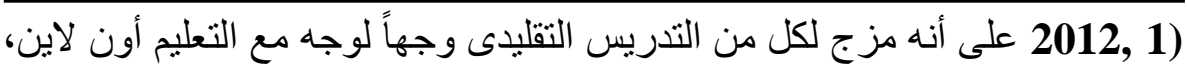

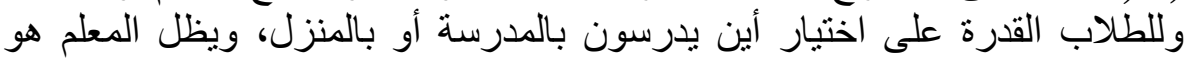

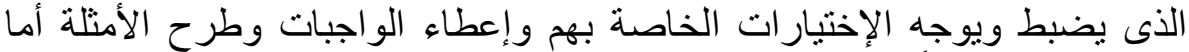
باقى التعلم يتم ذاتياً أون لاين Self-Study Work Online، كما أنثارت در اسة الأنة

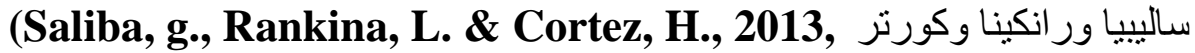
University of western إلى تعريف جامعة غرب سيدنى بأستراليا Sydney, Australlia (UWS)

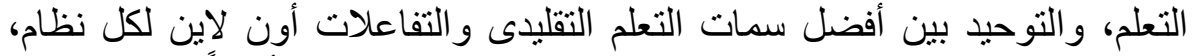

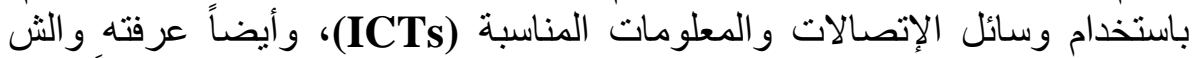
أنه تهجين Walsh, N.M., 2013, 3)

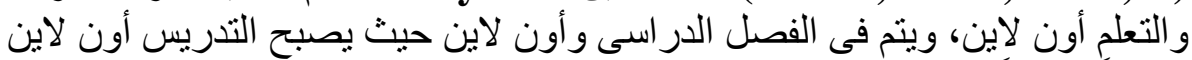

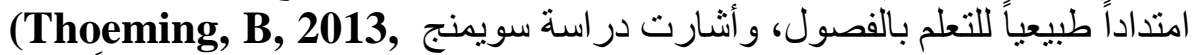

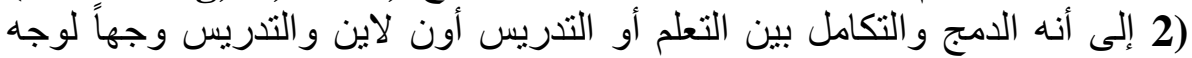

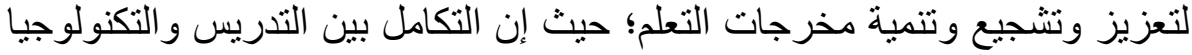
نمط تدريسى يُمد المعلم بالمرونة الإضافية للتدريس الجيد، وكذللك عرفه نيهادي (Nehadi, A.H., 2013, 2) (Wikipedia)

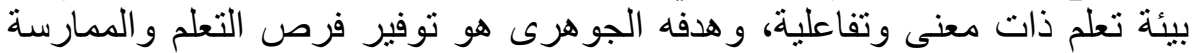

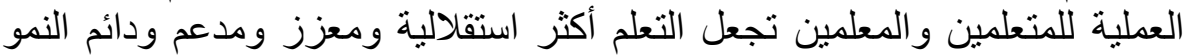

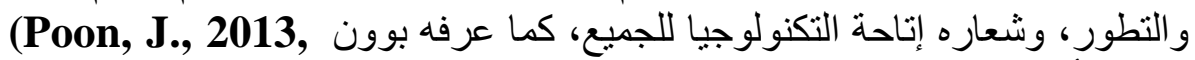

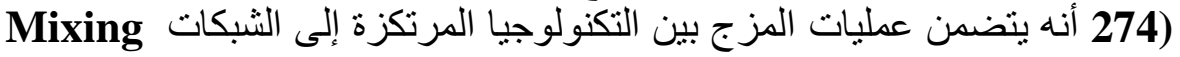
Web- based Technology

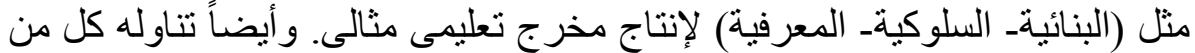

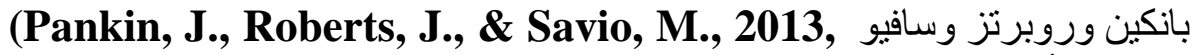

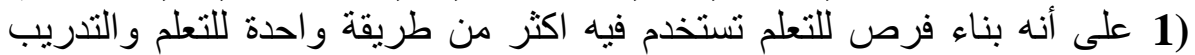
داخل وخارج الفصل، حيث يتضمن دمب دمج التعلم بطرق مختلفة مثل (المحاضرة

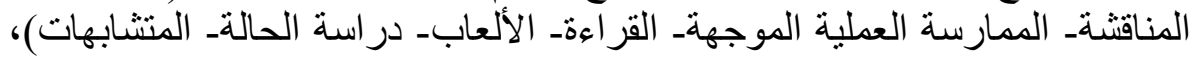

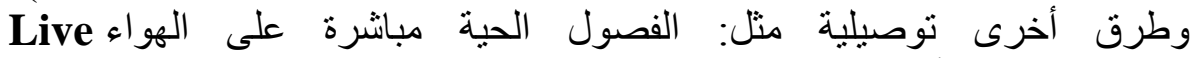

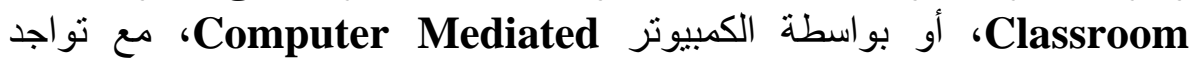

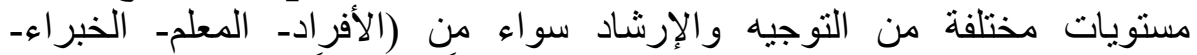

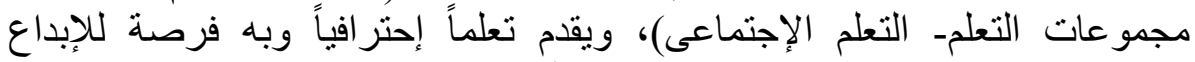
(Bailey, J., et al., 2013, و التجديد. وكذلك اتفقت در اسة كل من بايلي و آخرون) (Cohen, C., 2013, 5) ونون ونوردين (Nordin, D., 2011, 1) وستاكرو هورن (Staker, H. \& Horn, M.B., 2012, 3)، وفيندين (C), وزينسميستر (Vanderkam, L. \& Zinsmeister, K., 2013, 14) على أنه برنامج تعليمى، يتعلم فيه الطالب على الأقل فى جزء منه من خلال التوصيل أون أنه 


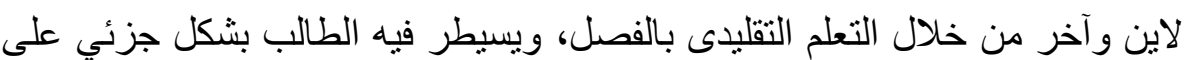

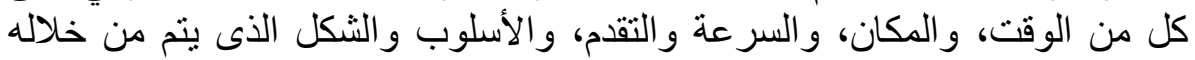

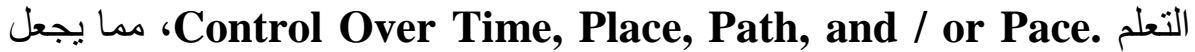

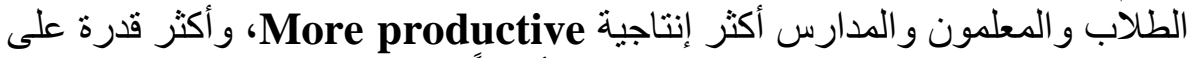

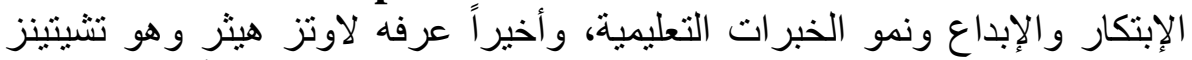
(Lautzen Heiser, D.K. \& Ho chleitner T., 2014, 3) بين التعلم التقليدى وجهاً لوجه والتعلم أون لاين، حيث يحدث تغير لدور التكنولوجيا

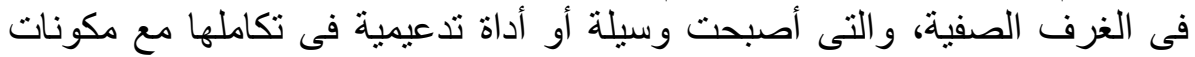

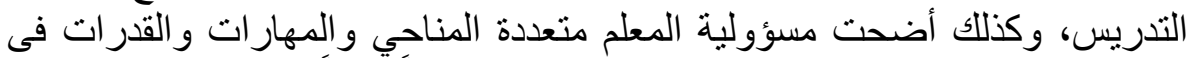
توصيل المحتوى داخل الفصل وخارجه بما يحقق تدريساً هادفاً وأكثر إنتاجية.

ومن خلال التعريفات السابقة يمكن تعريف استراتيجية التعلم المدمج إجلئ إجرائياً

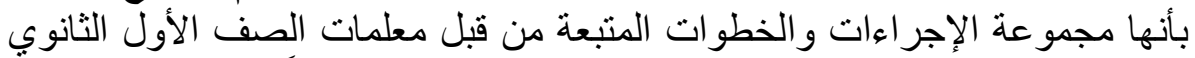

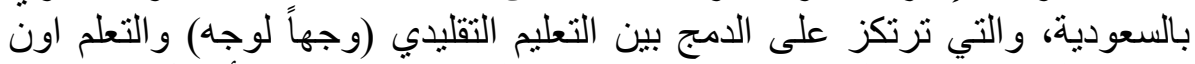

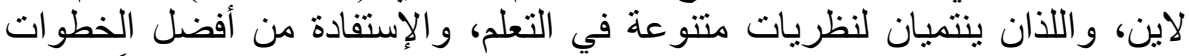

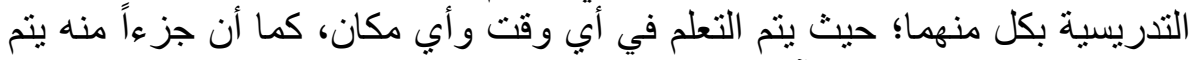

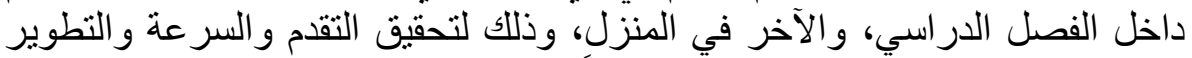

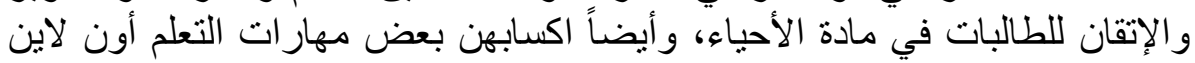
وبعض مهار ات التفكير العلمي.

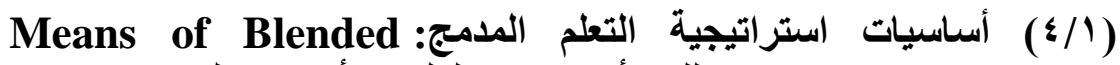
Learning Strategy

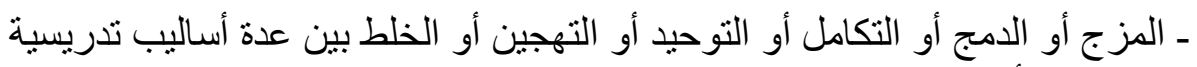

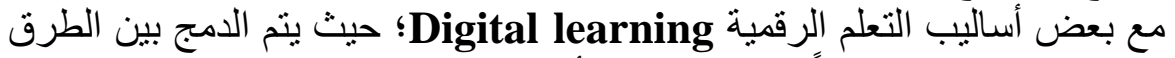
التقليدية اللاصفية (وجهاً لوجها الرفه والتعلم أون لاين، واستخدام التكنولوجيا الحديثة ودمجها فى التعلم.

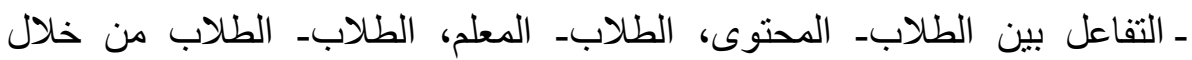
التو اصل بالطرق الحديثة أون لاين، ومن خلال الطلابل الأنثطة التعاونية أون لاين.

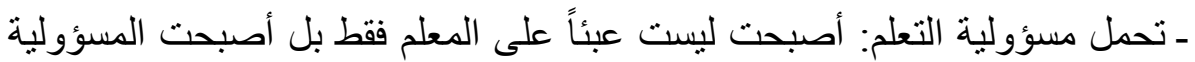

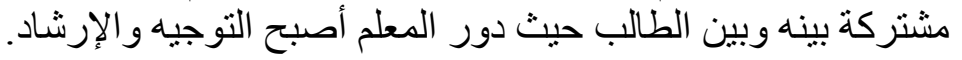

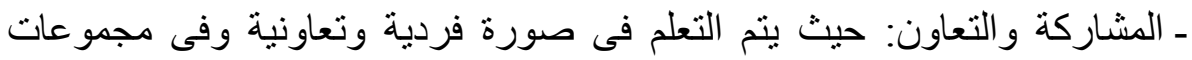

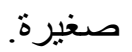

ـ الذاتية: الإعتماد على الذات فى كثير من الأحيان فى التعلم و التوصل للمعلومات. ـ الإستفادة من نظريات التعلم المختلفة والتى تتو افر جميعها فى استراتيجية التئية التعلم

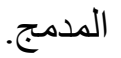




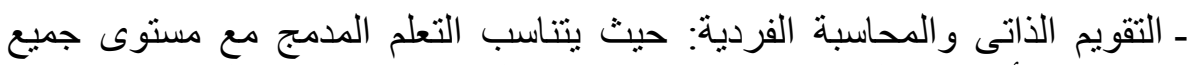

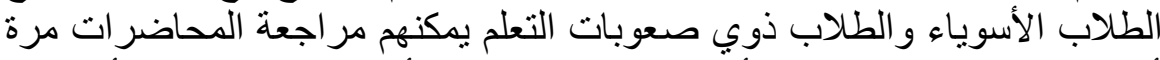

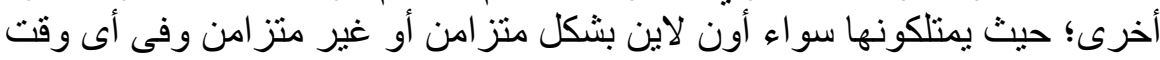
وفى أى مكان.

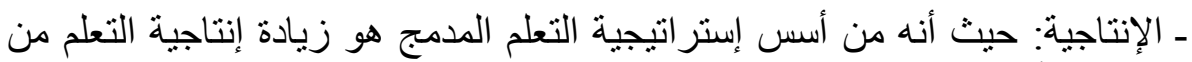

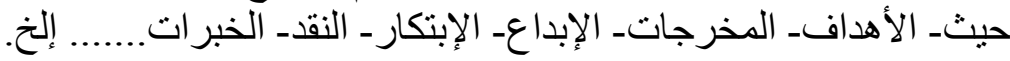

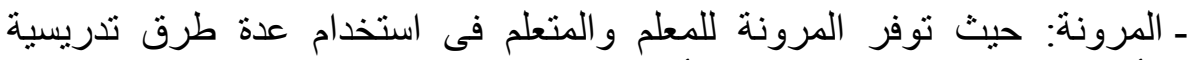

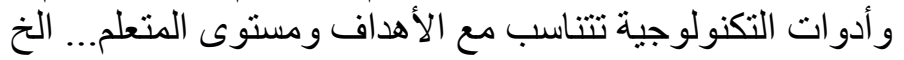

ـ تحرير الوقت والإمكانيات للمعلم والمتعلم ليكون التعلم المدمج فى متناول كافة لهنة المتعلمبن.

(o/1) فوائد استخدام استراتيجية التعلم المدمج: مearifites of Blended Learning Strategy (Battye, G. \& Carter, H., 2009, 5: 11) (Adas, D. \& و و آداس وباكير)، (Hadjerrouit, S., 2008, 181: 210) (Bailey, J \& وبايلى ومارتين وآخرون (Bakir, A., 2013, 254: 266)

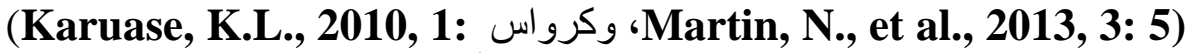
(The Oxford ومجمو عة أكسفورد وكينيو) (Poon, J, 2013, 276) و وكرون (T) 2) (School ومؤسسة سكوول وايرز group \& Kineoxeport, 2013, 13) و هوينموند (Honemond, F., 2010, 8: 9ires, 2012, 1: 6) النحو التالي: ـ المساعدة فى الوصول إلى الجودة العالية و الإهتمام باحتياجات تعلم الطلاب.

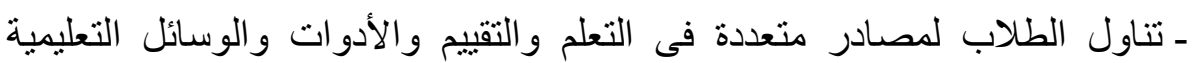
الرقمية للمساعدة المباشرة لتوجيه التقدم أو السرعة أو الإتقان وتشكيل التعلم.

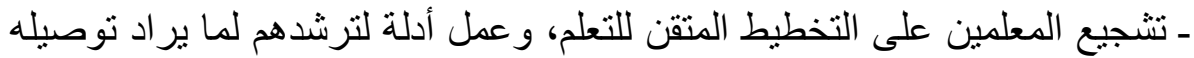

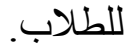

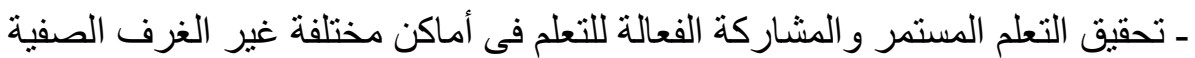

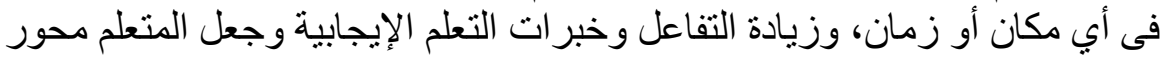

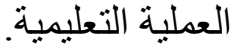

- زيادة قدرة الطالب على التعديل والتغيير وبقاء أثر التعلم لديه وجعل التعلم أسهل و أيسر. ـ احداث التوازن بين تحصيل المعرفة وامتلاك المهار ات الحياتية والتطبيقية وتقرير

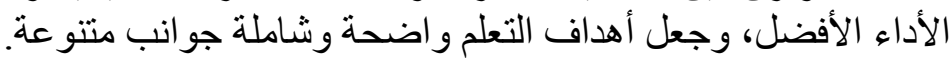
ـ تحقيق الإبتكار و الإبداع فى التعليم و التعلم، و الاهتمام بمردودات الهداء التعلم. 


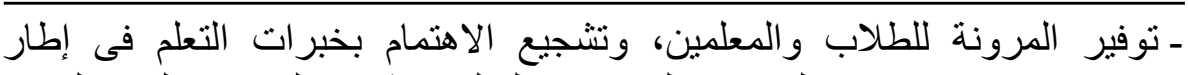

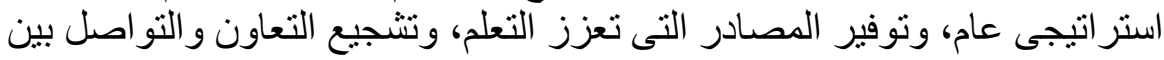
الطلاب فيما بينهم، وبينهم و المعلمين.

ـ مساعدة الطلاب على استخدام التكنولوجيا بفعالية فى المهام، وتدعيم فاعليتها. ـ تدعيم انتشار التعلم حول العالم، وجعله للجميع، توصيله من خلال التقنيات المختلفة.

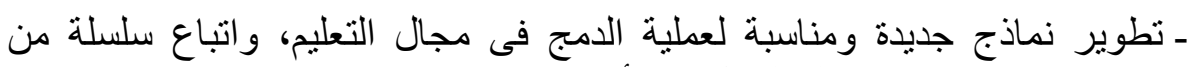
السلوكيات التى تقود للتعلم الفعال، و التأكيد على المهار فئ فئ ات البيشخصية.

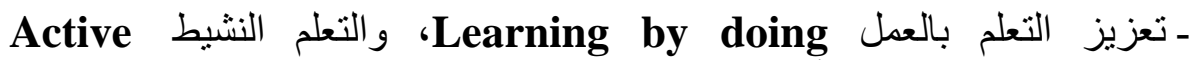
Learning و إستخدام أعلى مستويات التفكير كالتحليل والتخليق والتقويم بشكل أفضل

ـ التأكيد على مهار ات فاعلية المجمو عات، و التى تدعم فكرة التقافة التعاونية باستخدام

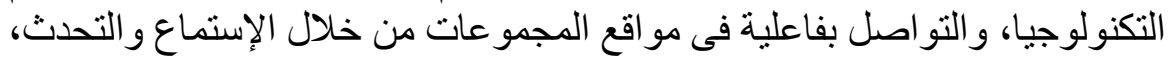
وتوفير التغذية الر اجعة المناسبة.

- يعد وسيلة وأداة للتعلم الرقمى، وتعزيز التقييمات وتعديلها في ضوء ما ما يتطلبه

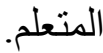

- يعتبر استر اتيجية هامة فى مجال التعليم و التدريب و التعلم وتحسين التعلم الذاتي.

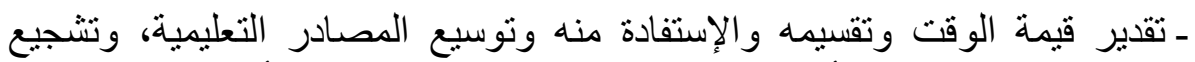

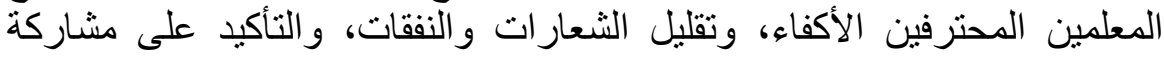
الآباء في التعلم.

ـ تحقيق أفضل مخرجات و أهداف تعليمية و عائدات وكذلك تنمية الخبر ات.

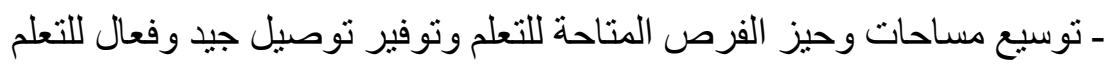

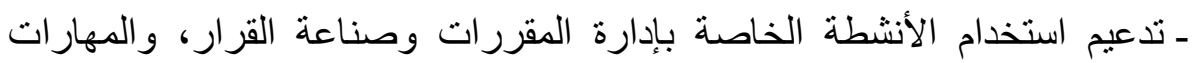

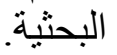

ـ تخفيض معدل التراجع التحصيلى للطلاب وتقوية وتعزيز بيئة التعلم المهنية

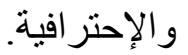

ـ التعلم المفضل لتعليم جماعات طلابية ذات كثافة عالية وتحسين الأداء. ـ التعلم السريع و المعجل للمشاركين، وتعجيل الإنجاز و التنفيذ، وتتمية مهارات التفكير العلمي.

Factors That (7/1) عوامل تعزيز نجاح استراتيجية التعلم المدميرج) Promote Successful Blended Learning Strategy المؤثرة فى فاعلية استر اتيجية التعلم المدمج ويمكن تبيانها بالاستعانة بدر اسة كل من: 
ستاسى وجيربيك (Stacey, E. \& Gerbic, P., 2008, 966: 967) و وأوليفير (Massoud, (Olivier, W., 2014, 1: 14) (Naaj, وناج وناتشوكى و أنكيت و Iqbal, U. \& Stockley, D., 2011, 8: 9) M., Nachouki, M. \& Ankit, A., 2012, 188: 191) وبانكين وروبرتز وسافيو (Wilka, M. \& Cohen, J., 2012, 1: 10) (Pankin, J, Roberts, J. \& Savio, M., 2012, 1: 2) (Adas, D. \& Bakir, A., 2013, 254: 266)

(أ) عوامل خاصة بالمعلم Factors Regarding Teachers:

ـ التطوير المهنى و التتمية المهنية المستمرة للمعلمين لوقت كاف وبشكل متميز ـ تدعيم تكنيكات و إجر اءات التدريس الحديثة خاصة التدريس المدمج

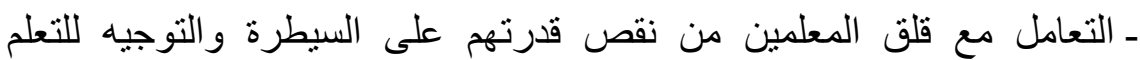

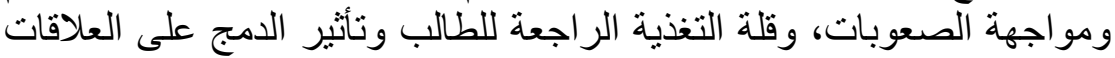

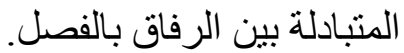

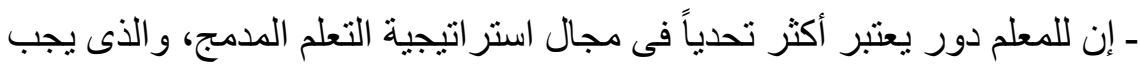

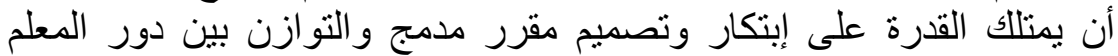

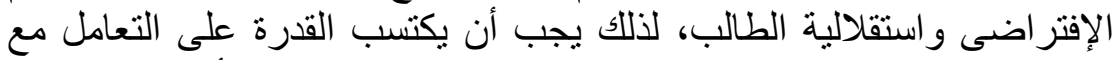

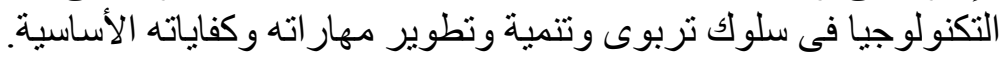

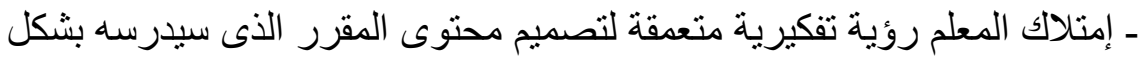

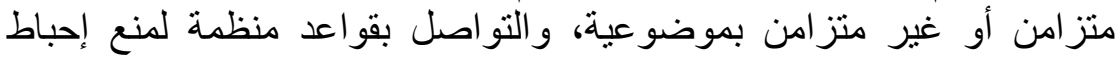

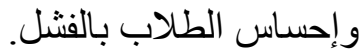

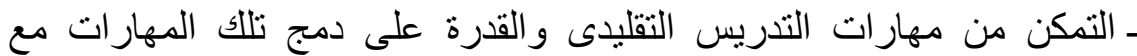
التدريس أون لاين فى تصرف مثالى، وأن يكونوا متمتعين بالمرونة في التدريس.

ـ القدرة على الإنسجام الفعال و النشط مع المناقثات أون لاين، والتهاب التغذية الراجعة

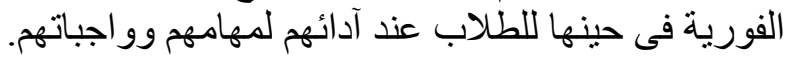

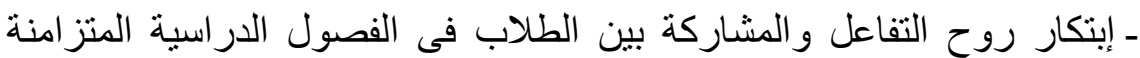

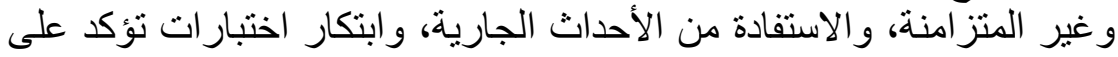
ذاتية الطالب و إجر اءات التقييم الذاتى. ـ تيسير التعلم باللغات الأجنبية فى المو اقف غير المعتادة . ـ توفير فرص التنافس بين الطلاب فى المخرجات التعليمية المختلفة والمتنو عة ـ القدرة على مناقتنة الطلاب بالفصل فى النقاط الرئيسة فى المحاضرات

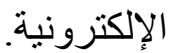




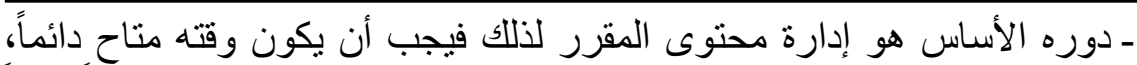

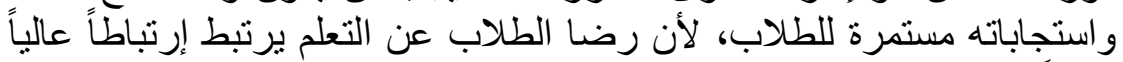

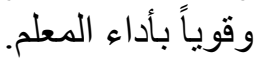

\section{(ب) عوامل خاصة بالطالب Factors Regarding Students:}

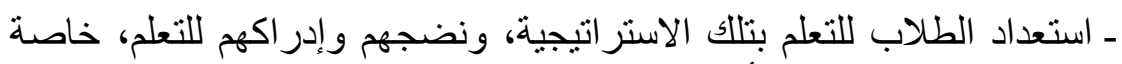

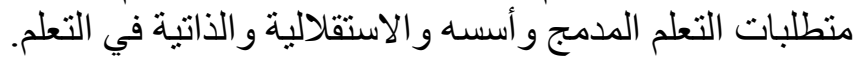

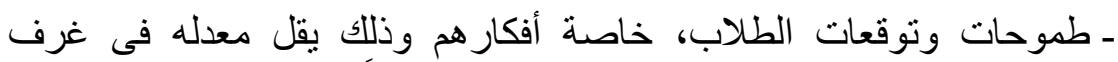

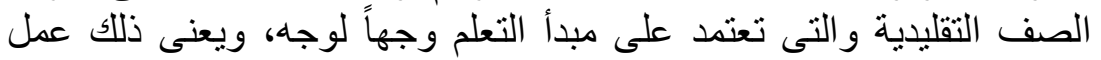

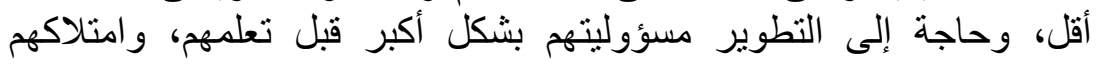

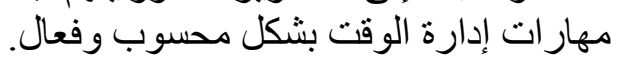

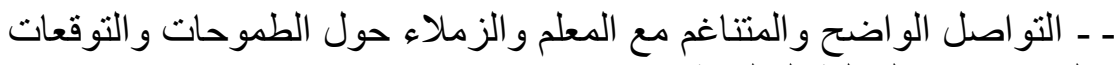
الجديدة من العملية التعليمية.

ـ تقييم وتقدير الذات والإنتظام فى استخدام اختبار ات التقويم الذاتى لتحديد نقاط الضعف و التأكيد على الذات و الثقنة بالنفس النفات

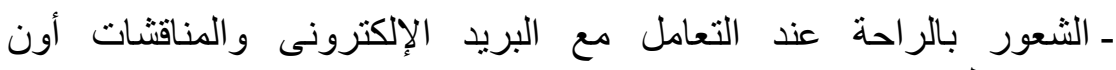

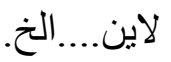

ـ الاستعداد للمساعدة والتعاون مع الآخرين فى مهام وواجبات المجموعة، و الفهم العميق اموضو عاد لات التعلم.

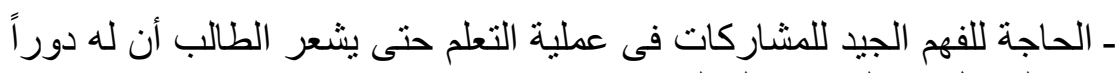
فى التفاعل مع القرناء و المعلم.

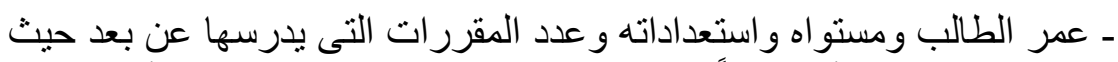

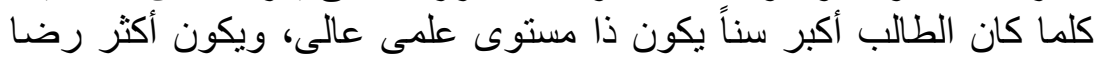

$$
\text { و واستجابة للمقررات الطيات المدمجة. }
$$

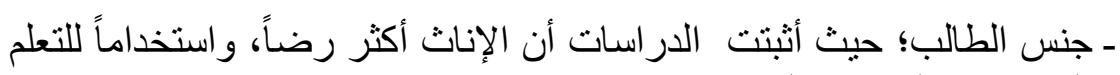

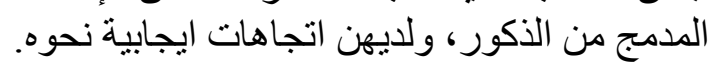

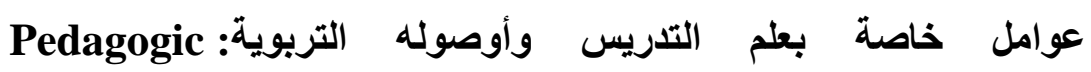

\section{Consideration}

ـ مر اعاة أن الدمج و التكامل بين بيئات التعلم التقليدى و الإفتر اضى و التعلم أون

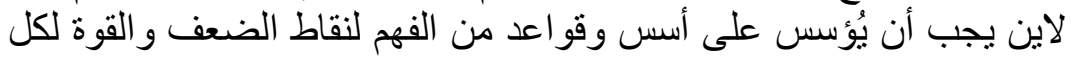

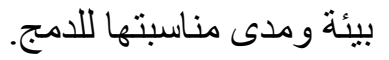

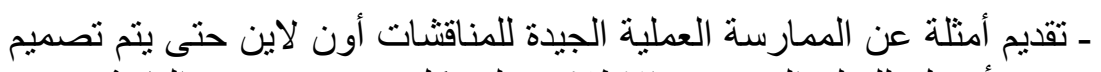

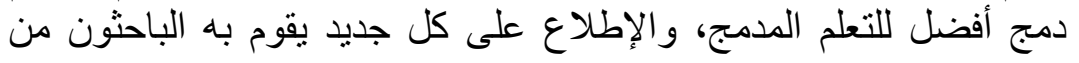




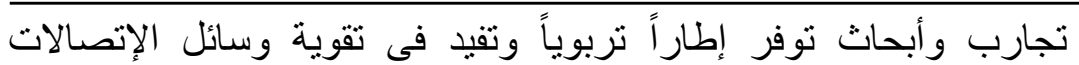
و المعلومات و الميديا و الأنشطة المتنو عة للتعلم.

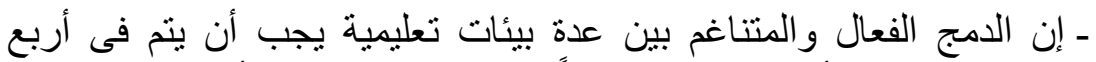

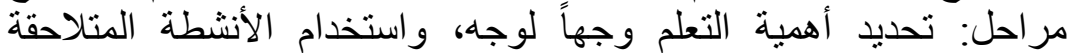

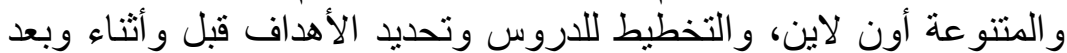

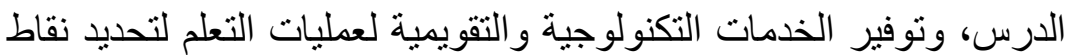
الضعف و القوة لكل البيئات المدمجة.

ـ ضمان الممارسة الجيدة لإستراتيجية التعلم المدمج بتحديد اجر اءاتها وتقدير

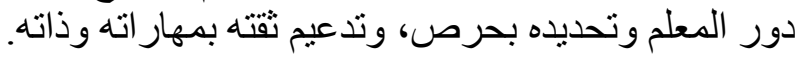

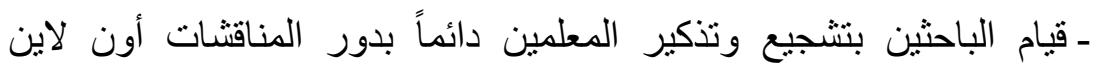

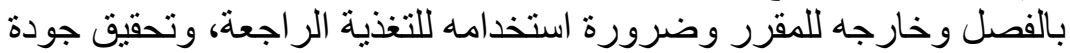

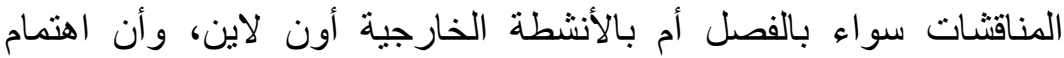

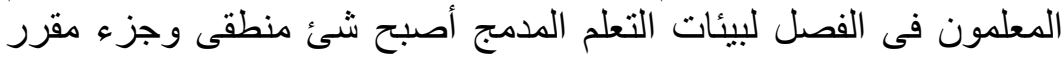

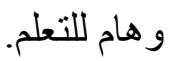

- إنتاج أطر تربوية Pedagogical Frameworks لتدعيم استراتيجية التعلم المدمج للطلاب و المعلمين، و عمل أور اق إرشادية توزع على التى المعلمين

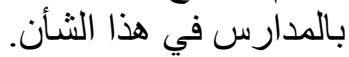

ـ نوفير الباحثين للأدلة التربوية والإرشادات لإستخدام استراتيجية التعلم

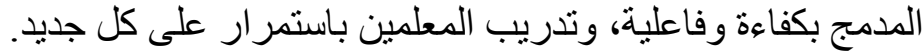

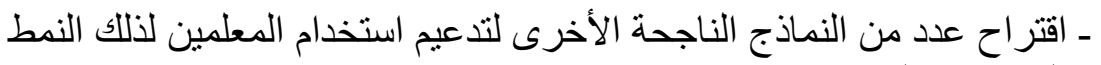

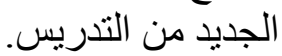

ـ تقديم شرح و افى لنظريات التعلم المتضمنة باستر اتيجية التعلم المدمج.

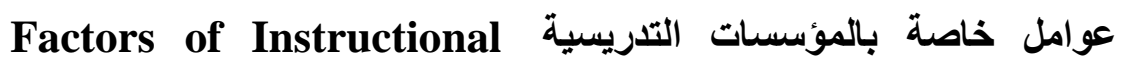

\section{:Institute}

- إن تنمية وتطوير استراتيجية التعلم المدمج ونماذجها تكون كإستجابة للاحتياجات المحلية والاجتماعية والتنظيمية أكثر من استخدام الإستراتية ونيجة التهية

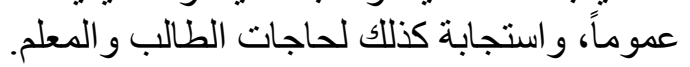

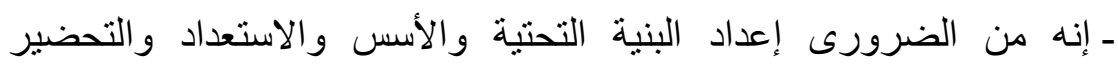

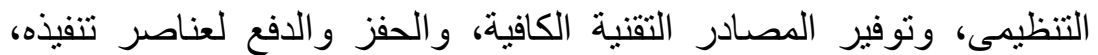
و إعداد قنوات إتصال جيدة وتغذية راجعة جيدة مع الطلاب و والمعلمين. - إعداد غرف للمعلمين مهيئة لتطوير وتتمية استخدامه للإستراتيجية التعلم المدمج. 
ـ تقديم استر اتيجية التعلم المدمج كعملية تصميمية متكيفة ومدرسية وتثقيفية

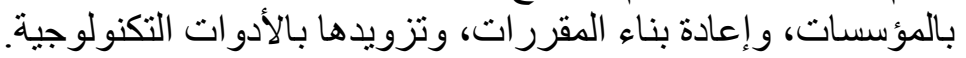

- يجب أن توجد ممارسات مؤسساتية تشارك فى تقويمات منظمة ومنشورة ومرتبطة بالمقرر ات ونشر نتائجها.

ـ توفير مو اقع شبكات كثيرة يسهل الوصول إلبها، خاصة بالمؤسسات التعليمية،

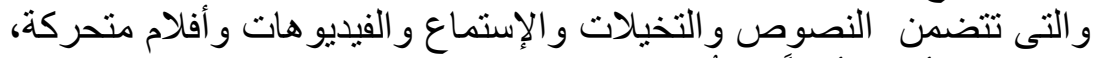

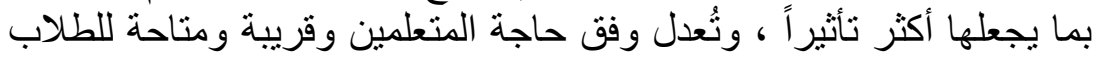
الأصحاء و المعاقين.

ـ عمل جداول زمنية للمقررات أون لاين وتحديد المهام فى تسلسل منطقى.

ـ تيسير التقويم الإلكترونى أون لاين، والإختبار ات الموجزة والطويلة. ـ إدارة نظم التعلم، وتوثيق المعلومات، وذللك يوفر الإدارة المركزية الأتوماتيكية للمعلمون والفصول، وتوفير الخبراء فى التكنولوجيا الحديثة لتقديم المساعدة.

Challenges Of تحديات تواجه استراتيجية التعلم المدمج: (V/l)

\section{Blended Learning Strateg}

ويمكن توضيح أهمها فى ضوء دراسة كل من: فاندر كام وزينسميستر

(Vander Kam, L., \& Zinsmeister, K., 2013, 63: 86) وآخرون (Perifanou, M., et al., 2010, 9: 11)، وهادجيروويت ‘(Poon, J., 2013, 276) وبورن) وبون) (Hadjerrouit, S., 2008, 181: 210) ووالنى (Walne, M., 2012, 1: 26) على النحو التالي: - حاجة المعلمين إلى مهارات تعليم جديدة نتيجة دمج التكنولوجيات فى طرق التدريس.

ـ حاجة الفصول الدراسية إلى نظام إدارة تعلم شاق وقوى ونشيط لمساعدة الطلاب على التكيف مع استر اتيجية التعلم المدمج.

ـ مو اقف التعلم المدمج تتطلب أن يكون ميسر اً للطلاب لممارسته بطريقة لإنتهم، وبتدخل قليل من الباغلين بالحد الأدنى له.

ـ قلة الدافعية و الحفز للطالب و المعلم على استخدام استر اتيجية التعلم المدمج - حاجة كل طالب بالفصل الدراسى إلى أجهزة إتصالات، وتكون متاحة له بالمنزل و المدر اس معاً.

ـ حاجة المعلمين إلى احترافية التدريب لأدوارهم الوظيفية فى استراتيجية التعلم المدمج.

ـ التكاليف الباهظة عند دمج بعض الطرق التى تتطلب وسطاً أكثر افتر اضية. 
ـ تحول التدريس ودوره إلى ميسر وموصل جيد للتعلم و المحتوى.

ـ جعل الجداول الزمنية للتعلم والتدريس أكثر مرونة، لأن معظمها لا تتناسب سوى

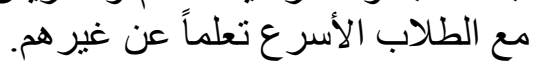

ـ قلة الأبحاث و الحاجة إلى مزيد من البحث العلمى لجمع معلومات معينة ومقاييس

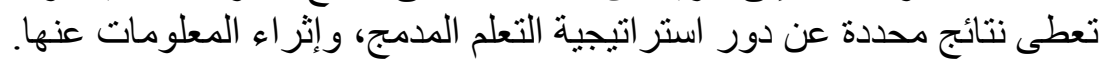

ـ من أبرز التحديات لإستر اتيجية التعلم المدمج هى تفاعلات ديلبرت Rhe Dilbert

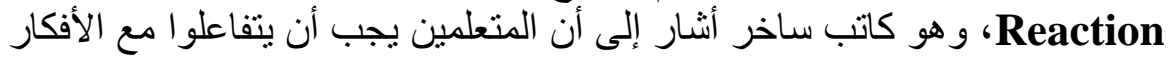

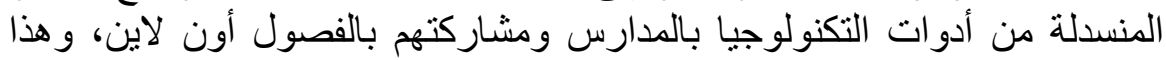

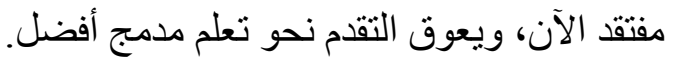

ـ الإفتقاد إلى إستخدام نمط الأدلة للتعلم حيث من تناولوا التعلم المدمج الأوائل كانت أفكار هم بسيطة وساذجة فى حين أن هذا النمط من التعلم يتطلب فكر متجدد ومرن

$$
\text { واجر اعات و اضمة واضهة }
$$

ـ القصور الذاتى والإتجاه للكسل و الجمود وضعف تطوير استر اتيجيات التعلم. ـ التوقعات الخيالية و غير الو اقعية للطلاب عند استخدامهم استر اتيجية التعلم المدمج

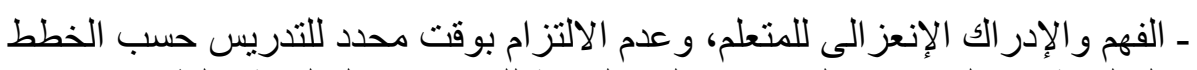
التعليمية هذا إلى جانب المشكلات التكنولوجية للمؤسسات التعليمية والطلاب.

ـ نقص التدعيم لإعادة تصميم المقرر ات فى ضوء التعلم المدمج. ـ صعوبة إكتساب أو امتلاك مهار ات تكنولوجية وتدريسية جديدة.

(^/1) بعض الوسائل التكنولوجية وخدماتها المستخدمة فى استراتيجية التعلم المدمج:

Tools \& Options of Technology in Blended Learning Strategy

(Walsh, N., M., ويمكن توضيحها فى ضوء دراسة كل من: والش

(Stolten Kamp, J. \& Kabaka, M., 2013, 1 : 5)

(Kwak, D.W., Menezes, 2013, 2321: 2454) F.M. \& Sherwood, C., 2013, 1: 24) ،(Chekour, M., Alachhab, M. \& Laafou, 2013, 1020: 1025) و إكاناياك وويشارت (Ekanayake, S. \& Wishart, J., 2011, 16: 30)

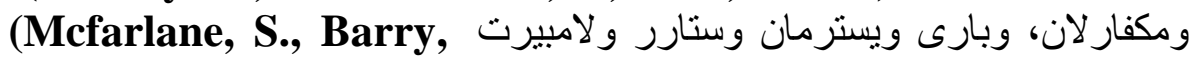
W., Westerman, S., Starr, S. \& Lambert, G., 2013, 1:10) النحو التالي: وتثضمن كل وسائل تنكنولوجيا المعلومات والإتصالات Information Communication Technology (ICT) 
لكافة التطبيقات التكنولوجية ويتضمن معمل الكمبيوتر Computer Labsetting، الرفيا

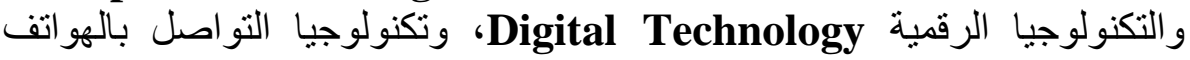
Tele Communication Technologies مثل الثبكة العالمية المنتشرة والإسطوانات المدمجة Electronic Information Resources Such as Wide Web \& CD Roms A Learning Management System (LMS) الإلكترونية plat forms للتوصيل المعلوماتى، والإنترنت The internet،

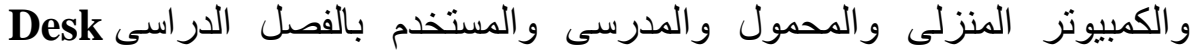
Personal E-Mail Laptop Computers

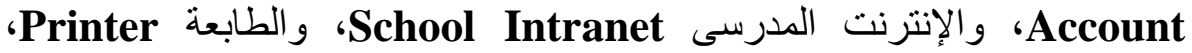
و الكاميرات الرقمية Digital Cameras، و البروجكتور الرقمى ولوحات التفاعل

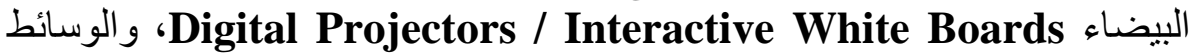
Excel بما تحوى من عروض البوربونيت والأكسل Multimedia المتعددة Demonstrations of Power Point Presentation المحمولة والتليفونات الذكية، ومواقع الثبكات Websites، ومعالجة النصوص

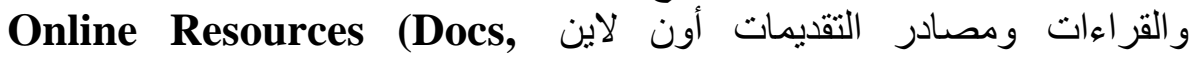
E- وقواعد البيانات والجرائد و المجلات الإلكترونية Presentation) Journals/Data Bases Screen, Capture, Recording الفيديوهات Videos Presentations ومردودات و انعكاسات الطلاب أون لاين Student Online Reflectionl PDP Mind و Online, Via A Discussion Board والخرائط الذهنية

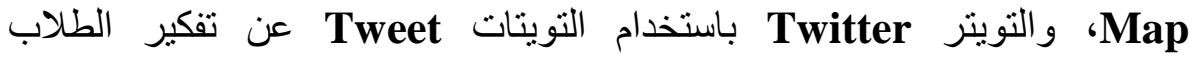
ومردوداتهم، والبلوجز Blogs وبريد البلوجى للطالب والمرئيات Cuisibles،

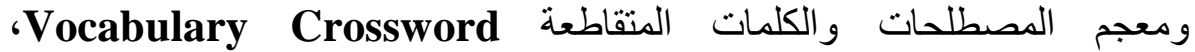
و القصص والمناقشات أون لاين Online Discussion \& Stories و التعلم المرنكز إلى المواقع Site-Based Learning، و الويب كويست Seb Quest

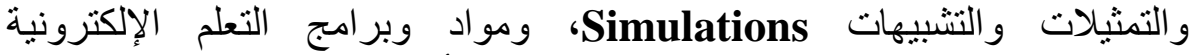
Group Content Management Software Activities

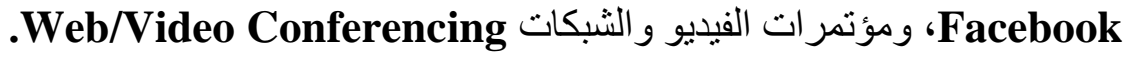

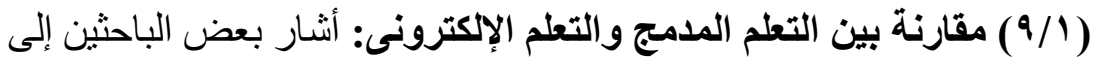

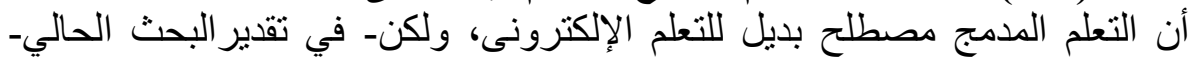
توجد العديد من الفروقات بين كلا المصطلحين وآليات استخدامهما في التعليم، وتنيان أهمها في الجدول التالي (1) (1) 
ويعنى به تلدعيم التعلم باستخدام

تطبيقات التكنولوجيا الحديثة

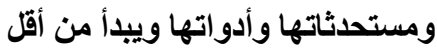

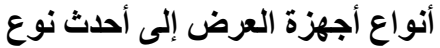
من التكنولوجيات الترات
مجموعة الإجر اعات والخطوات المتبعة من الأو

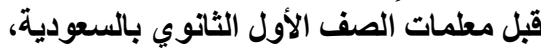
التعريف

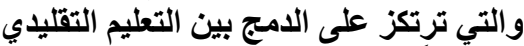

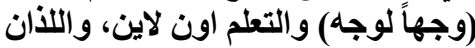

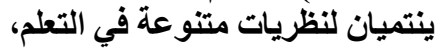
والإستفادة من أفضل الخطوات التدريسية

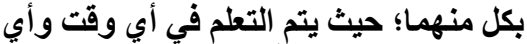

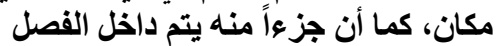

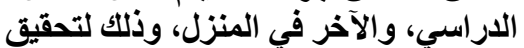
التقدم وألسر عة والآحر في التطوير والإتقان للطالبات

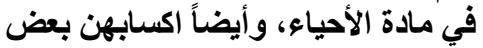

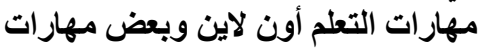
التقكير العلمي. الاين وني.

عرض برامج أو محتوى معين

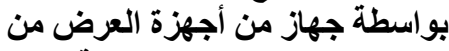
خلال مواد عرض منتوعة اجنة

وسيلة مساعدة جاذبة لانتباه المتعلم

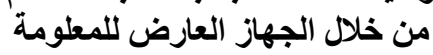
ومواد العرض.

يمثل بيئة تعلم وحيدة تعتمد كلياً على ألى أدوات ووسيائل التعلم مثل أجهزة كلئ علئ التعلم- الكمبيوتز.... الخ.

يتطلب معرفة الطالب بأسلوب التعامل مع أدوات العرض وأجهزة ومواد الطواد عرض المادة التعليمية. قد يكون دور المعلم ضئيلاً. المعرفة محدودة لأنها ترتبط بمقرر معروض وموضوع محدد.

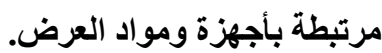
قد تختزل في مجرد وسائل تعليمية بالاضافة إلى طريقة التعلم التى تعلى يستخدمها المعلم

قد تعد جزعاً من التعلم المدمج إذا

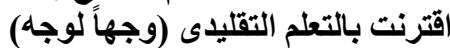

\section{دمج أو مزج نوعين من التعلم ينتميان إلى التى}

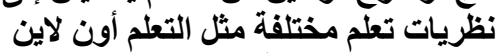

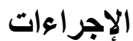

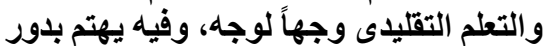
كل منهما في التعلم ووظائفهما.

جذب المتعلم وتغيير اتجاهاته نحو نوعى التملى التعلم المكونات للتعلم المدمج. تأثيره

\section{تجمع بين بيئيتين مختلفتين للتعلم يعتمدان} على الاستراتيجيتين المدمجتين. بيئة التعلم يتطلب قدر من خبرة الطالب بطرق التعلم

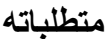
المدمجة.

\begin{tabular}{|c|c|}
\hline دور المعلم أسناس وجوهري. & دور المعلم \\
\hline تكون ثرية، لأنها تعتمد على مصادر أكثر & المعرفة المراد \\
\hline كثيرة ومتعددة الأنواع والمصادر. & الأنشطة \\
\hline استراتيجية تعلم؛ لها اجراعات وينود محددة & خصائصها \\
\hline أكثر شمولاً & الشمولية \\
\hline
\end{tabular}




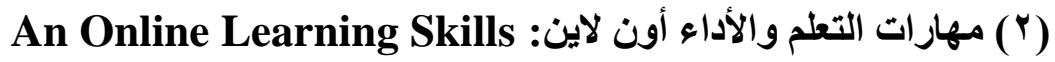

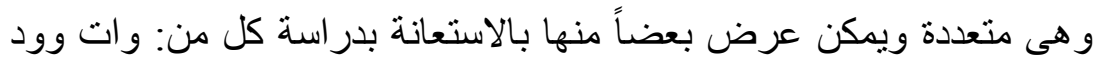

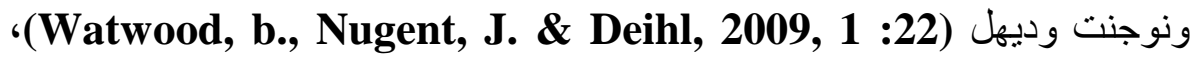

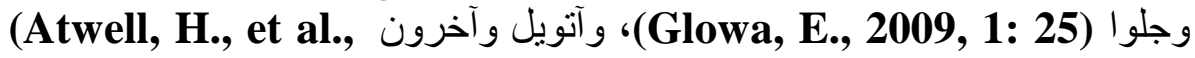
(Dipietro, M., Ferdig, ون 2011, 1: 16) (Hura, R.E., Black, E.W. \& Preston, M., 2008, 10: 35) و أندرسون (Smith, T.C., 2005, 1: 18) وسميث (g.,2008, 419: 425) (Sivin, (Anderson, T., 2005, 273: 294) Kachala, J. \& Bialo, e., 2009, 1: 7)

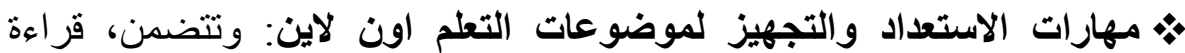

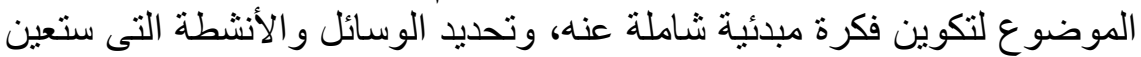

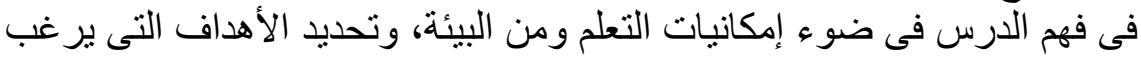

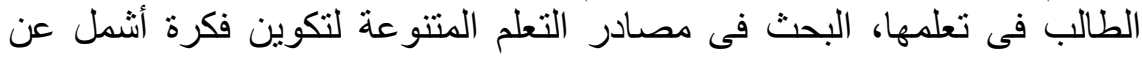

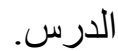

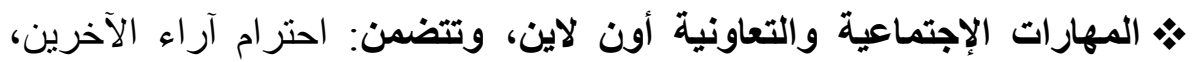

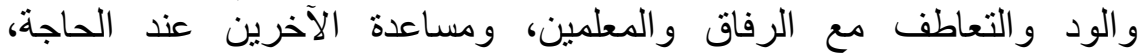

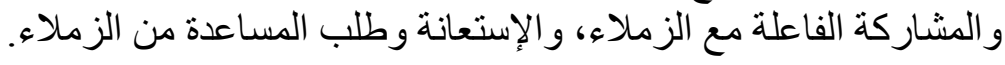

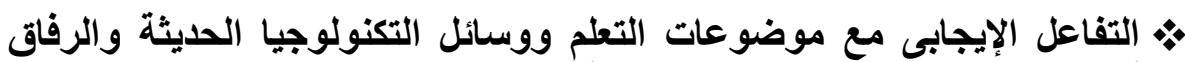

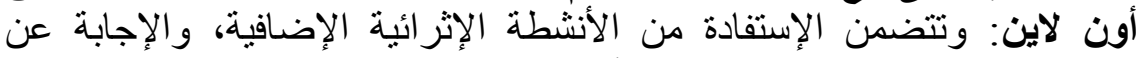

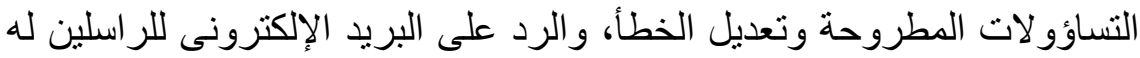

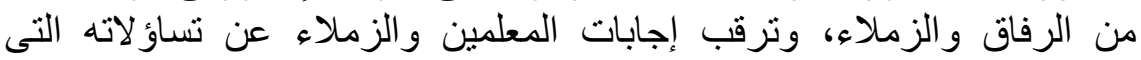

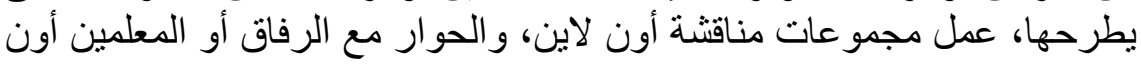
لاين

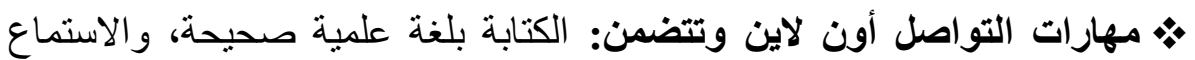

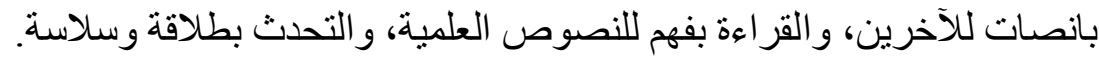

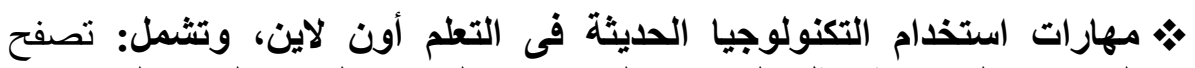

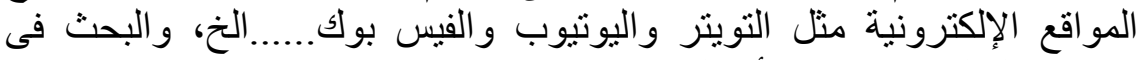

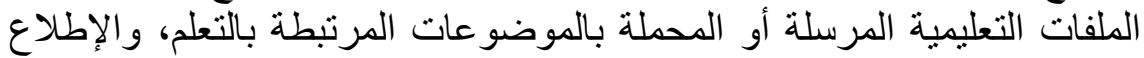

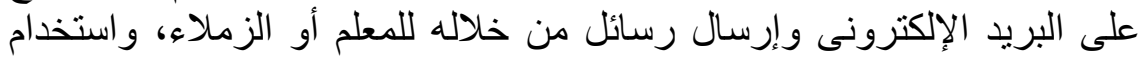

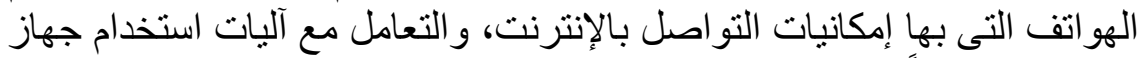

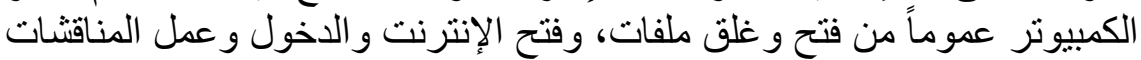

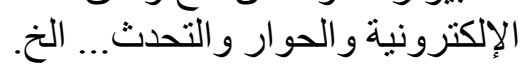

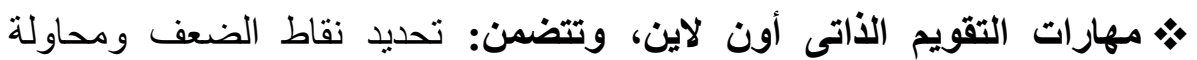

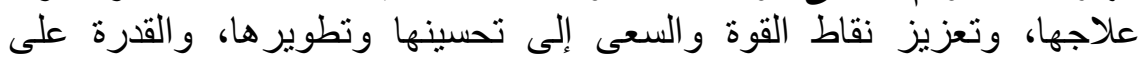




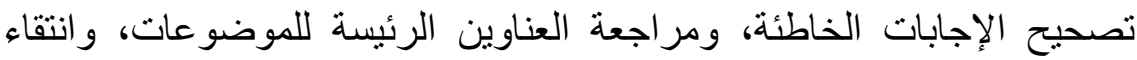

اختبارات تتناسب مع موضوعات التعلم، واستخدام التغذية الراجعة الفورية الفورية

باستمرار.

(r) (التفكير العلمي؛ أهميته، ومهار اته، خصائص المفكر علمياً:

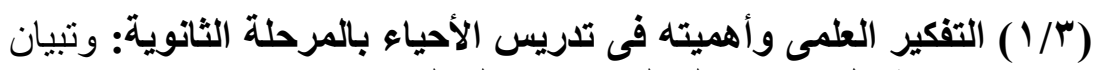

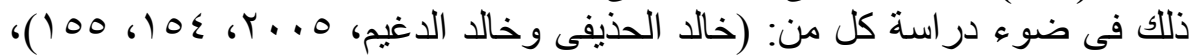

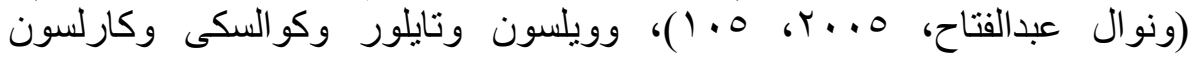
(Wilson, C.D., Taylor, J.A., Kowalski, S.M. \& Carlson, J., 2010, 276: 301) ـ الفهم العميق للمعرفة وتحصيل أفضل للمعارف العلمية وتحقيق أهداف تدريس

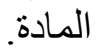

- إنتاج عقول متفتحة وو اعية ومفكرة.

ـ تنمية الثقافة العلمية لدى المتعلمين وفهم الظو اهر العلمية المرتبطة بالكائنات الحية

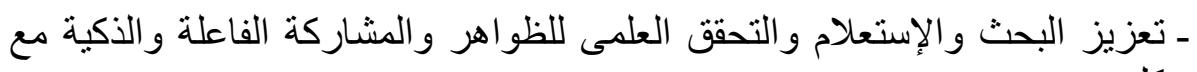

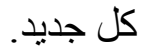

ـ تكوين أفكار دقيقة واستخدامها فى الحياة اليومية، ترسيخ مبدأ التعلم مدى الحياة. ـ ابتكار استر اتيجيات تدريسية جديدة تنمى أنماط التفكير المختلفة.

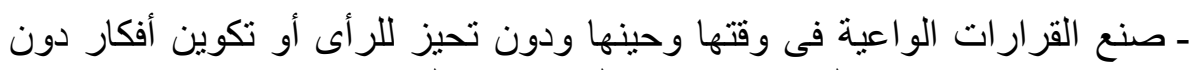

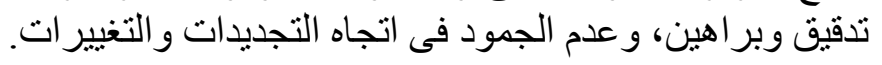

ـ التقويم المستمر للمعلومات و المعارف المتوفرة واستخدام التغذية الر اجعة الفورية. ـ ادر الك العلاقات بين الظو اهر المختلفة وتفسير ها فى خطو ات ات منطقية. ـ التتبؤ بعلاقات جديدة بين البيانات المعطاه.

ـ تقديم حلول للعديد من القضايا و المشكلات الحياتية التى يو اجهها الطالب و المعلم. ـ تنمية نمط التساؤلات الناقدة لدى الطالب و المعلم.

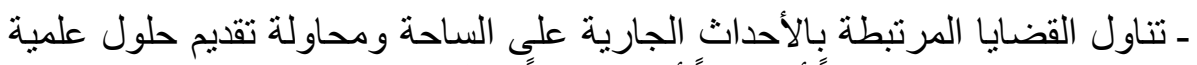

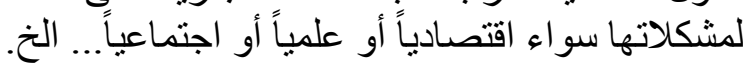

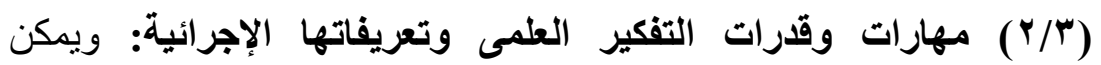

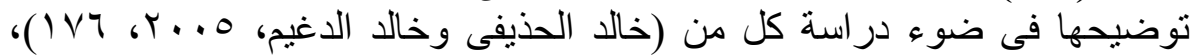

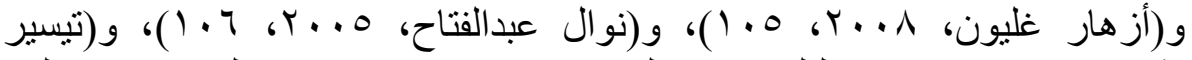

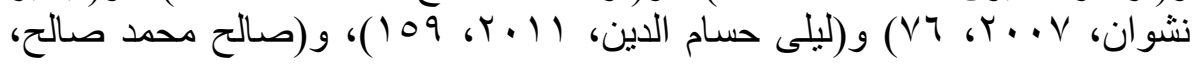




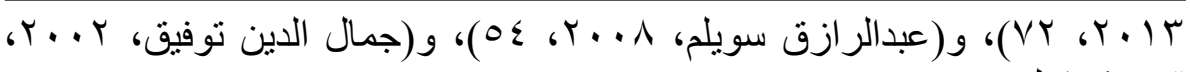

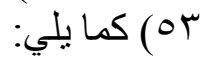

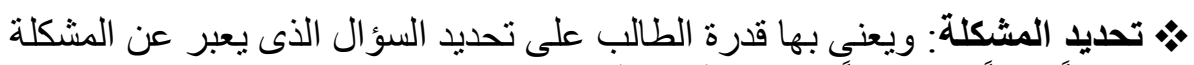

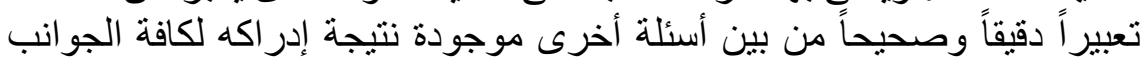

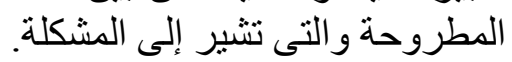

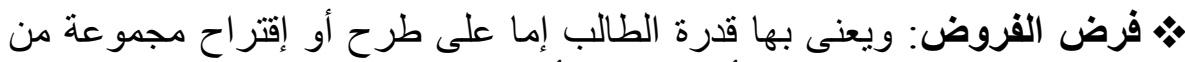

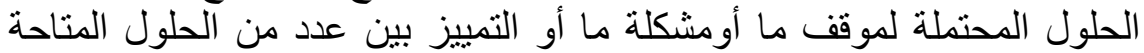

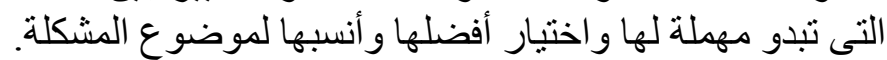

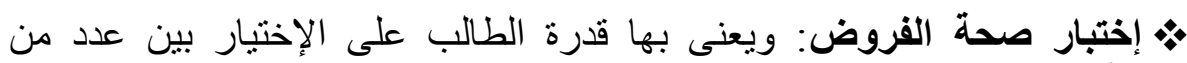

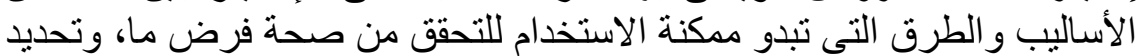

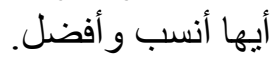

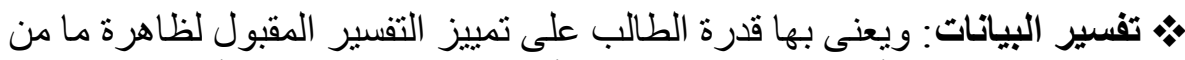

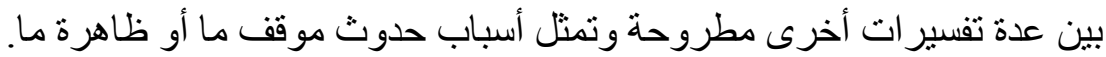

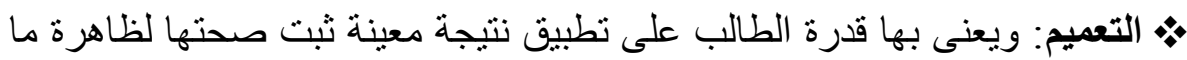

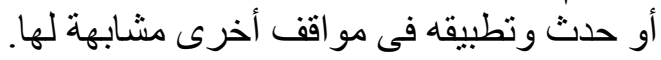

* (

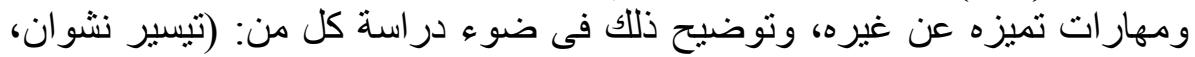

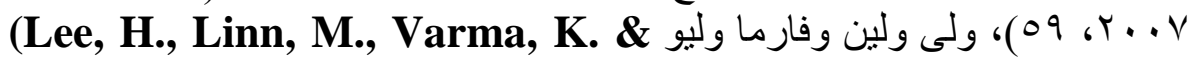

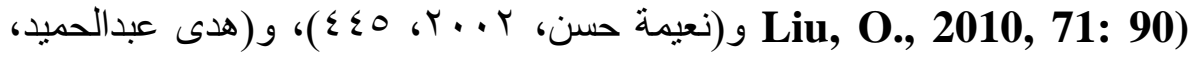
( م ـ متقبل ومولد للأفكار الجديدة ومتميز بحب الإستطلاع. ـ مدر الك المتناقضات ويفرض الفروض لتحديد المعلومات التى يحتاجها حول ظاهرة ما. - يخطط بشكل مدروس لكل سلوك أو تصرف يقوم به. ـ يقوم باستنتاج النتائج مقدماً ثم يقوم بالبحث ولثو التجريب. - يفرق بين الأفكار الصحيحة و الخاطئة. - يدرك ماور اء المعرفة واحياناً ماور اء التفكير نفسه. - يرتب المعرفة وينظمها ليستطيع الإستفادة منها جيداً. - يصنف البيانات ويتميز بالحرص الواعى و السعى إلى الفهر. - يمتلك اتجاهات إيجابية نحو العلم ونظرياته ويسنطيع الربط وعمل علاقات بين إلى لين

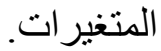


- يكتشف المشكلات ويسعى لحلها وتحديد وتفسير أسبابها ويحب المغامرة و المخاطرة.

ـ دائم طرح التساؤلات حول المعلومات المتاحة له.

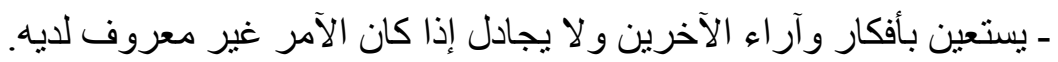
ـ يكتشف المفاهيم الخاطئة ويسعى لتصحيحها. - يفكر بموضو عية ويتجنب الذاتية و التحيز.

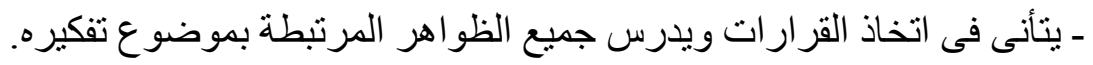

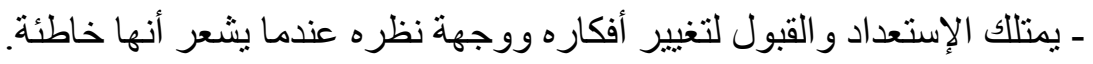
- يمتلك العديد من البدائل لاستخدامها عند الحاجة. - يبنى آر اءه ومعتقداته على أسس واجر اءات علمية مدروسة وثثبت نجاحها.

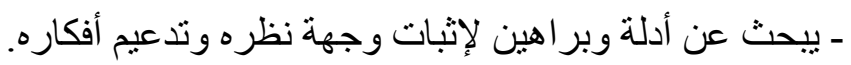
ثالثاً: إجراءات الدراسة التجريبية

للإجابة عن أسئلة البحث والتحقيق من صحة الفروض التهاءة التى تم وضعها اتبعت

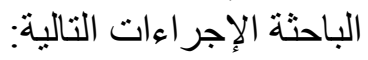

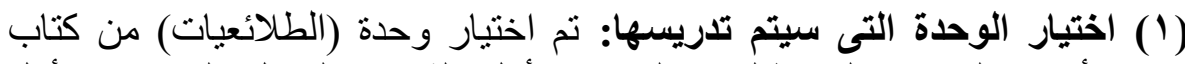

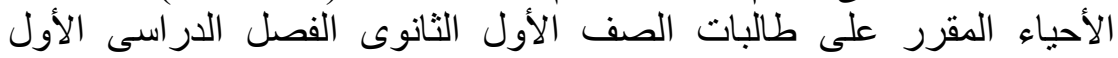

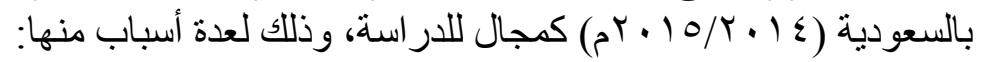

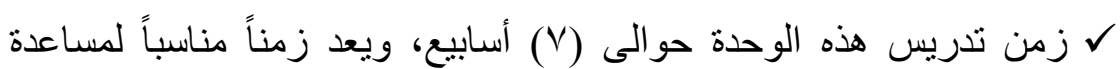

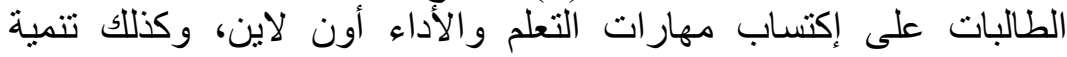

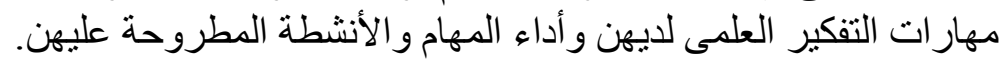

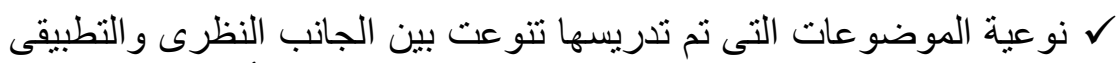

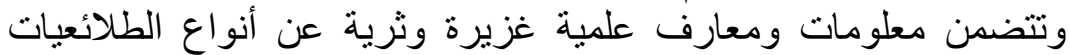

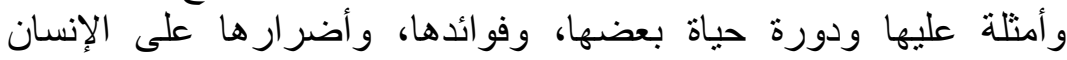

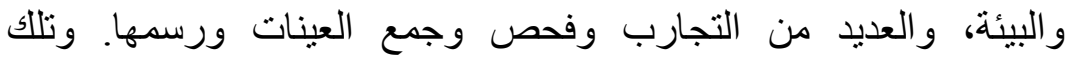

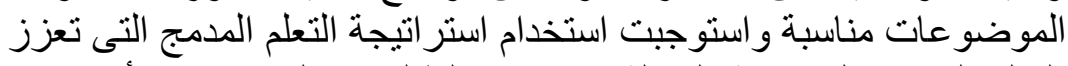

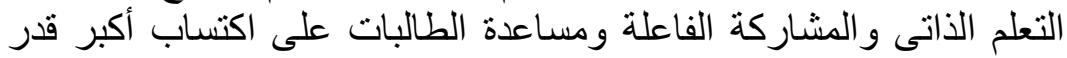

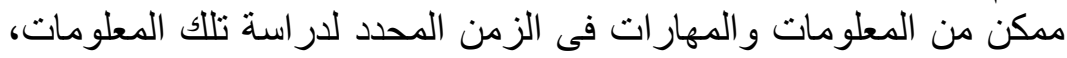

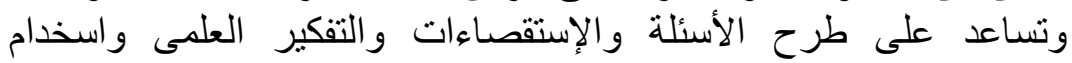

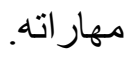

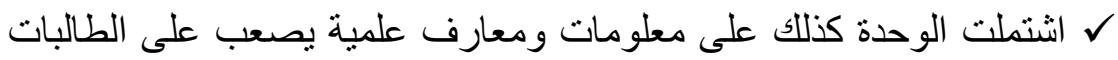
فهمها بالطريقة المعتادة لذلك يحتاج إلى تدعيمها باستر اتيجية تدريس أخرى الطي 
تمزج معها وتعتمد على التكنولوجيا وهى التعلم أون لاين لتنمية مهارات الأداء أون لاين أيضاً.

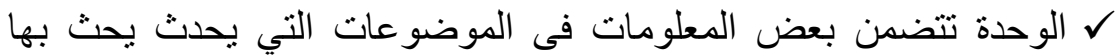

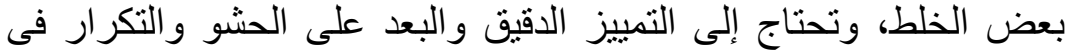

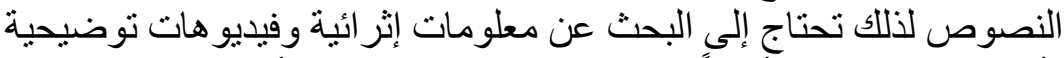

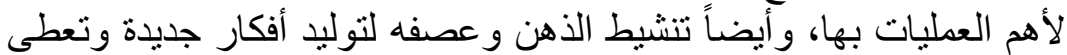

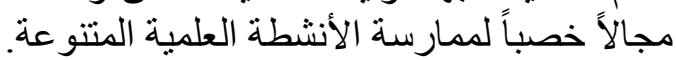

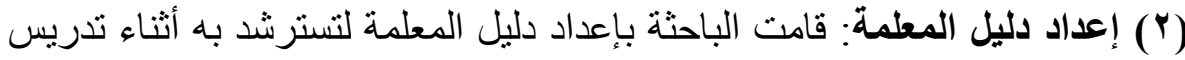

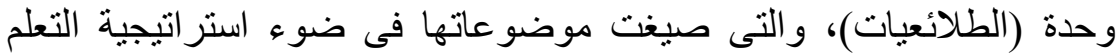

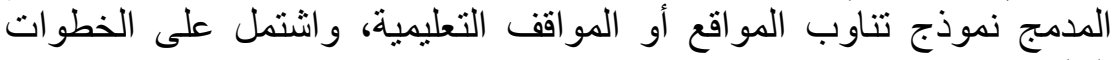

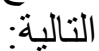

ـ مقدمة: وتضمنت الهدف من الدليل ونبذه عن استر اتيجية التعلم المدمج وأهميتها و إمكانية تطبيقها فى مجال تدريس الأحياء.

ـ الأهداف العامة للوحدات: وتنو عت بين (المعرفية، المهارية، الوجدانية)

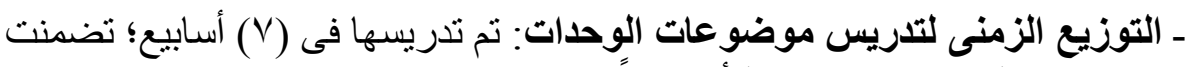

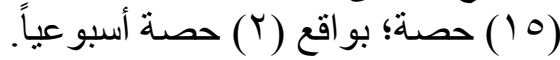

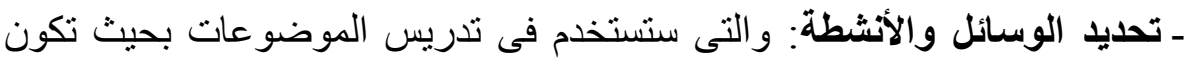
متنو عة ويلى ذلك بعض التوجيهات العامة للمعلمة عن استر اتيجية التعلم المدمج.

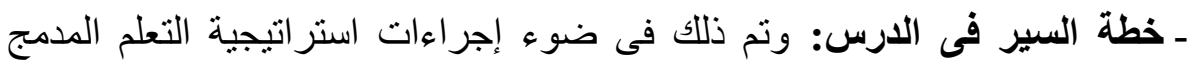

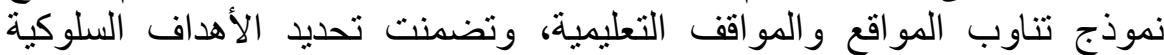

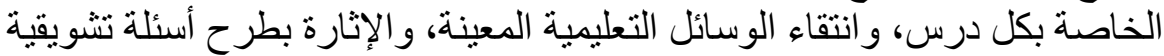

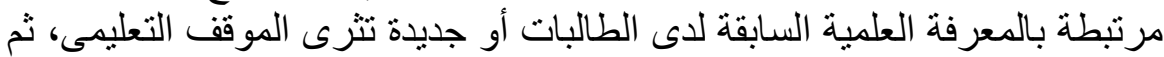

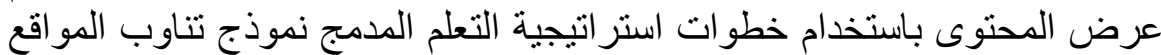

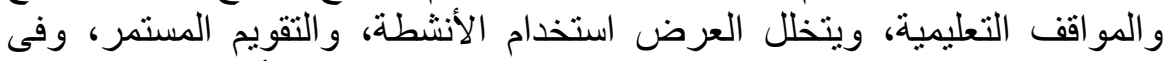

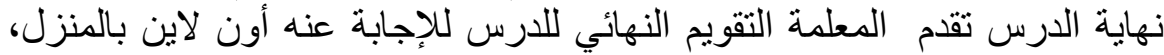

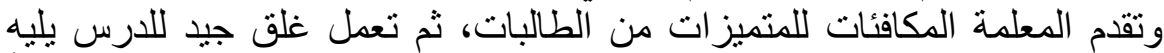
التقويم النهائى، وهنا تتكون خطوات التوات التدريس بالجمع بين التعليم التقليدي وجهاً

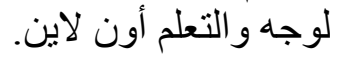

- وتم عرض الدليل بعد الانتهاء من إعداده على مجموعة من المحكمين من أساتذة

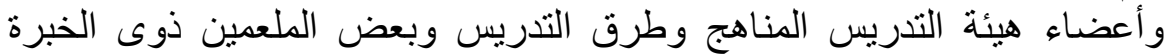

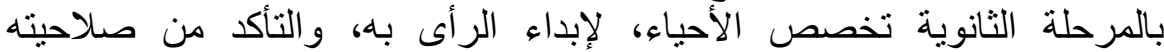

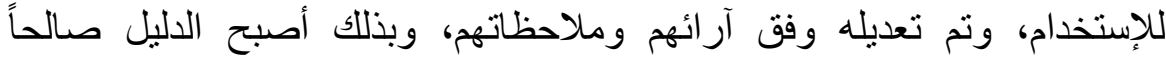
للإستخدام و التطبيق ولى تلى الطالبات. 
(أ) إعداد بطاقة ملاحظة أداء مهارات التعلم أون لاين للطالبات:

وتم إعدادها تبعاً للخطوات التالية:

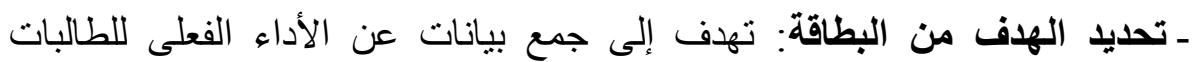

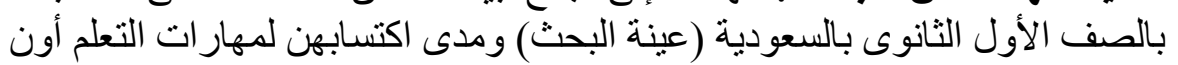

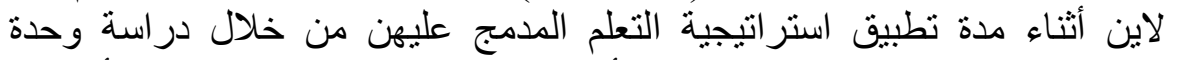

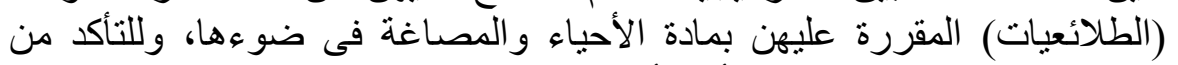

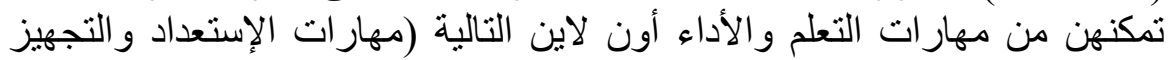

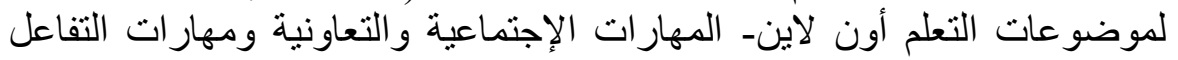

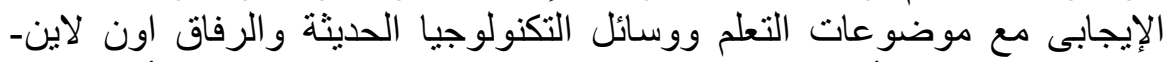

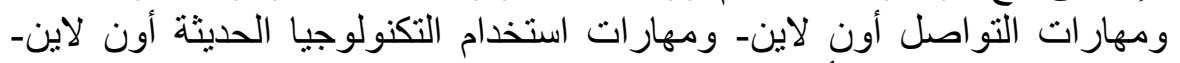

$$
\text { ومهار ات التقويم الذاتى أون لاين). }
$$

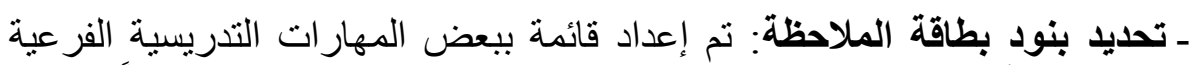

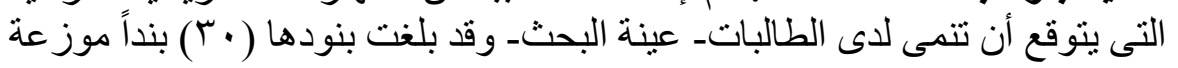

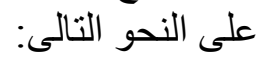

* مهار ات الاستعداد و التجهيز لموضوعات التعلم أون لاين، و عددها (؟) مهارة فر عية

* المهار ات الإجتماعية و التعاونية و عددها (0) مهارة فرعية.

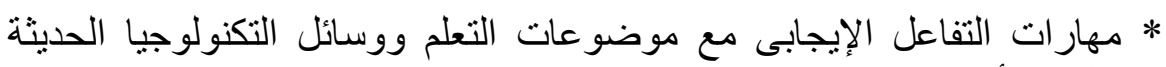

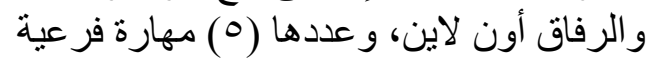

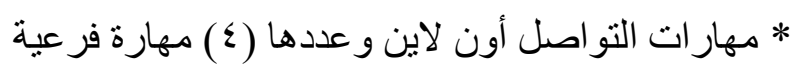

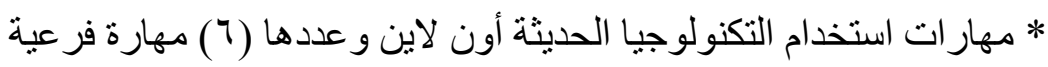

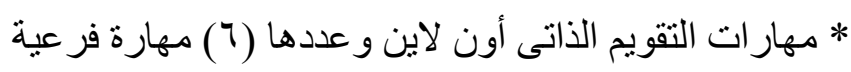

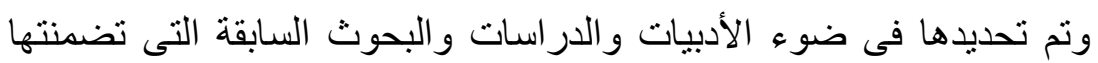
الدر اسة ـ صياغة تعليمات بطاقة الملاحظة: تم صياغتها لتوضح لطالبات الصف الأول الثانوى بالسعودية- عينة البحثـ كيفية أداء كل مهارة نوات نوعية.

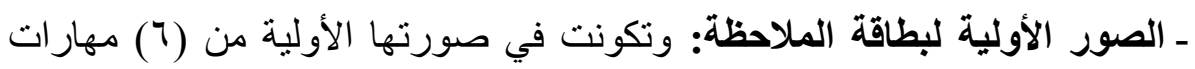

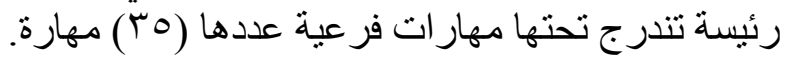

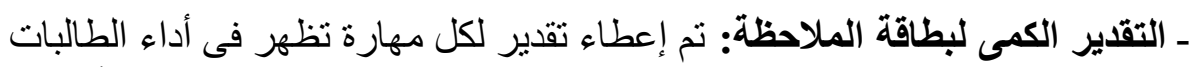

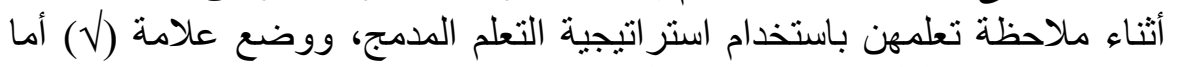

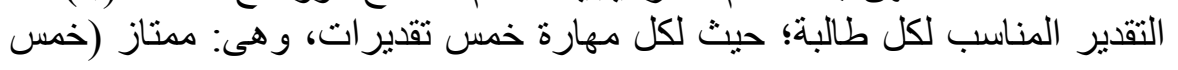




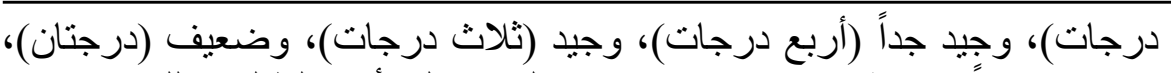

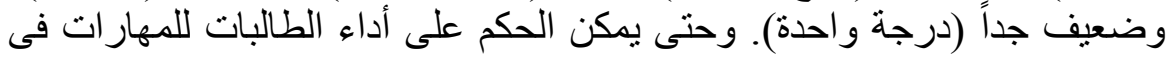

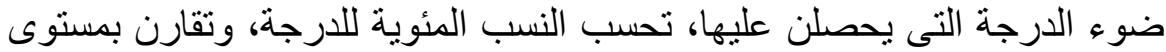

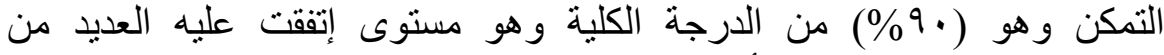
الدر اسات السابقة للحكم على أداء الطالبات حتى التمكن.

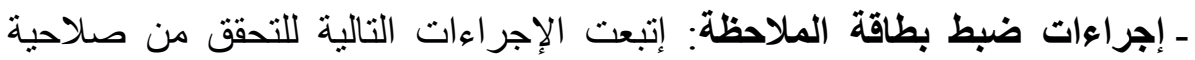
بطاقة الملاحظة لقياس أداء الطالبات، واعدادة التباد الصورة النهائية لها:

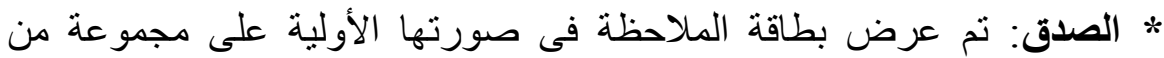

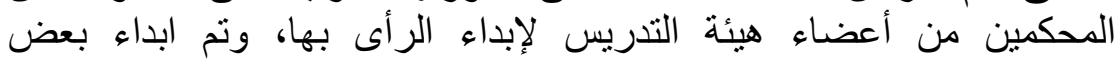
الملاحظات التى تم الأخذ بها، وتعديل بعض فقر اتها و إلغاء البعض الآخر.

بـ التجربة الإستطلاعية لتقدير ثبات بطاقة الملاحظة: نم تطبيق بطاقة الملاحظة

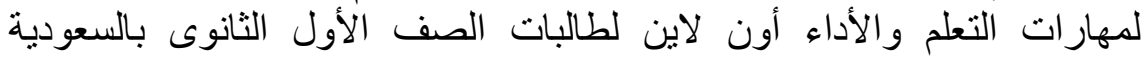

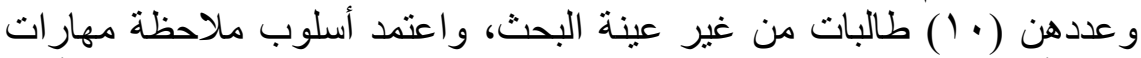

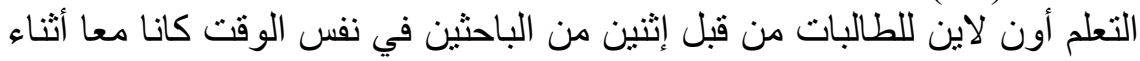

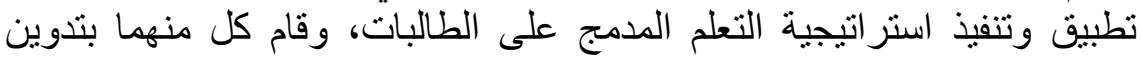

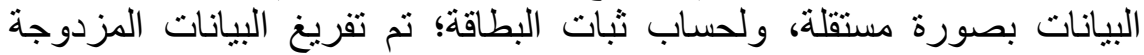

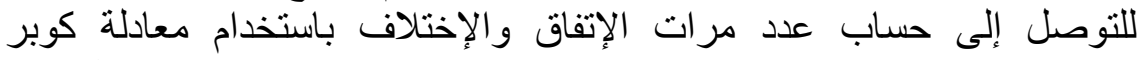
(Cooper)

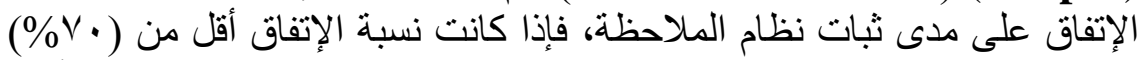

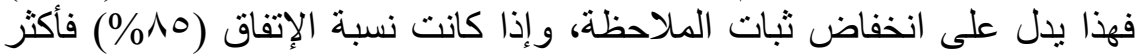

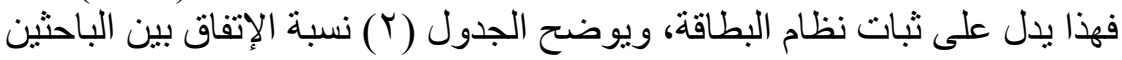

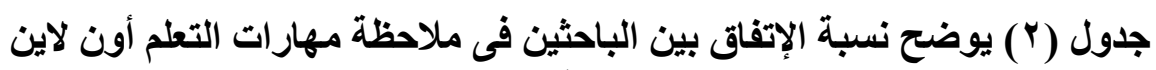

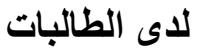

\begin{tabular}{|c|c|c|c|}
\hline نسبة الاتفاق & الطالبات & نسبة الاتفاق & الطالبات \\
\hline$\% \wedge \diamond$ & 7 & $\% \wedge \vee$ & -1 \\
\hline$\% \wedge 9$ & V & $\% \wedge 7$ & $-Y$ \\
\hline$\% \wedge$ ४ & $\Lambda$ & $\% \wedge 4$ & r- \\
\hline$\% \wedge \vee$ & 9 & $\% \wedge 0$ & $-\varepsilon$ \\
\hline$\% \wedge \wedge$ & 1. & $\% \wedge \wedge$ & -0 \\
\hline
\end{tabular}

ومن هنا نجد أن بطاقة الملاحظة ذات درجة ثبات عالية لعملية الملاحظة،

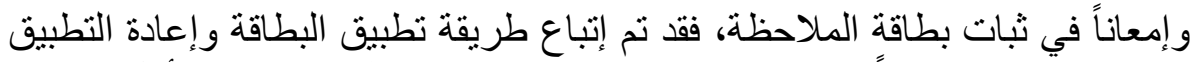

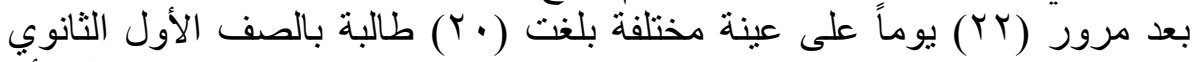

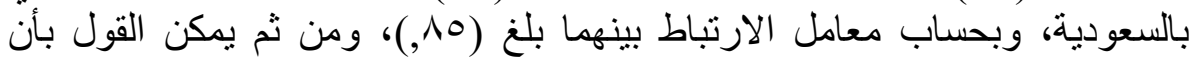




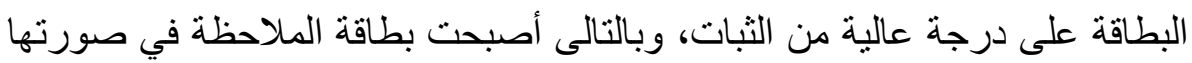

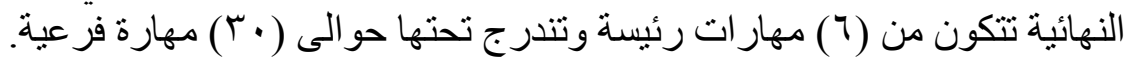

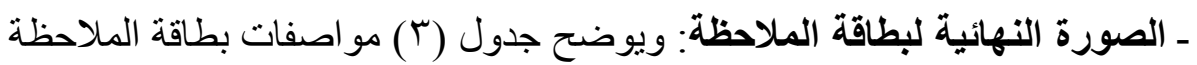

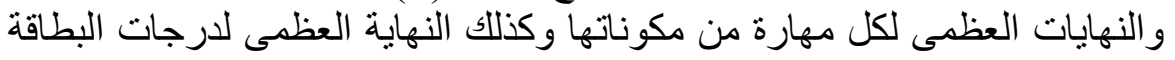
ككل، و هي كالتالى:

\begin{tabular}{|c|c|c|c|}
\hline النهاية العظمى الدجمع & المهارات & 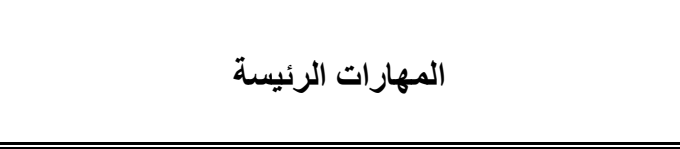 & b \\
\hline$r$. & $\varepsilon$ & مهارات الاستعداد والتجهيز لموضوعات التعلم أون & -1 \\
\hline ro & • & المهارات الاجتماعية والتعاونية أون لاين. & $-r$ \\
\hline ro & 0 & مهار ات التفاعل الإيجابى مع موضو التوفاق أون لاين. التعلم ووسائل & $-r$ \\
\hline r. & $\varepsilon$ & مهارات التواصل أون لاين. & $-\varepsilon$ \\
\hline$r$. & 7 & مهارات استخدام التكنولوجيا الديثة أون لاين. & -0 \\
\hline$r$. & 7 & مهارات التقويم الذاتي أون لاين. & -7 \\
\hline 10. & $r$. & البطاقة ككل & \\
\hline
\end{tabular}

(ب) إعداد مقياس مهارات التفكير العلمى: وذلك وفق الخطوات التالية:

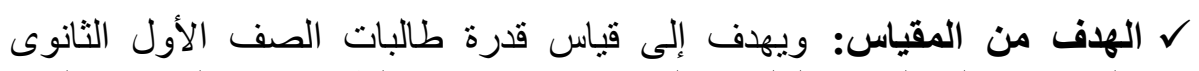

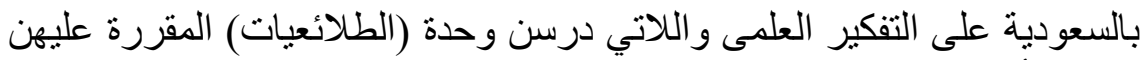

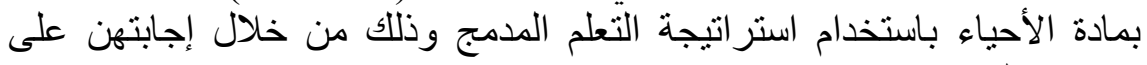
مفردات المقياس.

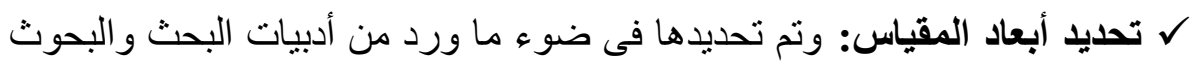

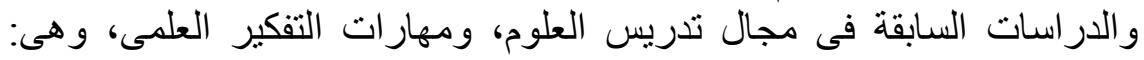

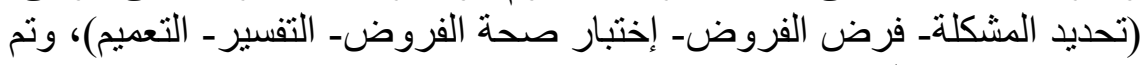

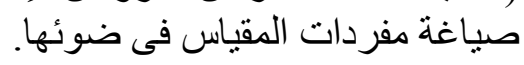

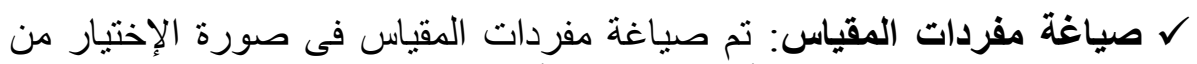

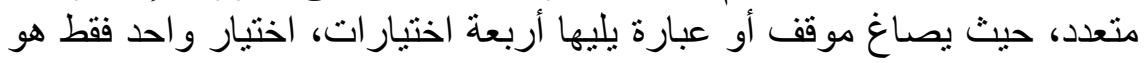

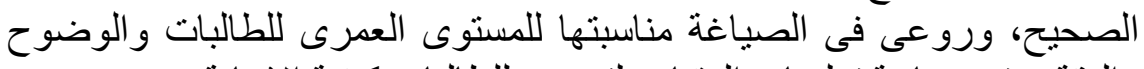
و الدقة، وتم صياغة تعليمات المقياس لتوضح للطيات للنالبات كيفية الإجابة.

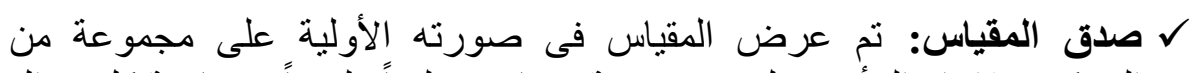

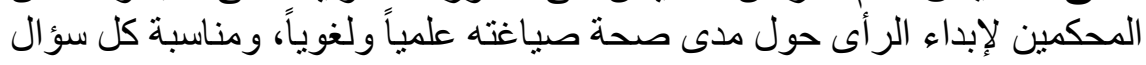


لمهارات التفكير العلمى المحددة، ومناسبته لمستوى الطالبات، وتم تعديله وفق عتر آر ائهم وتوصياتهم.

$\checkmark$ التجربة الإستطلاعية للمقياس: وقد طبق مقياس مهارات التفكير العلمي على التى

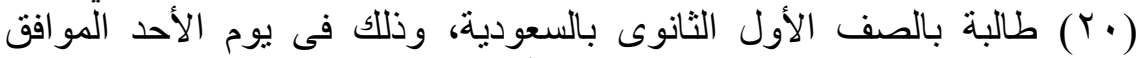

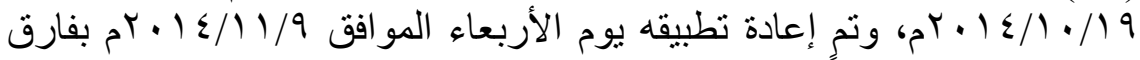

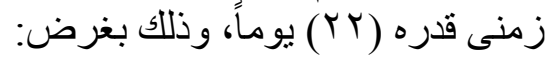

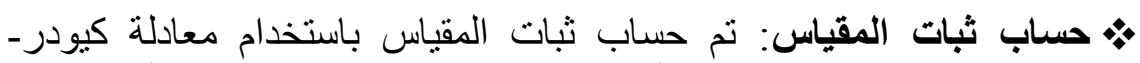

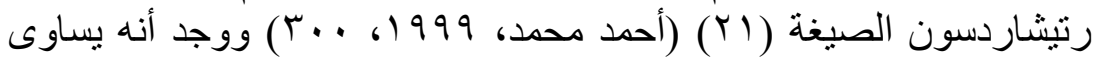

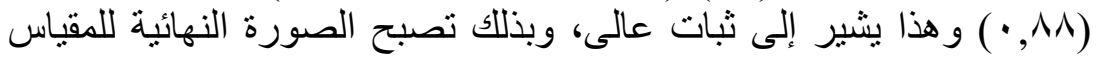
صالحة للنطبيق على عينة الدراسة. • تحديد زمن المقياس: ووجد متوسط الزمن اللازم للإجابة عن مفردات المقياس تساوى (من (0) دقيقة.

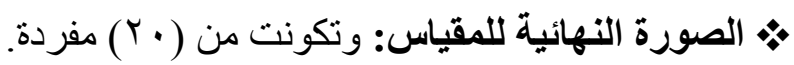

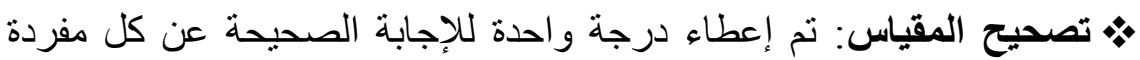

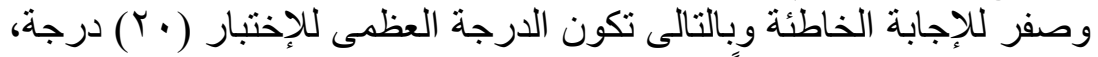

$$
\text { و الدرجة الصغرى (صفراً). }
$$

\begin{tabular}{|c|c|c|c|}
\hline 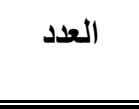 & المفردات & مهارات التفكير العلىى & b \\
\hline$\varepsilon: 1$ & $\varepsilon$ & تحديد المشكلة & -1 \\
\hline$v: 0$ & $r$ & فرص الفروض & $-r$ \\
\hline $1 \cdot: 1$ & $r$ & اختبار صحة الفروض & $-r$ \\
\hline $10: 11$ & ○ & التفسير & $-\varepsilon$ \\
\hline$r \cdot: 17$ & - & التعميم & -0 \\
\hline$r \cdot: l$ & $r$. & المجموع & \\
\hline
\end{tabular}

( ) عينة البحث وتنفيذ التجربة: وتضمنت عينة البحث مجموعة تجريبية وكانت

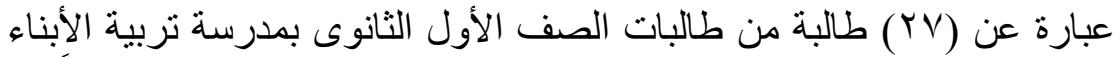

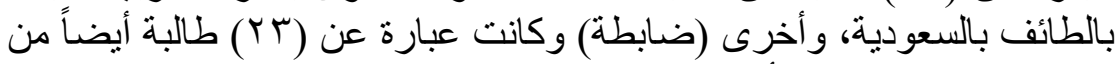

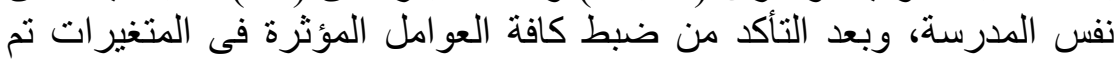
تنفيذ التجربة، كما يلى: التئي

ـ التطبيق القبلى لبطاقة ملاحظة أداء مهارات التعلم اون لاين للطالبات، ومقيد ولهياس

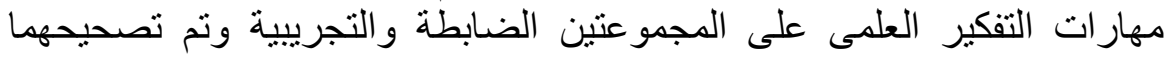


ورصد نتائجهما، ويبين جدول (0) التالى مدى التكافؤ بين المجموعتين حيث يوضح نتائج التطبيق القبلى لمقياس مهارات التفكير العلمى وبطاقة الملاحظة كما لئ بل:

جدول (0) يوضح المتوسط والإنحراف المعيارى وقيمة (ت) لنتائج التطبيق القبلى لئل

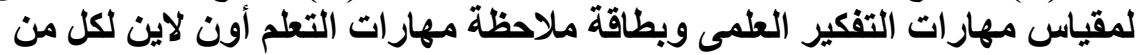
المجموعتين الضابطة و التجريبية

\begin{tabular}{|c|c|c|c|c|c|c|}
\hline \multirow{3}{*}{ مسرو النيا } & \multirow{3}{*}{ (ن) } & \multirow{2}{*}{\multicolumn{2}{|c|}{ 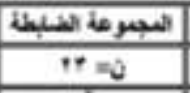 }} & \multirow{2}{*}{\multicolumn{2}{|c|}{ 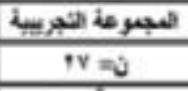 }} & \multirow{3}{*}{ نو } \\
\hline & & & & & & \\
\hline & & +2 & $\theta$ & $t$ & $\rightarrow$ & \\
\hline 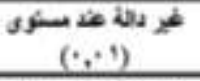 &, 17 & 14 & .4 & +1 & 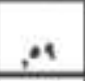 & 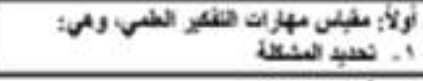 \\
\hline 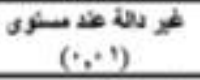 & 10 & $* 1$ & .78 & $\because A$ & $+x$ & 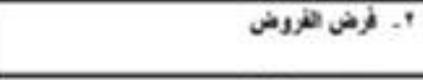 \\
\hline 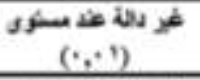 & $\therefore A$ & , vV & $\because+1$ & $A$ & $\because+\cdots$ & 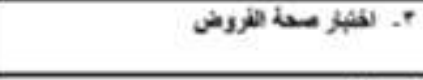 \\
\hline 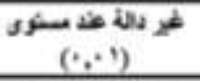 & iv & tA & 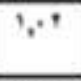 & $\because$ & 1,17 & -1 \\
\hline (1, t) & $\therefore 9$ & 74 & $\because+1$ & .0 & 1,14 & 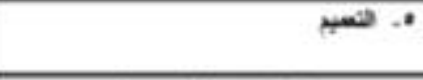 \\
\hline 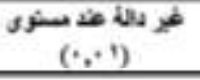 & $\because+7$ & $\because+1$ & 4,4 & $\because+1$ & t, IV & 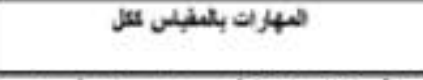 \\
\hline 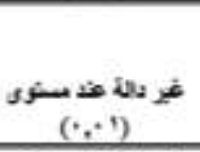 & iv & aA & $\because,+$ & 7,17 & $\pi, r$ & 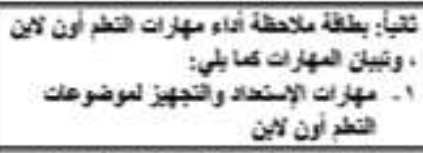 \\
\hline فر & 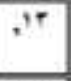 & $t, t+$ & 8,4 &,+ 48 & 4,10 & 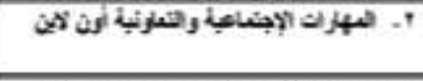 \\
\hline في & 10 & $\because, A$ & $A, Y Y$ & 5,70 & $\because, t+$ & 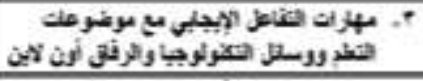 \\
\hline في & 12 & $\ddot{*+1}$ & $4,4=$ & $a, 7 t$ & 19,27 & 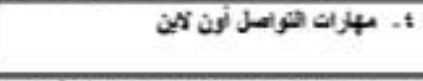 \\
\hline في & 19 & $3, T$ & $\because \because$ & $Y, t+$ & $17, t 7$ & a) \\
\hline 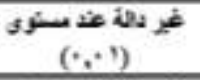 & 9 & $t, t a$ & nert & $5,4 x$ & $A, A A$ & 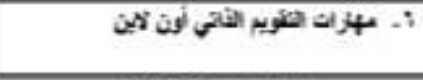 \\
\hline 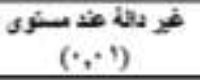 & $\because 2$ & $A,+1$ & $+1, A+$ & $\mathrm{A}, \mathrm{s}, \mathrm{T}$ & $\pi, \%$ & Jos \\
\hline
\end{tabular}

يتضح من جدول (0) أنه لا نوجد فروق ذات دلالة إحصائية بين متوسطات

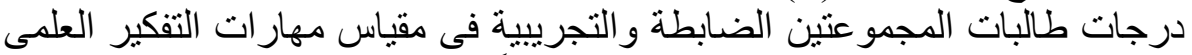

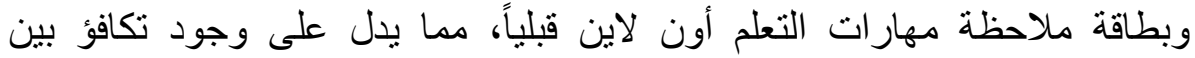

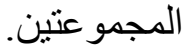

ـ تدريس وحدة (الطلائعيات) المقررة على طالبات الصف الأول الثانوى بالسعودية فى مادة الأحياء باستخدام استر اتيجية التعلم المدمج لطالبات الترات المجموعة التجريبية، 


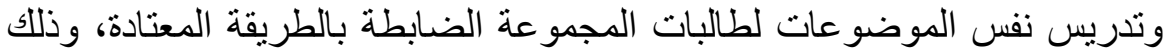

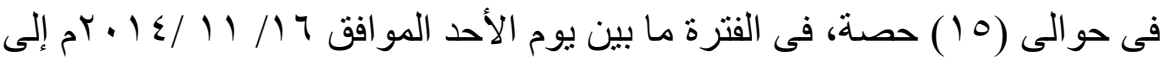

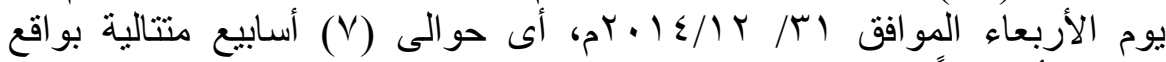

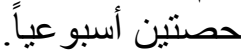

ـ وفى نهاية التدريس تم التطبيق البعدى لمقياس مهارات التفكير العلمى وبطاقة

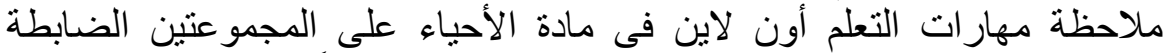
والتجرييية وتم تصحيحهما ورصد النتائج ومعالجتها إحصائياً.

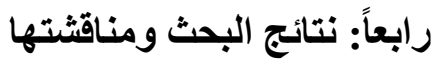

ولمعالجة نتائج البحث نم الإستعانة بالأساليب الإحصائية المناسبة لمعالجة البيانات و المتمنلة فى حزمة البر امج الإحصائية (Spss)، و التى من خلالها لتها تم ما يلى: * اختبار صحة الفرض الأول: وينص على "مستوى أداء طالبات الصف الأفير الأول

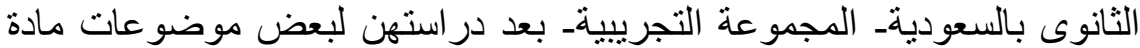

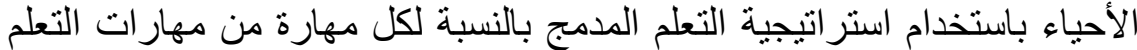

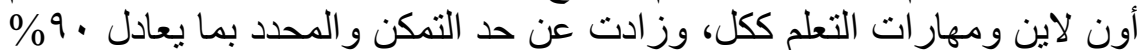
من الدرجة العظمى بينما قلت طالبات المجمو عة الضابطة عن هذا التهن الحن. - وقد تم حساب المتوسط و الإنحر اف المعيارى و النسبة المئوية لدرجات الطالبات فى في

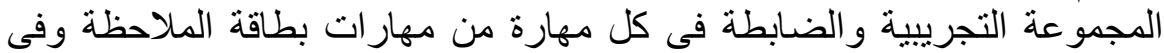

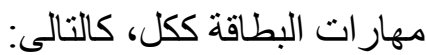

جدول (7) يوضح المتوسطات والإنحر افات المعيارية والنسب المئوية لدرجات الطالبات بالمجمو عتين الضابطة والتجريبية في كل مهارة من المهارات والئية والمهارت ككل (فى التطبيق البعدى)

\begin{tabular}{|c|c|c|c|c|c|c|c|c|}
\hline \multicolumn{3}{|c|}{ 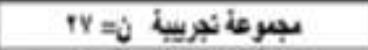 } & \multicolumn{3}{|c|}{ 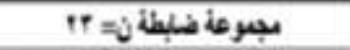 } & \multirow{2}{*}{ لالثرى } & \multirow[b]{2}{*}{ 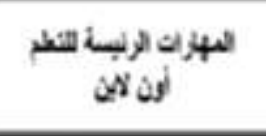 } & \multirow[b]{2}{*}{ ? } \\
\hline عزوبة & 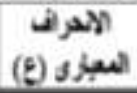 & $\begin{array}{c}b=\omega \\
(\rho)\end{array}$ & 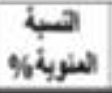 & 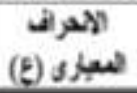 & $\begin{array}{c}b(j) \\
\text { (p) }\end{array}$ & & & \\
\hline 47,1 & 7,04 & 14,41 & $P A,+O$ & $1,+1$ & 1,11 & t. & 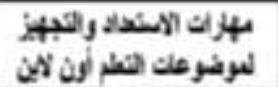 & , \\
\hline $17, y$ & $?, 4$ & 14,04 & 14,0 & $?+11$ & $0 \wedge 1$ & 10 & 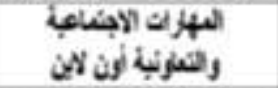 & t \\
\hline 41,7 & 7,17 & $1 \mathrm{~A}, \mathrm{t}$ & 70,10 & 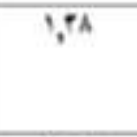 & $Y,+17$ & to & 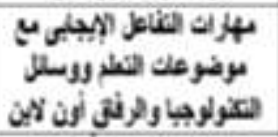 & + \\
\hline 10,1 & 1,04 & 10,11 & 17,90 & 1,11 & 4,10 & t. & باله & t \\
\hline 17,4 & $7, t+$ & $+7,10$ & $11,4 y$ & $\because "$ & $",+1$ & 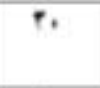 & 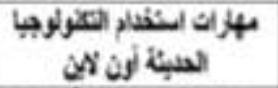 & $\bullet$ \\
\hline $4, y^{x}$ & $P, y$ & $+1,17$ & or & 1,01 &,,+ 0 & $*$ & 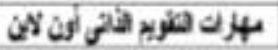 & 1 \\
\hline 37 & $P, 14$ & 11,10 & iA,AA & 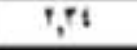 & at,io & 10. & Jكs & \\
\hline
\end{tabular}

مجلة التربية العلمية 
ويتضح من الجدول (7) السابق أن: النسب المئوية لطالبات المجموعة

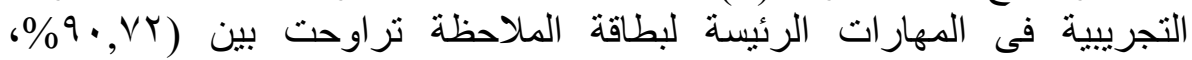

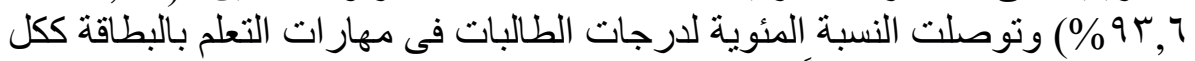

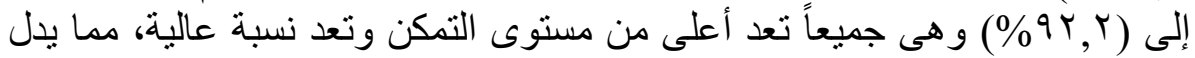

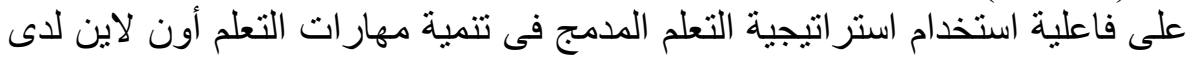

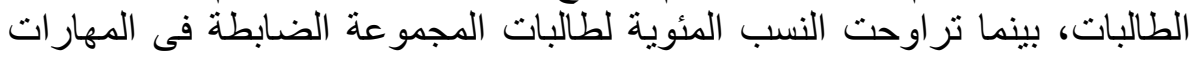

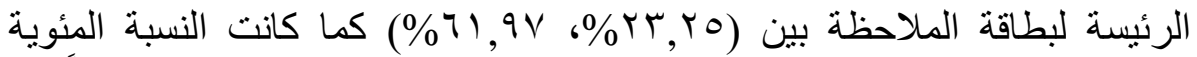
لارجات الطالبات فى مهار ات التعلم بالبطاقة ككل إلى (

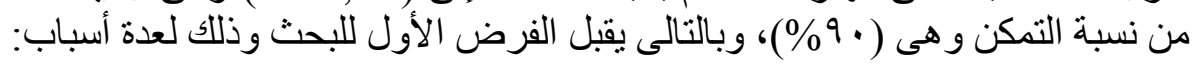

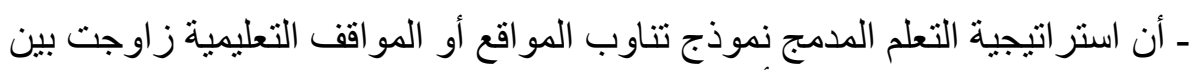

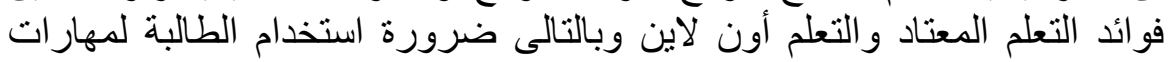
التعلم اون لاين كجز ألد هام من تنفيذ استر اتيجية التعلم.

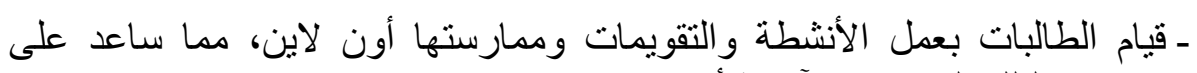
اكسابهن لتلك المهار ات الآدائية أون لائن.

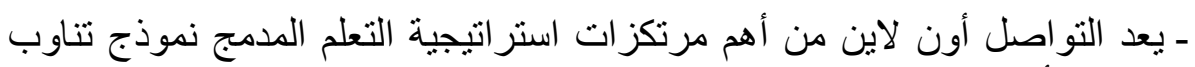

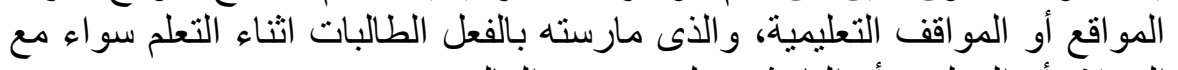

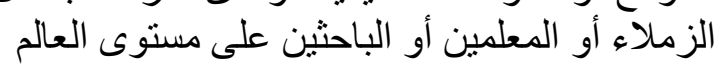

ـ التقويم المستمر لأداء الطالبات أون لاين وتقديم التغذية الر اجعة الفورية لهنئ.

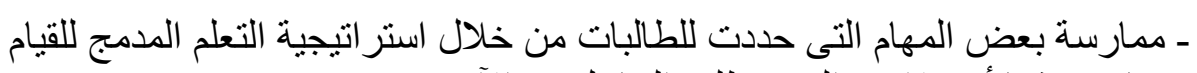
بها وتنفيذها أون لاين و التى تتطلب التفام لتفاعل مع الآخرين.

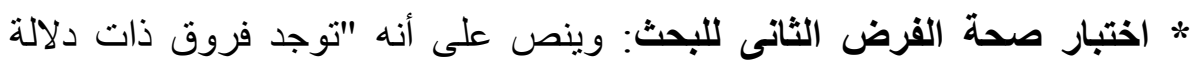

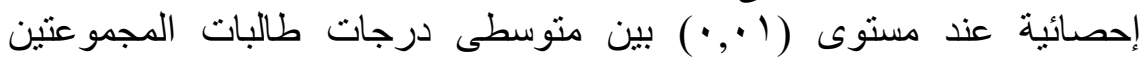

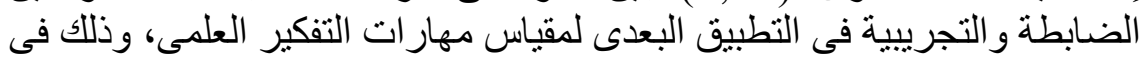

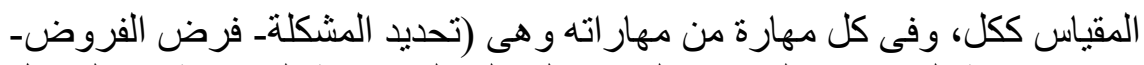

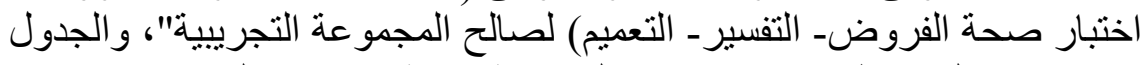

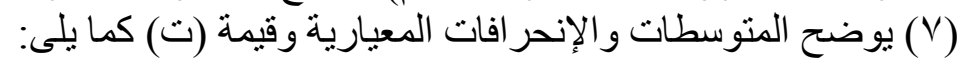


جدول (V) المتوسطات والإنحرافات المعيارية وقيمة (ت) لنتائج التطبيق البعدى

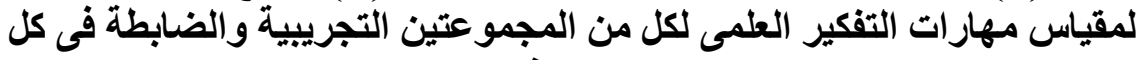
مهارة من مهار اته وفى المقياس كتين الجن

\begin{tabular}{|c|c|c|c|c|c|c|c|}
\hline \multirow{3}{*}{ مستوى الدلالة } & \multirow{3}{*}{ قيمة } & \multirow{2}{*}{\multicolumn{2}{|c|}{$\begin{array}{l}\text { التجريبية } \\
\text { ن }\end{array}$}} & \multirow{2}{*}{\multicolumn{2}{|c|}{ الضجابطة }} & \multirow{3}{*}{ التفكير العلفى مقياس } & \multirow{3}{*}{ p } \\
\hline & & & & & & & \\
\hline & & $\varepsilon$ & r & $\varepsilon$ & s & & \\
\hline 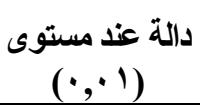 & $r, \wedge r$ & 1,98 & $r, 01$ & $\cdot, 00$ & $\cdot 97$ & تحديد المشكلة & 1 \\
\hline 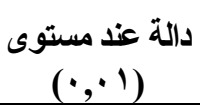 & $q, r r$ & $1, \cdot 1 r$ & r,qr & $\cdot, V$ & $1, \cdot 1$ & فرض الفروض & r \\
\hline 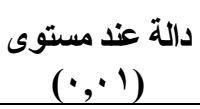 & $7,1 r$ & $1, \cdot r r$ & r,or & $\cdot, \leqslant r$ & $\cdot, \vee \wedge$ & اختبار صحة الفروض & $r$ \\
\hline 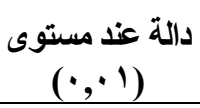 & $7, \times 1$ & 1, Irr & צ & $\cdot, 7$ & $1,1 \mathrm{r}$ & التفسير & $\varepsilon$ \\
\hline دالة عند مستوى & $v, q 1$ & $1,1 r$ & $\leq, 71$ & $\cdot, r r$ & $1, \cdot 1$ & التعميم & 0 \\
\hline $\begin{array}{c}\text { دالة عذد مستوى }(\cdot, \cdot(1) \\
\end{array}$ & $1 \leqslant, 9 V$ & $r, \wedge q$ & iv,qu & $1, \cdot r r$ & $0, \pi$ & الاختبار ككل & \\
\hline
\end{tabular}

ويتضح من الجدول (V) وجود فروق ذات دلالة إحصائية عند مستوى ( ال, " )

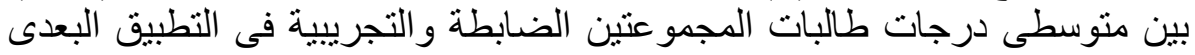

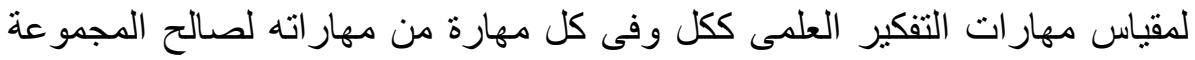

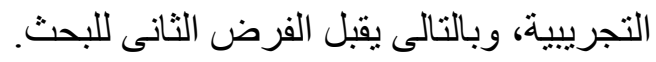

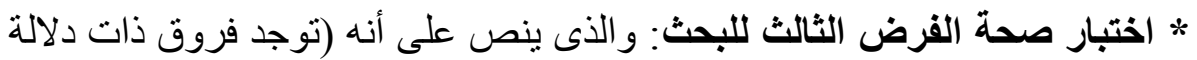

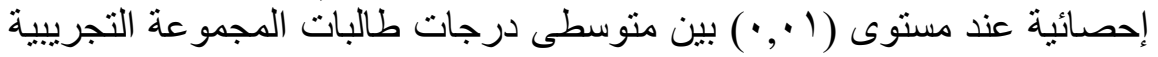

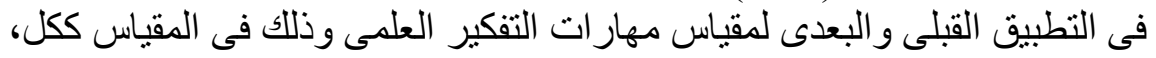

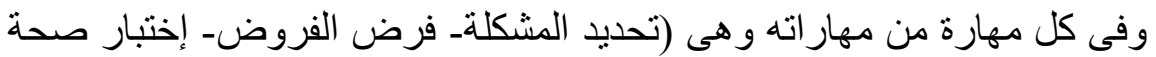

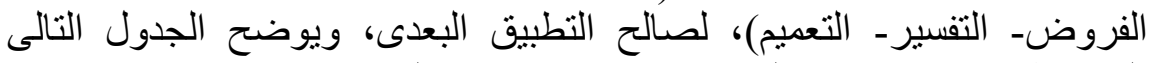
المتوسطات و الإنحر افات المعيارية وقيمة لهية (ت) كما يلى: ليعى 


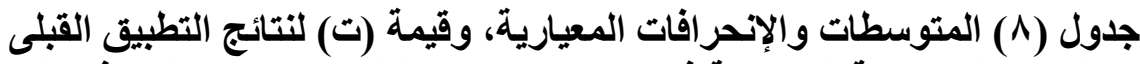

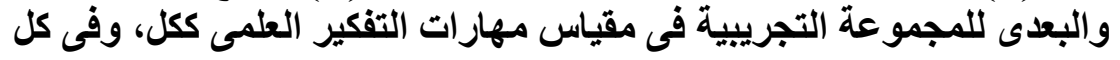

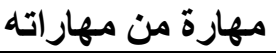

\begin{tabular}{|c|c|c|c|c|c|c|c|}
\hline \multirow{3}{*}{ مستوى الدلالة } & \multirow{3}{*}{ قيمة } & \multirow{2}{*}{\multicolumn{2}{|c|}{ 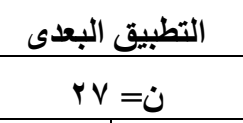 }} & \multirow{2}{*}{\multicolumn{2}{|c|}{ التطبيق القبلى }} & \multirow{3}{*}{ مهارات التفكير العلمى } & \multirow{3}{*}{ b } \\
\hline & & & & & & & \\
\hline & & $\varepsilon$ & 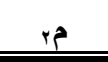 & $\varepsilon$ & 15 & & \\
\hline دالة عند مستوى & $\{, 91$ & 1,90 & $r, 01$ & $\cdot$ & $\cdot, 09$ & تحديد المشكلة & 1 \\
\hline 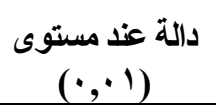 & $7, \leqslant Y$ & $1,+1 r$ & r,qr & $\cdot, 01$ & $\cdot,{ }^{\prime}$ & فرض الفروض & $r$ \\
\hline 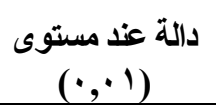 & $v, \cdot 1$ & $1, \cdot r r$ & r,or & $\cdot, \wedge 1$ & $1, \cdot r$ & اختبار صحة الفروض & $r$ \\
\hline 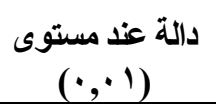 & $\checkmark, r r$ & 1, Irr & 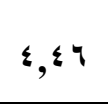 & $\cdot, 0$. & $1,1 \pi$ & التفسير & $\varepsilon$ \\
\hline 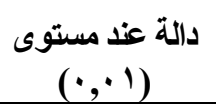 & $\vee, \wedge \vee$ & $1,1 r$ & $\leq, 7$ & •, & 1,19 & التعميم & 0 \\
\hline $\begin{array}{c}\text { دالة عند مستوى }(\cdot, \cdot(1) \\
\end{array}$ & $1 \leqslant, q \vee$ & $r, \wedge q$ & IV,qu & $1, r^{\prime}$ & $\varepsilon, T V$ & الاختبار ككل & \\
\hline
\end{tabular}

ويتضح من الجدول (^) وجود فروق ذات دلالة إحصائية عند مستوى ( ( , · )

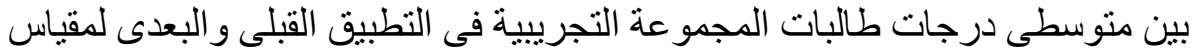

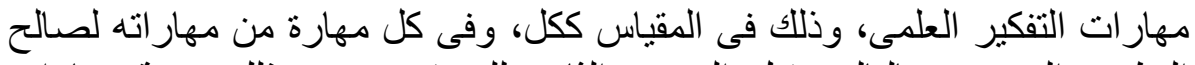

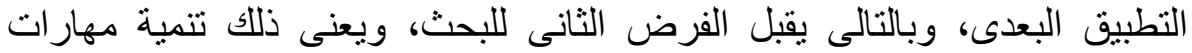

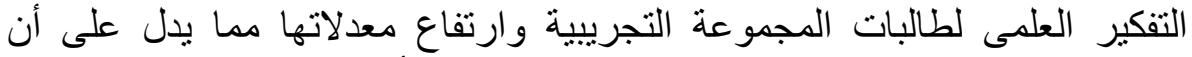

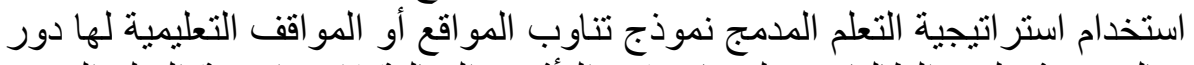

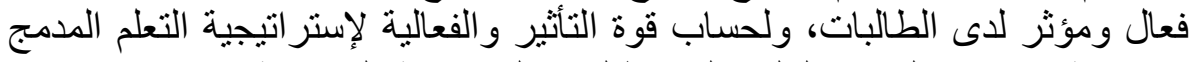

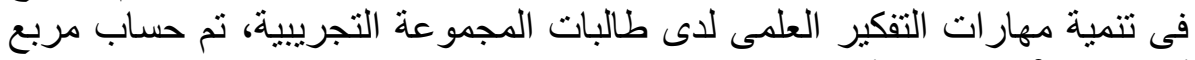

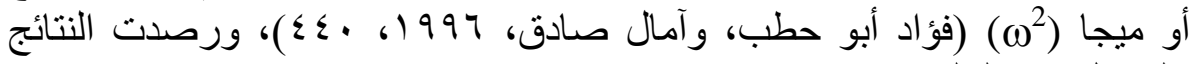

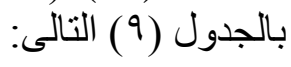

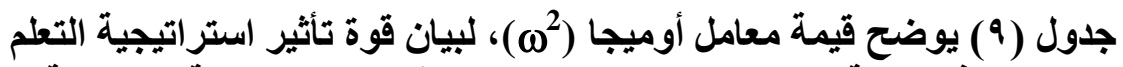

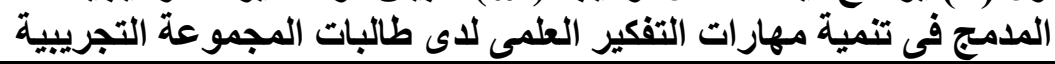

\begin{tabular}{|c|c|c|c|c|c|}
\hline قوة التأثير & قيمة (ف) & قيمة ت` & قيمة ت & عدد الطالبات & \\
\hline كبيرة & •, А৭४ & $r r r, 1 \ldots q$ & $1 \leqslant, 9 V$ & $r v=\dot{U}$ & \\
\hline
\end{tabular}




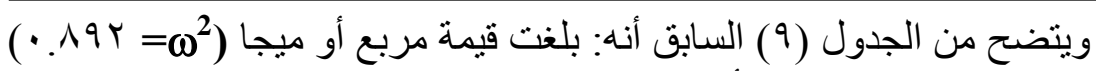

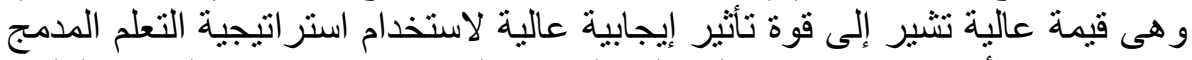

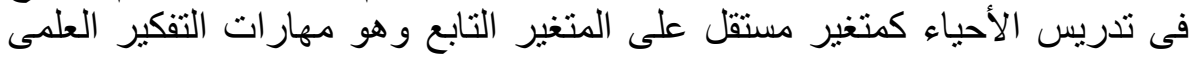

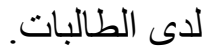

- ولبيان فعالية استخدام استراتيجية التعلم المدمج نموذج تناوب المواقئ اقع أو المواقف

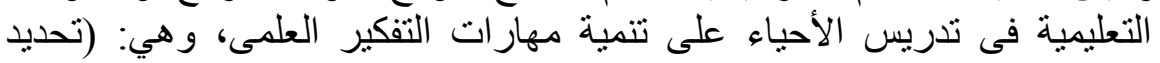

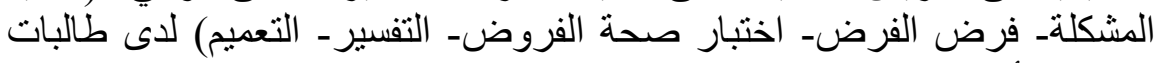

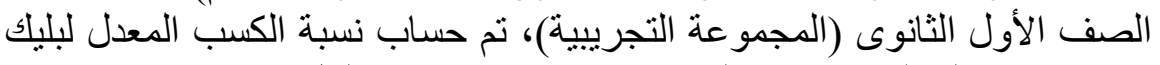
و الفعالية (محمد المفتى، (Blake)

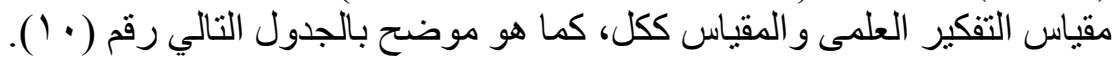

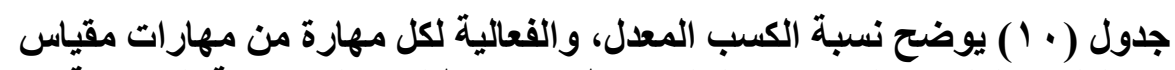
التفكير العلمى والمقياس ككل لمتوسط درجات طالبات المجموعة التجرية ديبية

\begin{tabular}{|c|c|c|c|c|c|c|c|c|}
\hline \multirow[t]{2}{*}{ الفعالية } & \multirow{2}{*}{ الكسبة } & \multicolumn{2}{|c|}{ 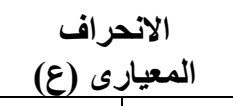 } & \multicolumn{2}{|c|}{ المتوسط (م) } & \multirow{2}{*}{ العظمى الدرجات } & \multirow{2}{*}{ مهارات التفكير } & \multirow{2}{*}{ p } \\
\hline & & بعدى & قبلى & بعدى & قبلى & & & \\
\hline$\cdot, \wedge 0$ & 1,01 & 1,90 & •,Or & $r, 01$ &., 09 & $\varepsilon$ & تحديد المشكلة & 1 \\
\hline$\cdot 99$ & $1, v$ & $1,1 r$ & $\cdot, 0 \wedge$ & r,qr & $\cdot, v_{1}$ & $r$ & فرض الفروض & $r$ \\
\hline$\cdot, \vee 7$ & $1, r$ & $1, \cdot r r$ & $\cdot, \wedge 1$ & $r, O r$ & $1, \cdot r$ & $r$ & الفتبار صحة & $r$ \\
\hline$\cdot, \wedge 4$ & $1,0 r$ & $1,1 Y r$ & $\cdot, 0$. & $\varepsilon, \leqslant 7$ & 1,11 & 0 & التفسير & $\varepsilon$ \\
\hline$\cdot, \wedge 9$ & 1,01 & $1,1 r$ & $\cdot, \leqslant 0$ & $\varepsilon, 71$ & 1,19 & 0 & التعميم & 0 \\
\hline$\cdot, 9 r$ & 1,01 & $r, \wedge q$ & $1, r 1$ & $i v, q r$ & $\varepsilon, 7 V$ & $r$. & الاختبار ككل & \\
\hline
\end{tabular}

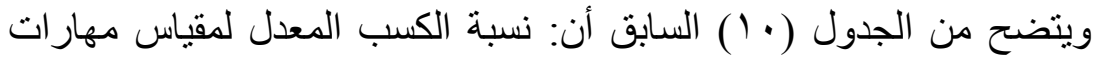

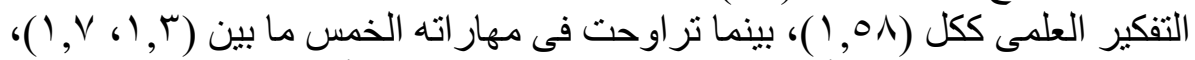

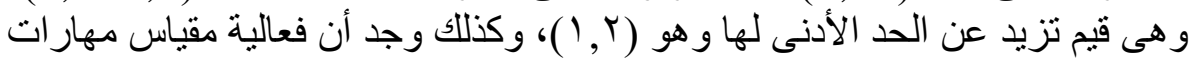

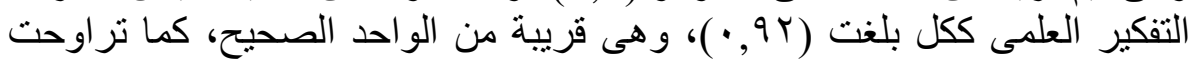

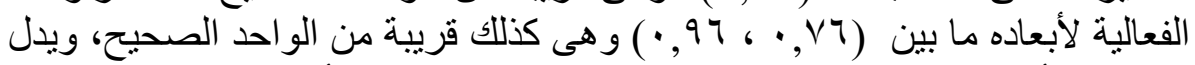

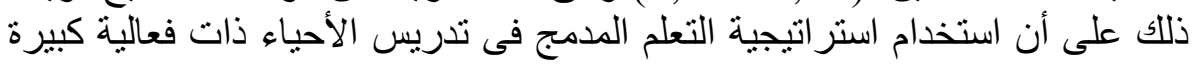

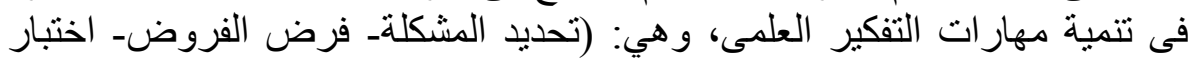

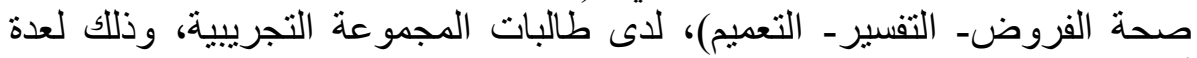

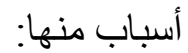
ـ لأنها استر اتيجية تسعى دائماً لإكساب الطالبات مهار ات البحث العلمى والإستقصاء و الفهم و التفكير العلمى، و عدم التلقين و الحفظ. 


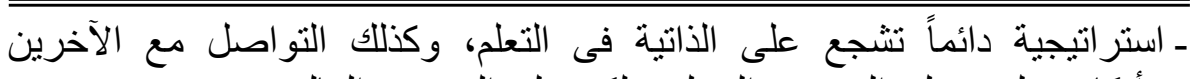
و أفكار هم ليس على المستوى المحلى لئى ولكن على المستوى العالمى.

ـ استر اتيجية تعمل على ايجابية الطالبة، وحفز رغبتها المستمرة فى التعلم و البحث.

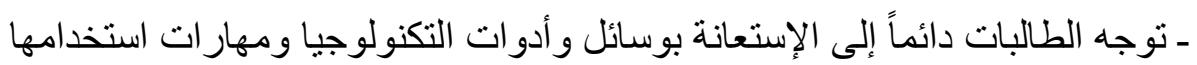
و الإستفادة منها فى التعلم وكذللك مصادر الإنة التعلم المتنو عة.

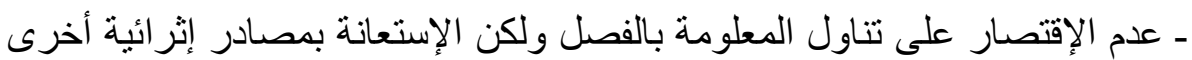

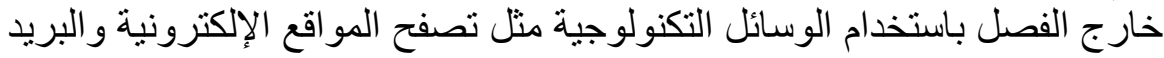
الإلكترونى، و الإنترنت، و الفيسبوكل.... الخ.

ـ استخدام التقويم المستمر و التغذية الر اجعة المستمرة أنثاء التعلم. ـ الإستفادة من الأنشطة الإثرائية المعتادة والإلكترونية لنتير متعة الطالبات و إكسابهن

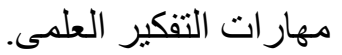
ـ تطرح قضايا علمية مثارة حالياً على الساحة لتقوم الطالبات تقديم تفسير ات وحلول لها من وجهة نظرهن.

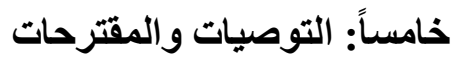
* توصيات البحث: توصلت الباحثة فى ضوء اءت نتائج البحث الحالى لمجموعة من التوصيات التالية:

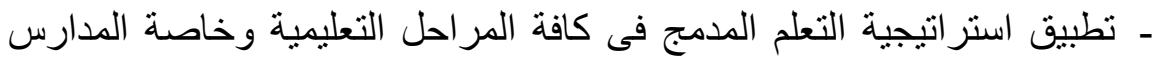
الثانوية و على الأخص فى مادة تدريس الأحياء للتأكيد على أهميتها كاستر اتيجية التئية حديثة.

- تضمين استر اتيجية التعلم المدمج فى برامج تدريب المعلمين للتدريب عليها وكذللك ضمن بر امج إعداد المعلم بالجامعات.

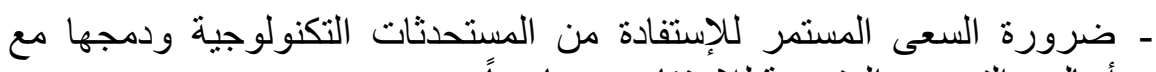
أساليب التدريس المنتو عة للإستفادة منهما معاً.

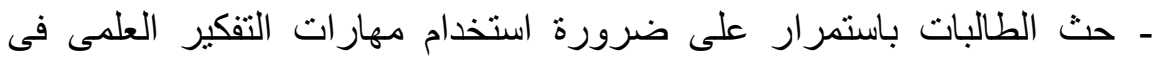
حياتهن اليومية و السعى الدائم للبحث والئ والاستقصاء.

ـ تنبيه الطالبات إلى السعى الدائم لإكتساب مهار ات اتل التعلم أون لاين لتحقيق الذاتية

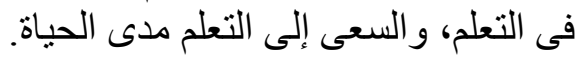

- عقد المزيد من الدورات التدريبية والندوات باستمرار، لتزويد إديد المعلمين بكل جديد فى مجال تدريس الأحياء.

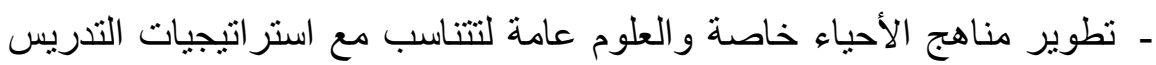
الحديثة مثل التعلم المدمج. 
- توجيه القائمين على العملية التربوية والباحثين على اجراء مزيد من البحوث

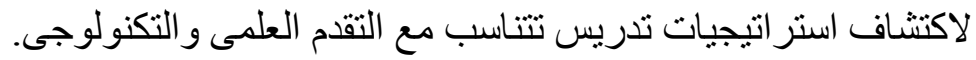

* مقترحات البحث: فى ضوء الإجراءات ونتائج البحث الحالى يمكن اجراء

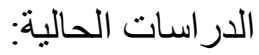

ـ فاعلية استخدام نماذج استر اتيجية التعلم المدمج فى تنمية التفكير الناقد و المفاهيم

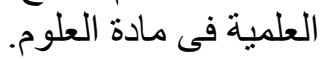

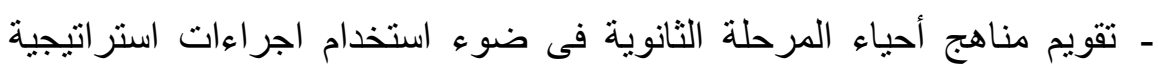

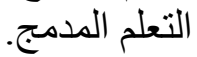

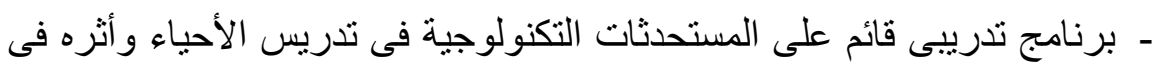

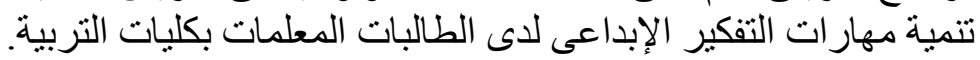

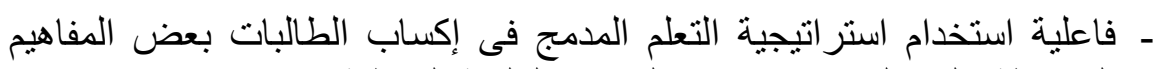
المرتبطة بالتكنولوجيا وتصحيح المفاهيم العلمية الخاطئة.

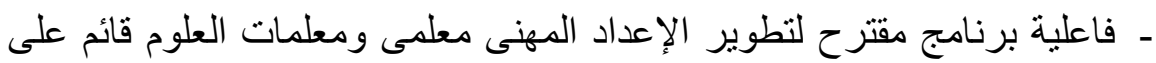

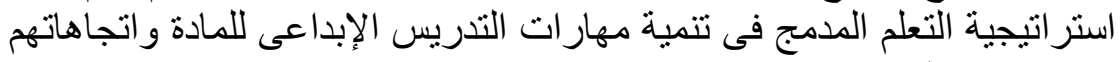
نحو تدريس المادة

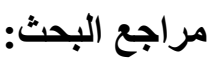

1ـ أحمد محمد الطيب (1999(1): الإحصاء في التربية و علم النفس، الإسكندرية، المكتب الجامعى الحديث، الأسكندرية.

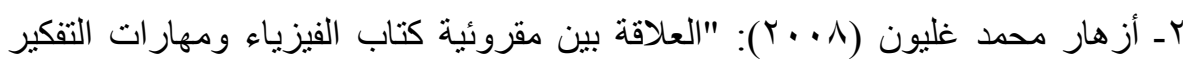

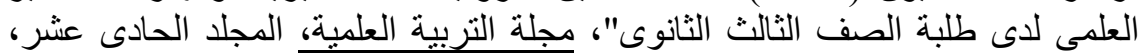
العدد الأول، الجمعية المصرية للتربية العلمية، مارس.

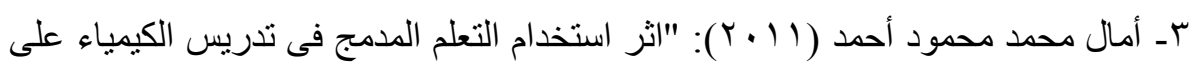

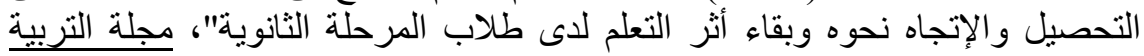

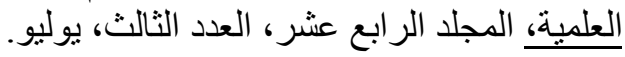

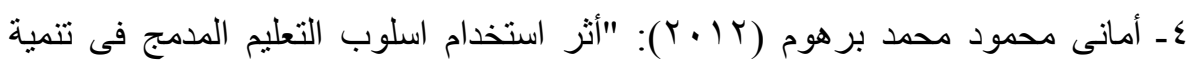

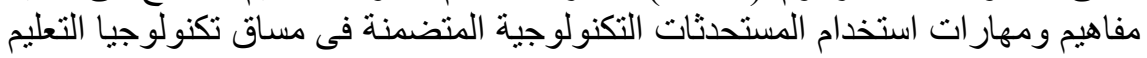

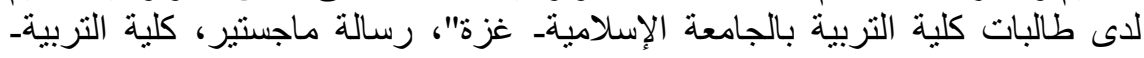

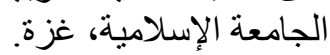

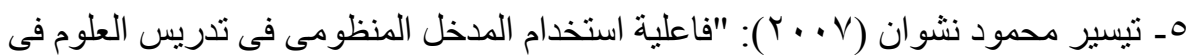

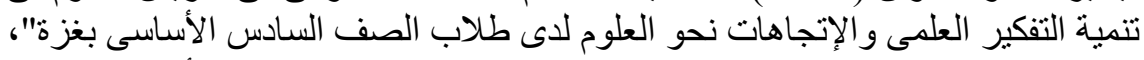

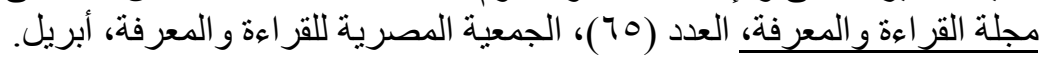


T- جمال الدين توفيق بونس عبدالهادى (Y . . . Y): "أنماط التعلم و التفكير و علاقتها بمهار ات

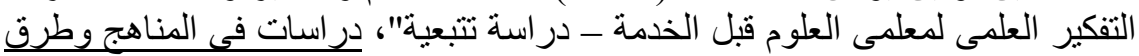
التدريس، العدد (VA)، الجمعية المصرية للمناهج وطرق التهية التدريس، فبر اير

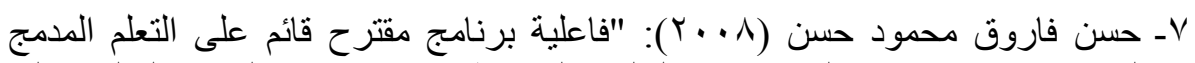

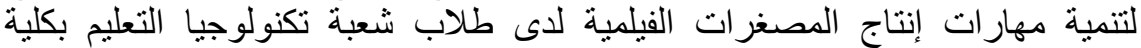

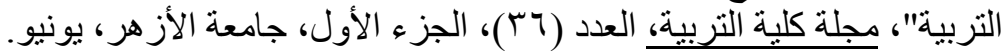

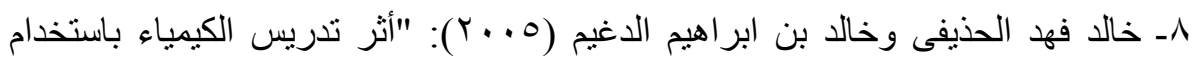

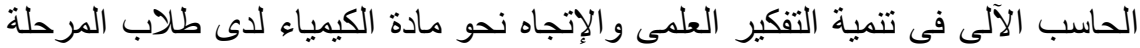

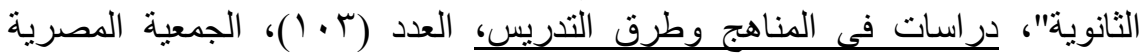
للمناهج وطرق التدريس، مايو

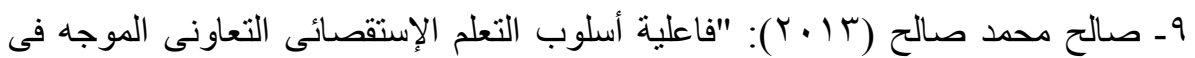

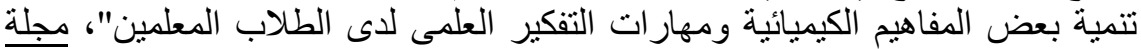

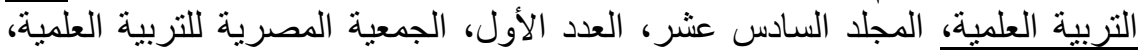
بناير

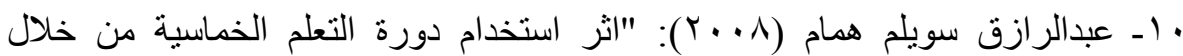

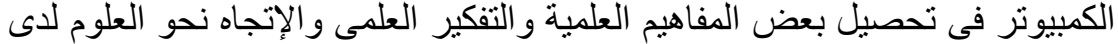

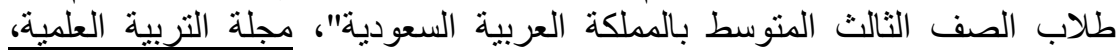
المجلد الحادى عشر، العدد الثانى، الجمعية المصرية للتربية العلمية، يناير المرية

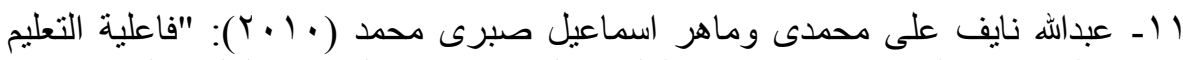

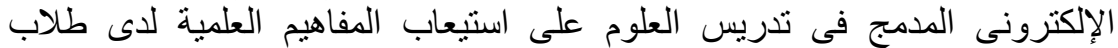

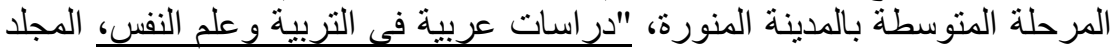

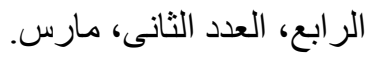

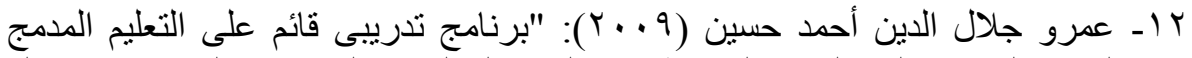

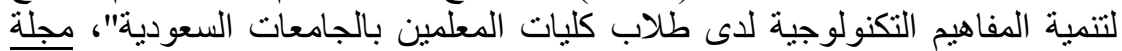

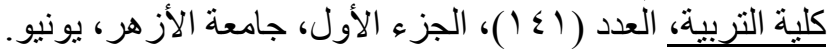

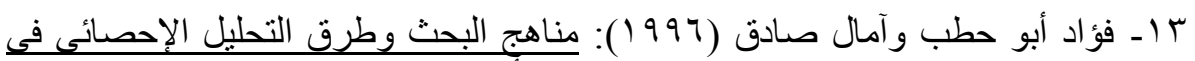

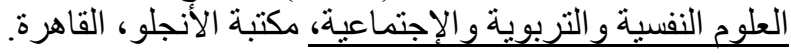

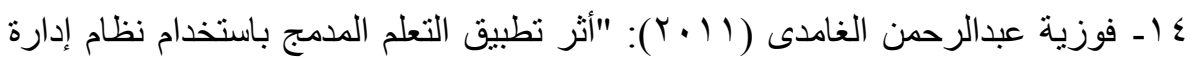

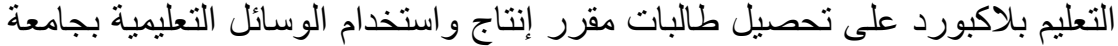
الملك سعود"، رسالة ماجستير، كلية التربية- جامعة الملك سعود، السعودية. 0 ـ ـ ليلى عبداله حسام الدين (1 (1 ب): "تدريس بعض القضايا البيئية بالجدل العلمى لتنمية

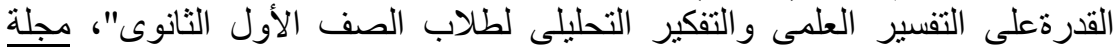

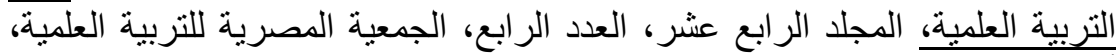
أكتوبر

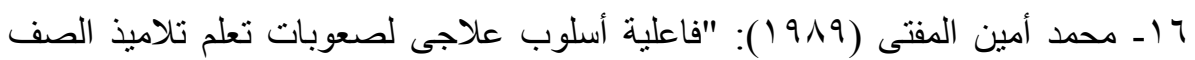

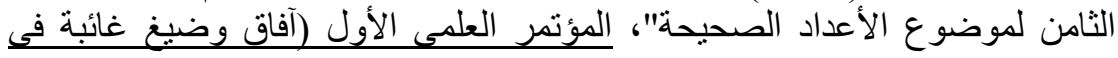


اعداد المناهج وتطويرها)، الجمعية المصرية للمناهج وطرق التدريس، الإسماعلية،

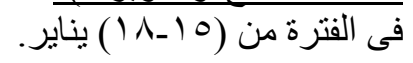

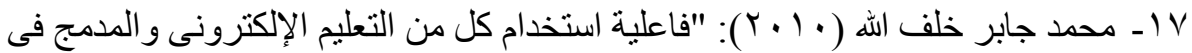

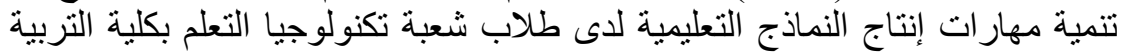

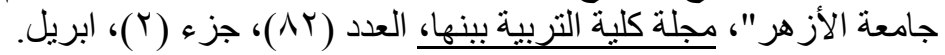

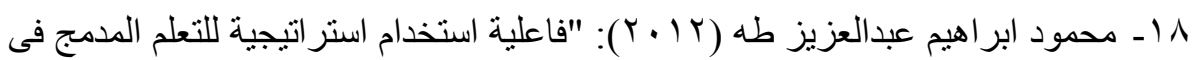

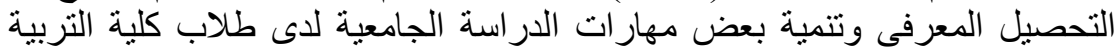

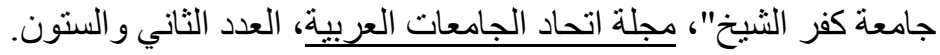

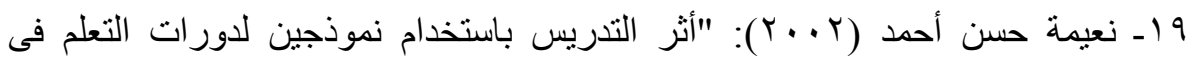

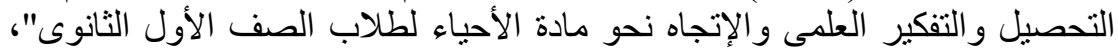

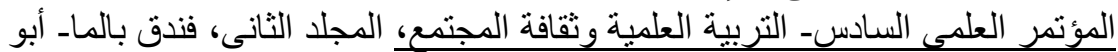

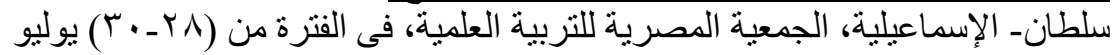

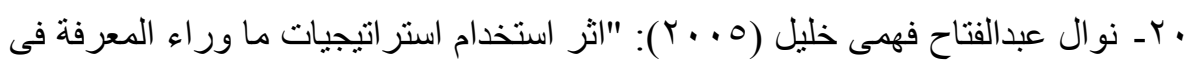

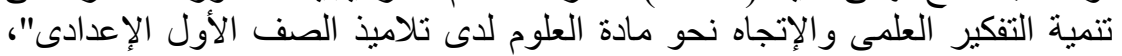

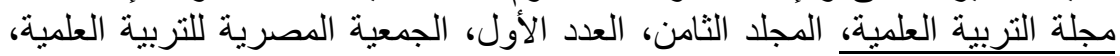
مارس

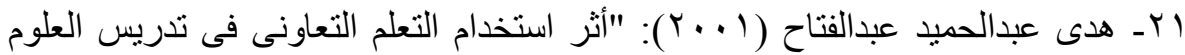

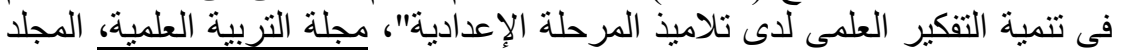

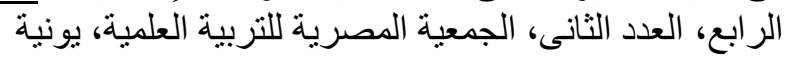

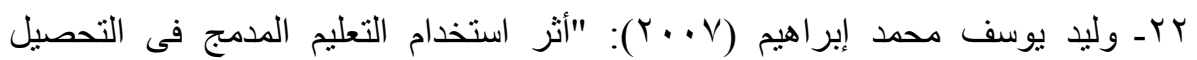

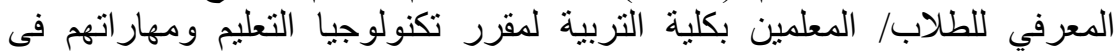

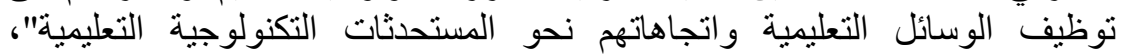

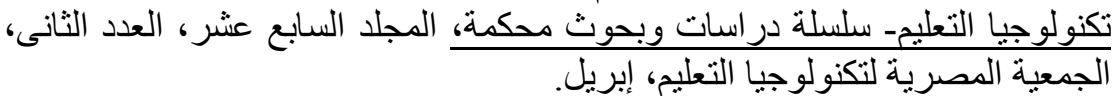

23- Ableidinger, J. et al., (2013); "A Better Blend A vision for Boosting Student outcomes with Digital Learning, www.publicimpact.com.

24- Adas, D. \& Bakir, A., (2013); "Writing Difficulties and New Solutions: Blended learning as an Approach to Improve Writing Abilities," International Journal of Humanities and Social Science, V. (3), N (9), May.

25- Akkoyunlu, B. \& Soylu, M.Y., (2008); "A study of Student's Perceptions in Blended Learning Environment Based on Different Learning Styles", Educational Technology \& Society, V. (11), N. (1).

26- Aladejana, F., (2008); "Blended Learning and Improved Biology Teaching in the Nigerian Secondary School", Proceeding of the 
World Congress on Engineering and Computer Science (WCECS), San Franscisco, USA, October.

27- Alebaikan, R.A., (2010); "Perceptions of Blended Learning in Saudi Universities", ph.D, University ofExeter.

28- Ally, M., (2008); "Foundations of Educational Theory Foronline Learning", in T. Anderson (Ed)., The Theory and Practice of Online Learning, Athabasc University, Athabasca, Canada.

29- Anderson, T., (2005); "Teaching in an online Learning", Theory and Practice of Oline Learning, Ath abasca University.

30- Atwell, H. et al., (2011); "Nationals Tandards for Quality Online Teaching", International Association for K-12 Online Learning. INACOL, Version (2).

31- Aygun, M., (2012); "Impact of Blended Learning Environments Based on Algo-Heuristic Theory on Some Variables", Mevlana International Journal of Education (MIJE), V. (2), N. (2), December.

32- Bailey, J. \& Martin, N. et al., (2013); "Blended Learning Implementation Guide Digital learning Now," (DLN) Smart Series, Version 2.0, September.

33- Battye, g. \& Carter, H., (2009); "Report on the Review of online and Blended Learning", University of Canberra, Australia's Capital university,

http://www.acode.edu.au/aboutus/acodebenchmkwksp/ default.htm.

34- Bergman, J. \& Sams, A., (2012); "Blended Learning \& Learning Plat forms- How You Can Start Blended Learning Tomorrow", www.itslearning.eu, Bergen.

35- Bray, S., Raley, N. \& Pinkus, A., (2013); "Stories of Excellence: Case Studies of Examplary Blended and Fully Online Learning", National Association of Independent Schools (NAIS), Washington, DC, www.nais.org.

36- Chekour, M., Alachhab, M. \& La a Fou, M., (2013): "Integration of Blended Learning in Teaching Computer Science in Moroccan High Schools", Int. J. Computer Technology \& Applications, V. (4), N. (6). Nov. - Decm. 
37- Cheung, W.S. \& Hew, K.F., (2011); "Design and Evaluation of Two Blended Learning Approaches: lessons Learned", Australasion Journal of Education Technology, V. (27), Special issue (8).

38- Cohen, C., (2013); "According to His Way: Blended Learning A White Paper About How Jowish Day Schools are using Blended Learning, "Jowishday School Afford Ability Knowledge Center A partnership of PEJE and The Ou, Boston, Aprile.

39- Dahinden, M. \& Faessler, L., (2011); "Monitoring Blended Learning Enviornments Basedon Performance Data", IADIS Internaitonal Conference e-learning, ISBN: 978-972-8939-28-0.

40- Dipietro, M., Ferdig, R.E., Black, E.W. \& Preston, M., (2008); "Best Practices in Teaching K-12 Online: Lessons Learned From Michigan Virtual School Teachers", Journal of Interactive Online Learning, V. (7), N. (1), ISSN: 1541: 4914, Spring

41- Dos, B., (2014); "Developing and Evaluating a Blended Learning Course", Anthropologist, V. (17) N. (1).

42- Ekanayake, S. \& Wishart, J., (2011); "Identifying The Potential of Mobile Phone Camer as in Science Teaching And Learning: A Case study under taken in srilanka", International Journal of mobile and Blended Learning, V. (3), N (2), April-June.

43- El-Mowafy, A., Kuhn, M. \& Snow, T., (2014); "A Blended learning Approach in Higher Education: A case study from surveying Education", Teaching and learning Forum, February.

44- Fahlvik, M., (2013); "The Blended Classroom How Teacher can use Blended Learning to Make Formative Assessment and Visible Learning Possible", Its learning A passion for Teaching, www.itslearning.eu, Bergen, Norway.

45- Forrest, J., (2014); "Measuring The Efficiency of Blended Learning Programs", The $6^{\text {th }}$ Annual National Blended Learning Conference-2014, 12: 13 March Novotel Sydacy, Darling Harbour.

46- Ginns, P. \& Ellis, R., (2007); "Quality in Blended Learning: Exploring The Relationships Between on Line and Face-To-Face Teaching and Learning"; Internet in Higher Education, V. (10). 
47- Glowa, E., (2009); "Guidelines for Professional Development of Online Teachers", SREB- Educational Technology Cooperative, Southern Regional Education Board, March.

48- Gonen, S., (2007); "A Study on Student Teacher Miscon ceptions and Scientifically Acce Ptable Conceptions About Mass and Gravity", Journal of Science Education Technology, V. (17), N. (1).

49- Greenberg, A.D., (2013); "Blended Learning Technology Navigating The Challenges of Large- Scale Adoption", White paper, Wain House Research, Echo ${ }^{360}$, March.

50- Hadjerrouit, S., (2008): "Towards a Blended Learning Model for Teaching and learning computer programming: A case study", Informatics in Education, V. (7), N. (2).

51- Hanover Research (HR), (2011); "Blended Learning Programs", Washington, www.hanoverresearch.com.

52- Honemond, F., (2010); "Blended Learning Approach"; Report From Department of Energy, December.

53- Hura, G., (2008); "Teaching Behavioral- Based Skills Online", MERLOT Journal of Online Learning and Teaching, V. (4), N. (3), September.

54- Isman, A. et al., (2012): "Using Blended Learning in Developing Student Teachers Teaching Skills", The Turkish Online Journal of Education, V. (11), Issue (4), October.

55- Kaza, P., (2013); "A Case Study of Blended Teaching and Learning in a New Zealand Secondary School, Using an Ecological From work", Journal of Open, Flexible and Distance Learning, V. (17), N (1).

56- Kazu, I.Y. \& Demirkol, A., (2014); "Effect of Blended Learning Environment Model on High School Students' Academic Achievement", The Turkishon Line Journal of Educational Technology, V. (13), N. (1), January.

57- Korner, A., Winkler, S. \& Breitenecker, F., (2014); Blended Learning is Science, Math Courses at the Vienna UT" Conference (Quality in Blended Learning), Wiener Neustadt, Austria, in 20: 22 February. 
58- Kraus, K.L., (2010); "Getting Started with Blended Learning", Griffith Institute For Higher Education (GIHE), Griffith University, www.grifith.ed,au/gihe.

59- Kwak, D.W., Menezes, F.M. \& Sherwood, C., (2013): "Assessing The Impact of Blended Learning of Student Performance", The evaluation unite at the University of Queensland's Teaching and Educational Development Institute (TEDI), The University of Queensland, October.

60- Lackovic, A., Bajic, M., \& Jandric, P., (2013): "Physical Performance in Virtual Education: Teaching Communication Skills Online," Proceedings of EDUL EARN13 Conference, $1^{\text {st }}$ 3rd July, Barcelona, Spain

61- Larson, R.C. \& Murray, E., (2008); "Open Educational Resources for Blended Learning in High Schools: Overcoming Impediments in Developing Countries", Journal of A synchronous Learning Networks, V. (12), Issue (1).

62- Lautzenheiser, D.K. \& Hochlei Tner, T., (2014); "Blended Learning in DC Public Schools", Education Policy Studies, American Enterprise Institute (AI), January.

63- Lee, H., Linn, M., Varma, K. \& Liu, O., (2010); "How do Technology- Enhanced Inquiry Science Units Impact Classroom Learning?", Journal of Research in Science Teaching, V. (47).

64- Lord, G. \& Lomicka, L., (2008); "Blended Learning in Teacher Education An Investigation of Classroom Community Across Media", Contemporary Issues in Technology and Teacher Education, V. (8), N. (2).

65- Massoud, A., Iqbal, U. \& Stockley, D. (2011); "Using Blended Learning to Foster Education in a Contemporary Classroom", Transformative Dialogues. Teaching \& Learning Journal, V. (5), Issue (2), November.

66- Matheos, K., (2012); "Innovative Practices Research Project", COHERE Report on Blended Learning, Collaboration of online Higher Education and Research (Co HERE), Human Resources and Skills Development Canada, University of Manitoba.

67- Mauch, L.H. \& Mauch, C., (2012); "Anonline Accessible Learning Environment For a Selection and Training Process of 
Teachers in The Public Education System in Brazill", Procedia Computer Science, V. (14).

68- Mcfarlane, S., Barry, W., Westerman, S., Starr, S. \& Lambert, G., (2013); "Blended Learning Staff Quick Guide", LTEU-Learning and Teaching Enhancement Unit, Version (3), Augost.

69- Minner, D., Levy, A. \& Century, J., (2010); "inquiry- Based Science Instructions- What is it and doesit Matter? Results from Areserach syntehesis years 1984 to 2002"; Journal of Research in Scinece Teaching, V. (47).

70- Naaj, M.A., Nachouki, M. \& Ankit, A., (2012); "Evaluating Student Satisfaction with Blended Learning in a GenderSegregated Environment", Journal of Information Technology Education, V (11).

71- Nehdi, A.H., (2013); "The Best of Both Worlds- Making Blended Learning Really Work by Engaging The Whole Brain", CEO, Herrmann International The Originators of Whole Brain, New York.

72- Nordine, D., (2011); "Blended Learning: Transforming The classroom", WisconsinVirtual School

(WVS), http://www.kpk12.com

73- Ocak, M.A., (2010); "Blended not to blend: Asstudy Investigating Faculty Members' Percptions of Blended Teaching", World Journal on Educational Technology, V. (2), Issue (3).

74- Olivier, W., (2014); "Techno-Blended Teaching \& learning Model for NCS Mathemtics \& Physical Science in Secondary Schools", FRF Maths Education Chair, Nelson Mandela metropolitan University South African, April.

75- Omiola, M.A., Enuwa, M.R., Awoyemi, S.O. \& Adebayo, R.F., (2012); "Effects of Blended Learning and Individualized Instructional Strategies on The Cognitive Learning Outcomes in Basic Technology", British Journal of Science, V. (16), N. (1), July.

76- Pankin, J., Roberts, J. \& Savio, M., (2012); "Blended Learning at Mit", White Paper, The MIT Training Alignment Team (TAI), July. 
77- Perifanou, M. et al., (2010); "Collaborative Blended Learning Methodology (CBLM), "Project Support From The European Commission Under The Lifelong Learning Programme Leonardo Dvinci, Education and Culture DG, Ver, 10, Project Number: 2010-1-LE005-11466

78- Poon, J., (2013); "Blended Learning: An Institutional Approach for Enhancing Students' Learning Experiences", MERLOT Journal of Online Learning and Teaching. N. (2), June.

79- Rabin, R., (2014); "Blended Learning for Leadershite The CCL Aproach", White paper, A Center For Creative leadership (CCL).

80- Reberllo, N., Salomon, F., Zallman, D.A., (2004); "Students, Mental Models of Newton's Second Law in Mechanics and Electro Magnetism", European Journal of Physics, V. (25), N. (1).

81- Saliba, G. \& Rankine, L. \& Cortez, H., (2013); "Fundamentals of Blended Learning" Learning and Teaching Unit (UWS), University of Westerm Sydney, Australli.

82- Sana, F., Fenesi, B. \& Kim, J.A., (2011); "A Case Study of The Introductory psychology Blended learning Model at McMaster university," The Canadian Journal for Scholarship of Teaching and Learning, V. (2), Issue. (1), Article (6), July.

83- School Wires, (2012); "Blended The Best of Online and Face-ToFace Learning to Improve Student Outcomes", http://www.schoolwires.com/domin/32.

84- Siemens, G., (2005): "Connectivism: A learning Theory for the Digital Ag", International Journal of Instructional Technology and Distance Learning, V. (2), N. (1).

85- Sivin- Kachala, J. \& Bialo, E., (2009); "Social Skills of Mainstream Students in Full-Time, Online Public Schools: How they Compare to Traditinal Public School Students", Interactive Educational Systems Design, Inc, New York, Ny 10024.

86- Smith, T.C., (2005); "Fifty- One Competencies For online Instruction", The Journal of Educators Online, V. (2), N. (2), July.

87- Stacey, E. \& Gerbic, P., (2008); "Success Factors for Blended learning", In Hello! Where are you in the Land Scape of Education Technology, Concis paper, proceeding Ascilite Melbourne, 
http://www.ascilite.org.au/conference5/melbourne08

/procs/stacey.pdf.

88- Staker, H. \& Horn, M.B., (2012); "Classifying K-12 Blended Learning,", INNOSIGHT Institute, www.Innosighte.org, May.

89- Than, K.O. \& Tham. C.K., (2011); "Blended Learning- A Focus Study On Asia", IJCSI International of Computer Science Issues, V. (8), Issue (2), March.

90- The Oxford Group Report\& Kineo, (2013), "Blended LearningCurrent use, Challenges and Best Bractices", www.kineo.com and www.oxford-group.com.

91- Thoeming, B., (2013): "Blended Learning Where Teaching Meets Technology, "Desire 2 learn, New Zealand In coporated,www. desirezlearn.com.

92- Soltenkamp, J., Kabaka, M. \& Braaff, N., (2013); "The Facilitation and Support of Blended e-learning Course for Science Educators in a Rural Setting, South Africa", Asian journal of Education and e-learning, V. (01), Issue. (04), October.

93- Tzimopoulos, N., (2014); "ICT Teachers Training The Implementation of the Program with Blended Learning in the Prefecture of the Cyclades, Conference Quality in Blended Learning, Wiener Neust adt, Austria in 20: 22 February.

94- Vander Kam, L., (2013); "Blended Learning Awise Giver's Guide to Supporting Tech-Assisted Teaching", Philanthropy Round Table Previous Guide Books on Education Reform Form The Philanthropy Round Table, Edited by: Zinsemeis Ter, K., Washingtom, April.

95- Vanicharoenchai, V. \& Toskul Kaew,V., (2010); Effects of Blended Learning, Using Online Data Searches and Action Learning, Upon Academic Achievement and Searching Skills of Nursing Student"; Journal of Nursing Science, V. (28), N. (2), April.

96- Vernadakis, et al., (2012); "The Impact of Blended and Traditional Instruction in Students performance", Procedia Technology, V. (1). 
97- Walne, M.B., (2012); "Emerging Blended-Learning Models and School profiles", Edustart LLC, Creater Houston- Community Foundation, September.

98- Walsh, N.M., (2013): "Boys and Blended Learning: Achievement and Online Participation in physical Education", Master of Education, The University of Canterbury.

99- Watwood, B., Nugent, J., \& Deihl, (2009); "Building From Content to Community: Rethinking the Transition to Online Teaching and Learning, Z., ACTE white. Paper, VCU, Center for Teaching Excellence, CTE, May.

100- Wilk A, M. \& Cohen, (2012); "It's not Just about The Model Blended Learning, Innovation, and Year 2 At summit Public Schools", Summit Public Schools Report, FSG, Boston, Wishington, http:www.fsg.org.

101- Wilson, C.D., Taylor, J.A., Kowa Lski, S.M. \& Carlson, J., (2010): "The Relative Effects and Equity of Inquiry- based and Common place Science Teaching On Students' Knowledge, Resoning And argumentation", Journal of Research in Science Teching, V. (47).

102- Winkler, S., Korner, A. \& Breitenecker, F., (2014) "Experiences and Quality issues in Teaching Science", Conference (Quility in blended Learning Wiener Neustadt, Austria, In 20: 22 Febraury.

103- Wong, M., (2014); "Blended Learning as a capability Development Strategy", The $6^{\text {th }}$ Annual National Blended Learning Conference-2014, 12: 13 March, Novotel Sydney, Darling Harbour.

104- Yapici, I.U. \& Akbayin, H., (2012); "The Effect of Blended Learning Model on High School Students' Biology Achievement and on Their Attitudes Towards The Internet", The Turkish Online Journal of Educational Technology, V. (11), Issue (2), April. 